\title{
A Comparison of Model Predicted to Observed Winds in the Coastal Zone
}

Michael Garstang

Roger A. Pielke

Joseph W. Snow

Department of Environmental Sciences

University of Virginia

July 1982

Prepared for

Pacific Northwest Laboratory

under Agreement B-93492-A-Q of

Contract DE-AC06-76RLO 1830

U.S. Department of Energy 


\title{
DISCLAIMER
}

This report was prepared as an account of work sponsored by an agency of the United States Government. Neither the United States Government nor any agency thereof, nor any of their employees, makes any warranty, express or implied, or assumes any legal liability or responsibility for the accuracy, completeness, or usefulness of any information, apparatus, product, or process disclosed, or represents that its use would not infringe privately owned rights. Reference herein to any specific commercial product, process, or service by trade name, trademark, manufacturer, or otherwise, does not necessarily constitute or imply its endorsement, recommendation, or favoring by the United States Government or any agency thereof. The views and opinions of authors expressed herein do not necessarily state or reflect those of the United States Government or any agency thereof.

\author{
PACIFIC NORTHWEST I.ABORATORY \\ operated by \\ BATTELLE \\ for the \\ UNITED STATES DEPARTMENT OF ENERGY \\ under Contract DE-AC06-76RLO 1830
}

\begin{tabular}{|c|c|}
\hline \multicolumn{2}{|c|}{ Printed in the United States of America } \\
\hline \multicolumn{2}{|c|}{$\begin{array}{l}\text { Available from } \\
\end{array}$} \\
\hline \multirow{4}{*}{\multicolumn{2}{|c|}{$\begin{array}{c}\text { National Technical Information Service } \\
\text { United States Department of Commerce } \\
5285 \text { Port Royal Road } \\
\text { Springfield, Virginia } 22151\end{array}$}} \\
\hline & \\
\hline & \\
\hline & \\
\hline \multirow{2}{*}{\multicolumn{2}{|c|}{$\begin{array}{l}\text { NTIS Price Codes } \\
\text { Microfiche A01 }\end{array}$}} \\
\hline & \\
\hline \multicolumn{2}{|c|}{ Printed Copy } \\
\hline & Price \\
\hline Pages & Codes \\
\hline 001-025 & $\mathrm{A} 02$ \\
\hline $026-050$ & $\mathrm{~A} 03$ \\
\hline $051-075$ & $\mathrm{~A} 04$ \\
\hline $076-100$ & $\mathrm{~A} 05$ \\
\hline $101-125$ & A06 \\
\hline $126-150$ & $\mathrm{~A} 07$ \\
\hline $151-175$ & A08 \\
\hline $176-200$ & A09 \\
\hline $201-225$ & A010 \\
\hline $226-250$ & A011 \\
\hline $251-275$ & A012 \\
\hline $276-300$ & A013 \\
\hline
\end{tabular}




\section{1}

A COMPARISON OF MODEL PREDICTED TO OBSERVED WINDS IN THE COASTAL ZONE

Michael Garstang

Roger A. Pielke

Joseph $W$. Snow

University of Virginia

Department of Environmental Sciences

Charlottesville, Virginia 22903

June 1982

Prepared for

Pacific Northwest Laboratory under Agreement B-93492-A-Q of Contract DE-AC06-76RLO 1830

U.S. Department of Energy

Pacific Northwest Laboratory

Richland, Washington 99352 


\section{EXECUTIVE SUMMARY}

Predictions of near-surface ( 10 to $100 \mathrm{~m}$ ) wind velocities made by a mesoscale numerical model on a $10 \mathrm{~km}$ grid over and near the coastline are checked against observations. Two comparisons are made. The first is between observed and model-estimated mean annual wind power density at locations where surface observations exist in three coastal areas: the Chesapeake Bay, the Apalachee Bay and the South Texas coastal area. The second comparison is made between model predictions over the Delmarva Peninsula and adjacent ocean and observations made over a $120 \times 30 \mathrm{~km}$ rectangle extending across the peninsula and out to sea.

In the first comparison, the surface observations are adjusted to $100 \mathrm{~m}$ using a climatologically derived $\alpha$-value. Within the uncertainties of the adjusted observations a skill rating for the annual average $100 \mathrm{~m}$ layer-mean power density of 778 is obtained for the first two regions. The model, without diurnal variation of the large-scale pressure gradient, shows no skill for the South Texas coastal area. The presence of inland sloping topography in south Texas and northeast Mexico is suspected as being the reason why model predictions fail in this location.

In the second comparison, the skill of the model in predicting wind speeds over the coastal waters and in predicting the occurrence, location and magnitude of strong horizontal gradients in the wind field is of particular interest. Three tests of skill are carried out:

1. Measurement Error Analysis, where the percent of model predicted winds falling within the error limits of the measured values is used to evaluate skill.

2. Linear Correlation, where the closeness with which the predicted wind series duplicates the variations in the observed series is measured.

3. Unbiased Error Analysis, which deals with the square of the differences between predicted and observed values of wind and thus more directly assesses the skill of the model with respect to wind energy.

We conclude that the unbiased error analysis skill ratings of $81 \%$ and $76 \%$ are attained for two days of prediction-observation comparisons. In the meantime, the skill of the model in duplicating individual coastal wind fields is taken as $78 \%$

In addition, a qualitative comparison is made between the predicted fields of wind and the observed wind field. The predicted wind field unquestionably reproduces the observed field. 
We conclude that for coastlines without inland sloping topography the mesoscale model usefully predicts the magnitude and location of the centers of maximum and mininum wind power. For coastal areas that border on inland sloping terrain a more complete initialization of the model is required. 
EXECUTIVE SUMMARY .............................. i

TABLE OF CONTENTS ............................. ii

LIST OE TABLES .............................

IIST OF FIGURES .............................. v

1. INTRODUCTION................................... I

2. COMPARISON OF MODEL PREDICTED AND OBSERVED ANNUAL AVERAGE WIND POWER DISTRIBUTIONS......................... 1

3. VERIFICATION OF MODEL PREDICTIONS FOR SPECIFIC METEOROLOGICAI CONDITIONS............................. 3

3.130 January $1980 \ldots \ldots \ldots \ldots \ldots \ldots \ldots \ldots \ldots \ldots \ldots \ldots \ldots \ldots \ldots \ldots$

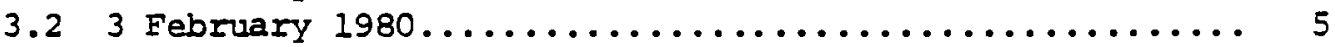

3.3 Determination of the Model's Skill for Specific Coastal zone situations...................... 6

3.3.1 Measurement Error Analysis................. 7

3.3 .2 Coefficient of Linear Correlations........... 8

3.3.3 Average squared Difference................. 10

3.4 Wind Power Density Prediction................... II

4. CONCLUSIONS..................................... 12

5. REFERENCES .................................. 14

TABLES..................................... 15

FIGURES ..................................... 34 
Table 1: Verification of the annual average, $100 \mathrm{~m}$ layermean power density using data recorded within three mesoscale coastal areas.............. 15

Table 2: Initialization and parameterization of the University of Virginia mesoscale model for the Chesapeake Bay Area on two operational days of the Wallops Island Verification Experiment....... 17

Table 3a: Observed and predicted wind speeds ( $\mathrm{ms}^{-1}$ ) for the morning flight on $30 \mathrm{Jan} 80$, initial and final

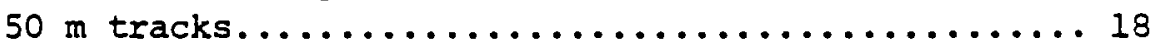

Table 3b: Observed and predicted wind speeds ( $\mathrm{s} \mathrm{s}^{-1}$ ) for the morning flight on $30 \mathrm{Jan}$, both $170 \mathrm{~m}$ rectangles. 19

Table 3c: Observed and predicted wind speeds $\left(\mathrm{m} \mathrm{s}^{-1}\right)$ for the midday flight on $30 \mathrm{Jan} 80$, initial and final

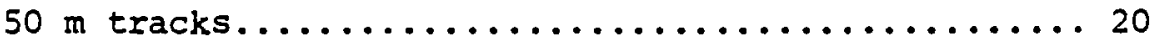

Table 3d: Observed and predicted wind speeds ( $m \mathrm{~s}^{-1}$ ) for the midday flight on $30 \mathrm{Jan} 80$, large $170 \mathrm{~m}$ rectange.... 21

Table 3e: Observed and predicted wind speeds $\left(\mathrm{m} \mathrm{s}^{-1}\right)$ for the afternoon flight on $30 \mathrm{Jan} 80$, initial and final

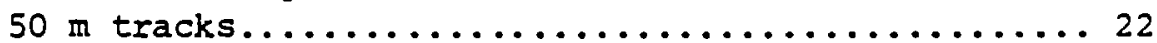

Table 3f: Observed and predicted wind speeds ( $\mathrm{m} \mathrm{s}^{-1}$ ) for the afternoon flight $30 \mathrm{Jan} 80$, both $170 \mathrm{~m}$ rectangles... 23

Table 4a: Observed and predicted wind speeds $\left(\mathrm{ms}^{-1}\right)$ for the morning flight on $3 \mathrm{Feb} 80$, initial and final 50 m tracks............................ 24

Table 4b: Observed and predicted wind speeds $\left(\mathrm{m} \mathrm{s}^{-1}\right)$ for the morning flight on $3 \mathrm{Feb} 80$, both $170 \mathrm{~m}$ rectangles... 25

Table 4c: Observed and predicted wind speeds $\left(\mathrm{m} \mathrm{s}^{-1}\right)$ for the midday flight on $3 \mathrm{Feb} 80$, initial and final $50 \mathrm{~m}$ tracks............................ 26

Table 4d: Observed and predicted wind speeds $\left(\mathrm{m} \mathrm{s}^{-1}\right.$ ) for the midday flight on $3 \mathrm{Feb} 80$, large $170 \mathrm{~m}$ rectangle.... 27 
LIST OF TABLES (cont.)

Page

Table 4e: Observed and predicted wind speeds $\left(\mathrm{m} \mathrm{s}^{-1}\right)$ for the afternoon flight on $3 \mathrm{Feb} 80$, initial and final

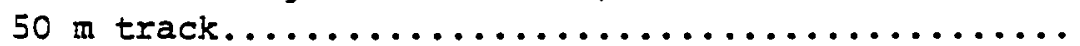

Table 4f: Observed and predicted wind speeds (m $\mathrm{s}^{-1}$ ) for the afternoon flight on $3 \mathrm{Feb} 80$, both $170 \mathrm{~m}$

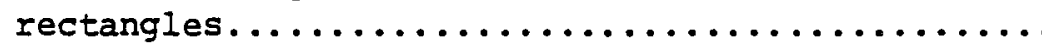

Table 5: Absolute error limits $\left(+\mathrm{m} \mathrm{s}^{-1}\right)$ for measured wind speeds from beginning to end of each flight component........................... 30

Table 6: Numbers of "correct" wind speed predictions and percentages by flight and daily total for two WIVEX days........................... 31

Table 7: Coefficient of linear correlation $(r)$ and significance tests for all pairs of predicted and

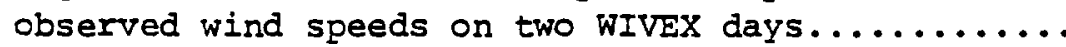

Table 8: Average of the square of the unbiased differences for all wind speeds on two WIVEX days.......... 32

Table 9: Skill ratings ( 8 ) determined by various analyses... 33 
FIGURES 1-3: Annual average power density $\left(\mathrm{W} \mathrm{m}^{-2}\right)$, layermean given for each $100 \mathrm{~km}^{2}(10 \mathrm{~km}$ northsouth $\times 10 \mathrm{~km}$ east-west) as determined from meteorological variables predicted by the numerical model of the atmosphere for the Chesapeake Bay, Apalachee Bay and South Texas

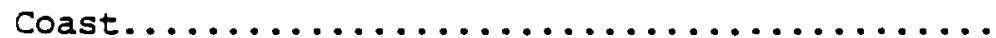

FIGURE 4: Outlines of the $120 \times 30 \mathrm{~km}$ aircraft flight track (solid rectangle) located within the $140 \times 100 \mathrm{~km}$ Wallops Island verification experiment study area (broken rectangle)......... 38

FIGURES 5A-7A: Observed wind speeds $\left(\mathrm{m} \mathrm{s}^{-1}\right)$ and wind directions (meteorological deg.) at $170 \mathrm{~m}$ above the surface for aircraft flights made on 30

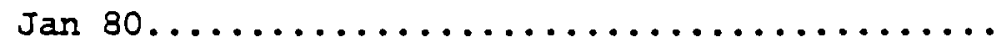

FIGURES 5B-7B: Predicted wind speeds $\left(\mathrm{m} \mathrm{s}^{-1}\right)$ and wind directions (meteorological deg.) at $170 \mathrm{~m}$ above the surface for $30 \mathrm{Jan} 80 \ldots \ldots \ldots \ldots \ldots \ldots \ldots$

FIGURES 8A-F: Space-time series of observed (solid dots) and predicted (open circles) wind speeds ( $\mathrm{m} \mathrm{s}^{-1}$ ) at 50 and $170 \mathrm{~m}$ above the surface within the WIVEx study area on $30 \mathrm{Jan} 80 \ldots \ldots \ldots \ldots \ldots$

FIGURES 9A-IIA: Observed wind speeds $\left(\mathrm{m} \mathrm{s}^{-1}\right)$ and wind directions (meteorological deg.) at $170 \mathrm{~m}$ above the surface for aircraft flights made

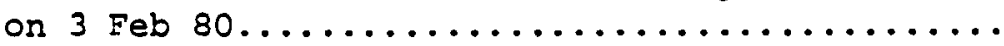

FIGURES 9B-11B: Predicted wind speeds $\left(\mathrm{m} \mathrm{s}^{-1}\right)$ and wind directions (meteorological deg.) at $170 \mathrm{~m}$ above the surface for $3 \mathrm{Feb} 80 \ldots \ldots \ldots \ldots \ldots$

FIGURES 12A-F: Space-time series of observed (solid dots) and predicted (open circles) wind speeds ( $\mathrm{m} \mathrm{s}^{-1}$ ) at 50 and $170 \mathrm{~m}$ above the surface within the WIVEX study area on $3 \mathrm{Feb} 80 \ldots \ldots \ldots \ldots \ldots \ldots \ldots$. 61

FIGURE 13A: Scatter diagram of wind speeds, 30 Jan $80 \ldots \ldots .68$

FIGURE 13B: Scatter diagram of wind speeds, 3 Feb $80 \ldots \ldots .669$ 
LIST OF FIGURES (cont.)

Page

FIGURE 14A: Scatter diagram of the cube of measured wind speed, $\mathrm{U}_{\mathrm{m}}{ }^{3}$, versus predicted wind speed, $U_{\mathrm{p}}$,

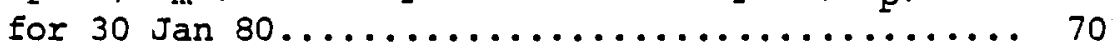

FIGURE 148: Scatter diagram of the cube of measured wind speed, $U_{\mathfrak{M}}{ }^{3}$, versus predicted wind speed, $U_{p}$,

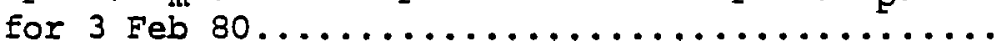

FIGURE 15: Areal distribution of measured wind power density $\left(10^{2} \mathrm{~W} \mathrm{~m}^{-2}\right)$ at $170 \mathrm{~m}$ above the surface, 0742-0859 EST, 30 Jan 80, within the WIVEX $120 \times 30 \mathrm{~km}$ aircraft track............... 72

FIGURE 16: Areal distribution of predicted wind power density $\left(10^{2} \mathrm{~W} \mathrm{~m}^{-2}\right.$ ) at $170 \mathrm{~m}$ above the surface at $0828 \mathrm{EST}$, for the WIVEX study area. Predictions made by the University of Virginia mesoscale model initialized for $30 \mathrm{Jan} 80 \ldots . .$. 
* 


\section{INTRODUCTION}

A mesoscale numerical model has been used to generate estimates of the wind field centered on the coastline and extending approximately $150 \mathrm{~km}$ inland and $150 \mathrm{~km}$ seaward of the shore. Snow (1981) describes the model and the methods used in detail and Garstang et al. (1982) outline how these techniques might be applied to the selection of a wind energy conversion site on or near the coast.

In the work cited above the model is used to generate wind information at $10 \mathrm{~km}$ intervals over an area of up to $300 \times 300 \mathrm{~km}$. The horizontal wind vector is generated at 12 levels in the atmosphere starting at $4 \mathrm{~m}$ and extending upwards to $6 \mathrm{~km}$. Winds are calculated every minute through twenty-four hours for weather conditions which are typical of the dominant meteorological regimes for a particular region of the coast. The regimes and regions are determined by analysis of the climatological record over a period of 10 years. The frequency of occurrence of the dominant meteorological regimes during the annual cycle is used to combine the model-predicted wind and wind power information into mean annual areal distributions of potential wind power.

The utility of the method outlined above depends in large part upon the validity of the model-predicted wind fields. The purpose of this report is to provide an estimate of the skill of the model in predicting the actual winds. We will present two comparisons:

*A comparison between model-estimated mean annual power density at various meteorological station locations for the layer of the atmosphere from the surface to $100 \mathrm{~m}$ and the "observed" mean annual power density based upon the observed winds at each of these stations.

*A comparison between winds observed by an aircraft over the coastal ocean and over land and model-predicted winds for the coastal zone on two selected days representing a dominant wintertime east coast wind energy regime.

\section{COMPARISON OF MODEI PREDICTED AND OBSERVED} ANNUAL AVERAGE WIND POWER DISTRIBUTIONS

Figures 1, 2 and 3 show the predicted annual average wind power distributions and the location of the surface stations to be used for the comparison. Table 1 provides details on each of these stations 
including the exponent a used in the power law to derive winds at heights other than the level of measurements. Using the fact that $P \sim \vec{u}^{3} \sim z^{3 \alpha}$ ( $P$ being the height-dependent wind power density), the annual average power density was calculated at 10, 30, 50 and $100 \mathrm{~m}$ and a layer mean was obtained by weighting each level by $0.20,0.20$, 0.35 and 0.25 respectively. The resulting $100 \mathrm{~m}$ layer-mean, annual average power densities are plotted below the solid dots which locate the verification stations in Figures 1,2 and 3 and are listed in Table 1 under "from data" column.

The corresponding model estimates are obtained by linear space interpolation of the $10 \times 10 \mathrm{~km}$ grid-square centered values used to generate Figures 1,2 and 3 . These are entered above the station symbol and are also given in Table 1 . The model-generated mean annual values shown in Figures 1,2 and 3 are obtained by combining the distributions of the three dominant wind regimes for each region. The climatological frequency of occurrence of each regime over the entire year is used to properly weight each regime distribution and thereby produce the annual average distribution.

Each wind power density value, observed (from data) or predicted, is an inexact estimate of the true wind power; i.e., each contains error. The errors in the observed values result primarily from uncertainties in the mean wind speed and in the value of the exponent $\alpha$. Allowing 1) the percent error in the annual average wind speed to be 1.08 for a period of data equal to 10 years plus an additional $0.5 \%$ for each year less than 10 years and 2) the uncertainty in the exponent to be 10.08 of $\alpha$ itself; then the percent error $(+)$ in the $100 \mathrm{~m}$ layer-mean, annual average wind power computed from meteorological data is calculated. These errors are listed in the last column of Table 1. In order to determine the percent error in the predicted wind power, it is assumed that the observed value is the best estimate of the true wind power. For each station in Table 1, the prediction error is then computed as ((predicted minus observed) 100/observed). These errors are given in the next-to-last column.

The predictive ability of the model is considered acceptable, and therefore useful, if the prediction error is within the limits of the observation error. Whenever the prediction error is greater than the observation error, then the excess error must be due to the deficiency of the prediction scheme. The skill of the prediction is determined as the ratio of the number of acceptable predictions to the total number of predictions. For the three mesoscale areas these skill ratings are $88 \%$ for the Chesapeake Bay area, $67 \%$ for the Apalachee Bay area and $0 \%$ for the South Texas coast area.

Good skill is demonstrated for the Chesapeake Bay area, acceptable skill for the Apalachee Bay area and no skill for the South Texas 
coast. Separate analysis (Snow, 1981) shows that over the South Texas coast the model underestimates the observed wind primarily as a result of the influence of topography. The east-facing slopes of the southern Rocky Mountains and the Sierra Madre oriental represent an elevated heat source by day and heat sink by night. The result is a diurnal oscillation in the pressure gradient force which was not dealt with in the model simulations.

We conclude that for the Chesapeake Bay and Apalachee Bay areas, the skill rating for annual average, $100 \mathrm{~m}$ layer-mean power density is near $77 \%$ and that for the meteorological and topographical conditions prevailing along the U.S. Atlantic and eastern Gulf coasts the model can provide reliable assessments of the average annual wind power density.

\section{VERIFICATION OF MODEU PREDICTIONS FOR SPECIFIC METEOROLOGICAL CONDITIONS}

Two important characteristics of coastal zone wind power are not directly addressed in the verification carried out in Section 2 which treated only land-based, average annual statistics. These are the numerical model's accuracy over the seaward portion of the coastal zone and the ability to duplicate strong spatial wind power gradients. There is no a priori evidence which suggests that a skill developed over land can be extended over the ocean. More importantly, in the annual average distributions, the gradients in wind power are not as strong as those found on some days because the summation over different distributions tends to eliminate strong, relatively short-lived gradients. Here the model's ability to reproduce strong gradients and to follow time changes in the wind field as dictated by the diurnal cycle of heating and cooling is tested.

A specific experiment, the Wallops Island Verification Experiment (WIVEX) was designed and carried out between 24 Jan and 5 Feb 1980 to provide an observational framework within which the model could be tested. In the analysis which follows, aircraft (National Center for Atmospheric Research's (NCAR Queen Air) winds obtained at $50 \mathrm{~m}$ and $170 \mathrm{~m}$ over the rectangular flight-track shown in Figure 4 are used. The aircraft obtained winds out to approximately $60 \mathrm{~km}$ seaward of the shore line three times a day: early morning, near noon and late afternoon. The flight-track required 2 to 3 hours to complete. Winds, based on an inertial navigation system, were recorded once every second.

Two days, $30 \mathrm{Jan}$ and $3 \mathrm{Feb} 1980$ both representative of the most dominant wintertime wind energy regime, are used for analysis. 


\subsection{January 1980}

The general meteorological conditions in the vicinity of the Delmarva Peninsula on the 30 th were as follows. It was essentially clear although some areas of rain middle-level clouds were found in late morning. These thickened and increased in amount during the afternoon. A small and fast-moving ridge was present in the middle atmosphere and high pressure centered on the south-central portion of Canada extended southeastward into the Carolinas. The initial geostrophic wind, determined primarily from the wallops Island rawinsonde released at $1200 \mathrm{GMT}(0700 \mathrm{EST})$ on the 30 th, was $340^{\circ}$ at $11.5 \mathrm{~m} \mathrm{~s}^{-1}$. The final value, based upon the rawinsonde of 0000 GMT on the 31 st (1900 EST on the $30 \mathrm{th}$ ), was $320^{\circ}$ at $10.5 \mathrm{~m} \mathrm{~s}^{-1}$. The resulting low-level wind flow in the WIVEX study area was moderate northwesterly backing and diminishing in intensity with the passage of time after sunrise. Air temperature (shelter-height) was approximately $-4 \mathrm{C}$ and no precipitation occurred within the WIVEX study area during the daylight hours.

Between sunrise and sunset the standard three flights were made. Wind information obtained during these flights at levels $50 \mathrm{~m}( \pm 9 \mathrm{~m})$ and $170 \mathrm{~m}( \pm 15 \mathrm{~m})$ above the surface is used in subsequent comparisons as averages of 120 individual measurements, i.e., two-minute averages.

In general the wind field in the WIVEX study area close to sunrise is shown in Figure 5A. North-northwesterly flow was particularly strong, $\simeq 12.0 \mathrm{~m} \mathrm{~s}^{-1}, 40$ to $50 \mathrm{~km}$ offshore. The minimum speeds, $=7.0 \mathrm{~m} \mathrm{~s}^{-1}$, occurred over the land areas most removed from coastlines. Within two hours after sunrise the winds had increased both over land, $\approx 9.5 \mathrm{~m} \mathrm{~s}^{-1}$, and over water, $\approx 13.0 \mathrm{~m} \mathrm{~s}^{-1}$. A midday backing into the northwest and decrease in speeds, especially over water, is seen in Figure 6A. BY late afternoon, Figure 7A, winds were still northwesterly and were nearly uniform in speed, $\simeq 7.5 \mathrm{~m} \mathrm{~s}^{-1}$, over both land and water.

Complete details of the initialization of the University of virginia mesoscale model are given in Table 2. Two significant refinements are incorporated into the model for these WIVEX simulations. The first is the use of a time-varying geostrophic wind, discussed at the bottom of Table 2, and the second is the computation of the aerodynamic surface roughness according to the formulation of $\mathrm{H}$. Lettau (1969).

Wind predictions were made by the model for the entire Chesapeake Bay area at one-minute intervals from one hour before sunrise until sunset. The fields of various meteorological variables for the WIVEX study area, at the 50 and $170 \mathrm{~m}$ levels, were printed out every $15 \mathrm{~min}-$ utes throughout the integration. The fields of the horizontal winc components were used to produce Figures $5 B-7 B$ (and $9 B-11 B$ ) which are the prediction analogues to the wind observations contained in Figures 
$5 A-7 A$ (and $9 A-11 A$ ). All of these prediction fields are composed of information from more than one 15-minute printout. Even though the predictions are made at one-minute intervals throughout the integration it is not necessary to retain information at intervals closer than 15 minutes. Meteorological conditions at a particular grid point change relatively slowly, in terms of wind speed, rarely more than 0.2 m $\mathrm{s}^{-1}$ per 15 minutes.

Because the aircraft took between 2 and 3 hours to complete a given circuit, comparisons are made sequentially along the track, for each level, between model-predicted wind at 15-minute intervals and 2 minute averaged observed flight wind. The space and time series of wind speeds taken from $F$ igures $5 A-7 A$ and $5 B-7 B$ are plotted in Figure 8 . (The smoothness of the predicted series confirms the procedure of analyzing predictions at intervals no closer than 15 minutes.) The predicted values are obtained by isotach analysis of the wind speed fields in the vicinity of each solid square (aircraft location) in Figures $5 \mathrm{~B}-7 \mathrm{~B}$.

The results on $30 \mathrm{Jan} 1980$ show a spatial and temporal correspondence between model-predicted and observed winds over the coast. strong gradients near shore are observed and reproduced by the model during the early morning. As the day progresses these gradients weaken. General trends as well as some of the shorter time changes in the observed wind speed are followed by the model in the time series shown in Figure 8.

\subsection{February 1980}

The mid-tropospheric flow pattern over eastern North America on the 3 rd was a narrow, nearly cut-off ridge centered over the province of Ontario and the upper Mississippi Valley, and a cyclone centered over the province of New Brunswick. In the lower atmosphere a shallow dome of cold, dry air, which had been centered in the Illinois-Indiana area during the previous day, weakened as it drifted southeastward into the Virginia-North Carolina area. Over the WIVEX study area these features resulted in clear skies throughout the daylight hours of the $3 r d$ with an average shelter-height temperature of $-5 \mathrm{C}$. The geostrophic wind near sunrise was $330^{\circ}$ at $13.5 \mathrm{~m} \mathrm{~s}^{-1}$ and by sunset it had backed and slackened to $305^{\circ}$ at $11.5 \mathrm{~m} \mathrm{~s}^{-1}$.

The standard three aircraft flights were again completed on 3 Feb 1980 and examples of the morning, midday and afternoon observed and predicted values along the flight tracks are shown in Figures 9 , 10, llA\&B. Table 2 provides the values used to initialize the model and Table 4 the comparison between the predicted and observed winds 
along the flight track. Figure 12 shows the complete series of observed and predicted winds for $3 \mathrm{Feb} 1980$.

Time and space simulation by the model of the observed winds again appears reasonable although large individual departures of the predicted from the observed winds are more frequent on this day than on the 30th Jan. An analysis of the observed and predicted winds on these two days follows in the next section.

\subsection{Determination of the Model's Skill for Specific Coastal Zone Situations}

Determination of the skill of the model in duplicating individual meteorological situations is based upon the two days representative of the dominant wintertime wind energy regime. Because this is a dominant condition with high wind speeds relative to all other wind regimes occurring over the Chesapeake Bay and Eastern Shore, it is an important and somewhat difficult test of the model. Success or failure to simulate these conditions will not provide unequivocal evidence as to the model's usefulness but it will provide a very sound basis upon which at least a qualitative judgment can be made.

Three different determinations of skill are made. The first is similar to that applied to annual average wind power values. The second deals with the magnitude and significance of the coefficient of linear correlation and the last is based on the average squared departure between predicted and observed wind speeds.

The skill of the model is the primary topic of interest. However, in any numerical simulation both the integration and the initialization influence the results. The model's skill resides in the formulation and integration of the equations which comprise the physical principles on which the model is based. But the accuracy of the initialization is wholly dependent upon the skill of the numerical experimentor. The separation of these skills is never complete, but any verification scheme is preferable which emphasizes the model's contribution to the results. Initial conditions are reflected more in overall mean values than in variations; this is especially true for the winds. Initially, at any particular height, all grid-points in the model domain have the same wind vector. If the surface were uniform throughout the domain and if no diurnal heating-cooling cycle occurred, then all winds would remain invariant at their initial value. However, given surface contrasts and given a complete diurnal heat cycle, circulations develop in response to these forcings. These circulations, once initialization is complete, are solely the results of the model's operations; they are controlled entirely by the model's equations. Therefore, the spatial 
and temporal variations are model-generated whereas the overall mean values reflect the experimentor's skill. The best specifications of the model's performance emphasize the variations.

Four variables are involved in the computation of wind power: three thermodynamic variables (pressure, temperature and water vapor content) and the wind speed. Of these the thenmodynamic variables determine the air density. The percent variation of wind speed during any particular day in an area such as the coastal zone is at least 25 times, typically 50 times greater than that of air density. In addition, the cubic relationship between wind speed and wind power triples the impact of wind speed variations and therefore, for any particular day, the affect of changes in thermodynamic variables on wind power estimates is typically $10^{2}$ smaller than that due to wind speed changes. The variations in wind power can therefore be determined from the analysis of the wind speed alone.

The following consideration allows wind direction to be ignored. The average discrepancy between predicted and observed wind directions for the two days is $10^{\circ}$ to $11^{\circ}$ (the maximum is $25^{\circ}$ ). Only the component of the wind normal to the plane defined by a rotating windmill blade is able to do useful work. That component varies as the cosine of the angle between the wind vector and the perpendicular to the plane of rotation. Therefore, the predicted wind directions are, for wind power purposes, at least $918(\cos (25))$ and on the average better than 988 (cos(11)) accurate. This substantially exceeds wind speed accuracy and therefore wind directions need not be analyzed further.

\subsubsection{Measurement Error Analysis}

An analysis similar to that applied in section 2 can be used to estimate the skill in predicting the WIVEX wind speeds. In particular, the percent of predicted values which fall within the measurement error Iimits of the observed values is a specification of the reliability of the prediction scheme. Both measurement and prediction are inexact estimates of the true wind speed, i.e., both contain error. The rationale applied is to allow the predicted wind an acceptable error limit equal to that of the observed wind. Thus, if the departure between observed and predicted values can be explained as due to error in measurement, then it is so explained and the prediction is characterized as "correct." But, if the departure is too large to be explained as measurement error, then the error in prediction must exceed that in measurement and the prediction is "wrong."

The error in the wind speed measured by the aircraft depends upon two onboard systems, the inertial navigation system (INS) and the air sensing probes system. During the WIVEX operations these systems per- 
formed especially well and the time-independent absolute (2 standard deviations) wind speed error is $\pm 0.5 \mathrm{~m} \mathrm{~s}^{-1}$. The INS is subject to a linear drift with the time elapsed since its alignment, a procedure carried out before each flight. Thus the wind speed error increases as the flight time increases. The net result is a total systematic error in the horizontal wind speed of $+0.5(1.0+t) \mathrm{m} \mathrm{s}^{-1}$, where $t$ is the time elapsed (hrs) since the alignment of the INs. Any error in the measurements which is not accounted for by this expression is wholly random and, in the average of 120 individual values, is negligibly small. Therefore, the absolute measurement error for the two-minute average wind speed, viz. the total systematic plus the random error, is given by the above expression. For the six flights completed on the two days analyzed the values at the beginning and end of each flight are given in Table 5.

The percent of the total number of predictions which fall within the absolute measurement error limits, i.e., the percent which is "correct," is a specification of skill. In Table 6 the skill ratings for each flight and for all flights of each day and for both days combined are presented. Overall a $75 \%$ rating was attained. Prediction ability was most variable for the midday flight, $88 \%$ to $44 \%$; and most consistent for the morning flight, $84 \%$, on both days.

The skill determined by this simple error analysis applies to the whole prediction scheme, model operations and initialization combined, since it is influenced by the mean value of the wind speed. The magnitude of the geostrophic wind is the element in the initialization which most affects the mean wind speed at any height in the model. If the initial value of the geostrophic wind were changed somewhat, then the resulting skill, as determined by measurement error analysis, would also change. But the model's skill would be unaltered by such a change. Therefore this skill rating is sensitive to the initialization. The development of a method for determining skill which discriminates against the effect of initialization is needed in order to better assess the skill of the model itself.

\subsubsection{Coefficient of Linear Correlation}

The coefficient of linear correlation provides a measure of the closeness with which the predicted series of wind speeds duplicates the variations occurring in the observed series. Since the total-series mean values are not emphasized in the correlation analysis, it is a more unbiased test of the model's skill than the analysis based on the size of departures relative to measurement error, previously carried out. Testing the statistical significance of the correlation is an integral part of this skill specification. 
In Table 7 are given the total number of prediction-observation pairs $\mathrm{N}$ and the value of the correlation coefficient $r$ between predicted and observed wind speeds for all flight operations on the 30th and the 3rd. The meaning of these correlations is vague until they are tested for significance. Although the closer the value of the coefficient is to unity the better, unless the possibility of chance correlation or correlation by way of associations with a mutual third item is reasonably excluded, the value is not a measure of skill. The F-statistic is used for the test (Panofsky and Brier, 1968).

In general, the larger the value of $F$, the more significant the correlation is. More specifically, assuming that the correlation is really zero, the question is asked; How likely is it that a correlation coefficient of the magnitude found occurred due to random chance? If this likelihood turns out to be smaller than a pre-specified limit, then the correlation found is acceptable as real, i.e. is acceptable as significantly different from zero. The values of the F-statistic for which there is only a $0.5 \%$ likelihood that the correlation coefficient occurred by chance are listed in Table 7 . Stated positively, if the calculated F-value exceeds the $0.5 \%$ test value, then the probability is at least 99.58 that the predicted series is really duplicating the observed series to some extent. The acceptance limits are set high because $\mathbf{N}$ is large but mainly because there is a third item to which both the observations and predictions are related, specifically the large-scale pressure gradient. Also, the number of degrees of freedom $\mathrm{n}$ needed in the computation of $\mathrm{F}$ is conservatively set at $\sqrt{\mathrm{N}}$. If the computed $F$ is larger than the test value, then the measure of the extent to which prediction duplicates observation is the value of the correlation coefficient.

The correlation coefficients for both days are significant and the overall skill rating is the average of the two values, specifically 77\%. (Since the skill of the model is of primary interest, the determination of an overall r-value from the two daily values and not from the combined total of 409 pairs is appropriate. Inter-day differences are included in the model simulations by way of initialization and are in no way controlled by the model.)

Whereas the value of $r$ is little influenced by differences in the full-day (total-series) means of the predicted and observed wind speeds, it is affected by the degree to which a trend in the observation series is reproduced in the predicted series. Due to the differential warming of the land, some slackening of the offshore flow is expected during the afternoon. This effect is controlled by the model in the simulation. However, on both days studied the strength of the large-scale pressure gradient decreased from sunrise to sunset; in terms of the geostrophic wind the changes were $-1.0 \mathrm{~m} \mathrm{~s}^{-1}$ on the $30 \mathrm{th} ;-2.0 \mathrm{~m} \mathrm{~s}^{-1}$ on 
the 3rd. In the numerical simulations this large-scale effect was made a function of time, as detailed at the bottom of Table 2. Therefore the trend which the prediction series effected on each day is due partly to the model's integration and partly to the updating of the geostrophic wind, essentially an initialization function. The overall skill rating of 778 determined by the correlation coefficient analysis is not completely free of the influence of initialization.

Figures $13 A \& B$ are the scatter diagrams of predicted and observed wind speeds for the two comparison days. The regression lines (broken) and the perfect prediction line (solid) are shown. On the 30th, the tendency was to over-predict in the lower half of the speed range. The overall scatter on the 3 rd was greater than on the 30 th and the tendency was to under-predict the lower speeds. Although any bias is undesirable, the different sign on the two days suggests initialization and not a systematic flaw in the model as the error source.

\subsubsection{Average Squared Difference}

The third determination of skill is the least affected by initialization and is therefore the best estimate of model's skill. Given two comparable series $\left(x_{i}, y_{i}\right)$, the average of the squared difference between them which is not biased by any disparity in means is

$$
E=\overline{\left(x_{i}-y_{i}-\delta\right)^{2}}
$$

where $\delta=\bar{x}-\bar{y}$. Expansion of this expression gives

$$
E=\sigma_{x}^{2}+\sigma_{y}^{2}-2 \sigma_{x y}^{2}
$$

where $\sigma^{2}$ represents the variances or the covariance of the subscripted variables. If a maximum value of $\mathrm{E}$ can be determined, then the skill with which predictions, the $y$-series, duplicates the observations, the $x$-series, is

$$
\varepsilon=\left(E_{\max }-E\right) / E_{\max }
$$

The condition which results in a maximum $E$-value is that the $x$ 's and $y^{\prime} s$ be totally uncorrelated, i.e. $\sigma_{x y}{ }^{2}=0$. If, in addition, the greater of the two variances $\sigma_{x}{ }^{2}$ or $\sigma_{y}{ }^{2}$ is used then

$$
E_{\max }=2 \sigma_{\max }{ }^{2} \text {. }
$$

From Figures 8 and 12 it is evident that $\sigma_{\max }{ }^{2}=\sigma_{x}{ }^{2}$, i.e. the variance of the observed series is greater than that of the predicted series. The skill rating $\varepsilon$ minimizes the impact of differing means and therefore emphasizes the model's influence on the predictions. 
In Table 8 are listed $E$, its maximum value and $\varepsilon$ for all wind information on the $30 \mathrm{th}$ and $3 \mathrm{rd}$. Skill ratings for the two days are $81 \%$ and $76 \%$, giving the estimate for the overall skill of the model by this method as the simple average, $78 \%$.

The skill ratings determined by each analysis are listed in Table 9 for the 30 th and 3 rd. As has been pointed out, the analysis based upon the average of the square of the unbiased differences is probably the best estimate of the model's skill in predicting boundary layer winds. An overall rating of $78 \%$ for the two WIVEX days studied is respectable. As regards the ratings determined by the other methods, the measurement error analysis provides the best estimate of skill for the prediction scheme as a whole, i.e. the model's skill and the numerical experimentor's skill combined. Assuming that these two skills operate simultaneously, continuously and with approximately equal impact on the results, then any skill evaluation containing both is roughly the average of the two skills. From the overall ratings in Table 9 , the implication is that the skill of the experimentor, specifically the skill involved in the initialization, is lower than that of the model's operation; $2(75)-78=728$.

\subsection{Wind Power Density Prediction}

A skill rating of 788 implies a total percent error of 228 , i.e. percent error limits of $\pm 11 \%$. Since wind power varies as the cube of wind speed, it is anticipated that the percent error in the wind power prediction ((prediction-measurement) (100)/measurement) will be 3 times that in the wind speed, approximate limits of \pm 338 . In Figure 14 are plotted the various observed values of measured wind speed cubed for each predicted wind speed. (As discussed previously, uncertainty in density on any particular day are totally negligible in comparison to that associated with the wind speed cubed.) The perfect prediction line and the $\pm 25 \%$ and $\pm 50 \%$ error isopleths are also entered on the diagrams. If a tolerance of $I$ standard deviation is allowed, i.e. 68\% of all cubed wind speeds are included within these limits, then the percent error in wind predictions is $\pm 30 \%$ on the 30 th, $\pm 35 \%$ on the $3 r d$, giving an average of $\pm 33 \%$. The meaning is that ( 1 ) the distribution of errors is approximately nomal and (2) the total percent error, 100 minus the skill rating, is close to the \pm 1 standard deviation limits.

Although the percent error in wind power prediction is considerable, specifically \pm 338 , it is not much larger than that inherent in wind power computations made from wind speed measurements. The wind speeds measured by the instrumented aircraft contain an average 2 standard-deviation measurement error of $\pm 1.4 \mathrm{~m} \mathrm{~s}^{-1}$ (refer to Table 5 ). 
The average measured wind speeds for the $30 \mathrm{th}$ and 3 rd are $9.5 \mathrm{~m} \mathrm{~s}^{-1}$ and $10.4 \mathrm{~m} \mathrm{~s}^{-1}$, respectively. The 2 standard deviation percent errors are therefore +158 and +138 , or \pm 148 overall, resulting in an average 1 standard deviation error of $\pm 7 \%$. Wind power computed from such data can be expected to contain a \pm 218 error.

Finally, a comparison of the measured and the predicted wind power density field in the WIVEX study area during the morning of 30 Jan is made. Figure 15 presents the areal distribution of wind power density within the large aircraft track for one circuit of the $120 \times 30$ $\mathrm{km}$ flight track. The values were computed from the aircraft measurements of wind speed and the requisite thermodynamic variables. The complete flight track required more than one hour to complete. The predicted distribution at a time approximately half way through the aircraft flight is given in Figure 16. Model-predicted values of wind speed and the thermodynamic variables were used to generate this field. The overall predicted pattern of power density is unmistakenly that which was observed. The strong near-shore gradient and the phenomenon of a distinct maximum between 40 and $50 \mathrm{~km}$ offshore are quantitatively well reproduced. Over land, however, the predicted minimum values exceed those observed. In spite of some large individual discrepancies, the usefulness of numerically generated products such as Figure 16 in wind power assessment is evident.

\section{CONCLUSIONS}

Areal distributions of annual average, $100 \mathrm{~m}$ layer-mean wind power are produced for three areas of the U.S. Atlantic and Gulf coastal zone by numerical simulation of the most prevalent wind regimes. Long-term meteorological data for 14 locations within these areas are used to calculate similar layer-means. In two of the three areas, Chesapeake Bay and Apalachee Bay, the comparison of the wind power values calculated from the data with those generated by the numerical model indicates that in $77 \%$ of the cases, roughly in 3 out of 4 cases, the disparity between the values is smaller than the error inherent in the layer-mean wind power computed from the data. In the third area, the south Texas coastal zone, the complete physics of the low-level atmosphere was not included in the model simulations and therefore no predictive skill was demonstrated there.

A total of 409 prediction-observation pairs of wind speeds are analyzed to determine the skill of the numerical model in duplicating specific meteorological situations in the coastal zone. The measurements were made on two wintertime days by a low-flying instrumented aircraft making repeated transects of the Delmarva Peninsula coastal zone. The predictions were generated by the 3-dimensional version of the University of Virginia mesoscale model, initialized with pre-dawn 
conditions for the two days. An overall skill rating of $78 \%$ was determined for the predicted wind speeds. The resulting total percent error $22 \%$ suggests percent error limits of $\pm 3 \%(22 / 2)$ for predicted wind power. Analysis of the predictions confirms that the \pm 1 stancard deviation error limits in predicted wind power are \pm 338 . The comparable limits in wind power computed from the wind speed measurements are \pm 21\%. In spite of errors which in individual cases may be large, the areal distributions of predicted wind power in the coastal zone contain a great deal of useful information. 


\section{REFERENCES}

Bethea, R. M., B. S. Duran and T. L. Boullion. 1975. Statistical Methods for Engineers and Scientists. Marcel Dekker, Inc., Publishers, New York, New York, $583 \mathrm{pp}$.

Garstang, M., R. Pielke and J. W. Snow. 1980. Coastal Zone Wind Energy, Part III. A Procedure to Determine the Wind Power Potential of the Coastal Zone. Draft final report submitted to Battelle Pacific Northwest Laboratory, under contract B-93492-A-Q, 42 pp.

Lettau, H. H. 1969. Note on Aerodynamic Roughness-Parameter Estimation on the Basis of Roughness-Element Description. J.Appl. Meteor., $8,828-832$.

Panofsky, H. A. and G. W. Brier. 1968. Some Applications of Statistics to Meteorology. The Pennsylvania State University, University Park, Pennsylvania, 224 pp.

Snow, J. W. 1981. Wind Power Assessment Along the Atlantic and Gulf Coasts of the United States. Ph.D. Dissertation, Department of Environmental Sciences, University of Virginia, Charlottesville, Virginia. 
Table 1. Verification of the annual average, $100 \mathrm{~m}$ layer-mean power density using data recorded in the three mesoscale coastal areas.

\begin{tabular}{|c|c|c|c|c|c|c|c|c|}
\hline $\begin{array}{l}\text { Station } \\
\text { Name }\end{array}$ & $\begin{array}{l}\text { Anemometer } \\
\text { llelght (m) }\end{array}$ & $\begin{array}{c}\text { Years of } \\
\text { Dnta }\end{array}$ & $\begin{array}{c}\text { Single-level } \\
\text { Annual Average } \\
\text { Power Density }\left(\mathrm{W} \mathrm{m} \mathrm{m}^{-2}\right)\end{array}$ & Exponent $(\alpha)$ & $\begin{array}{r}100 \mathrm{~m} \\
\text { Average } \mathrm{P} \\
\text { From Data } \\
\end{array}$ & $\begin{array}{l}\text { yer-Mean Annual } \\
\text { er Densily ( }\left(\mathrm{m}^{-2}\right) \\
\text { From Figs. } 21,25 \text { or } 29\end{array}$ & $\begin{array}{l}\text { Prediction } \\
\text { Error (8) } \\
\end{array}$ & $\begin{array}{l}\text { Observed } \\
\text { Error (1) }\end{array}$ \\
\hline $\begin{array}{l}\text { Chesapeake Bay } \\
\text { Area: }\end{array}$ & & & & & & & & \\
\hline Dover, $\mathrm{DE}$ (AFB) & 4.6 & $1957-64$ & 85 & $0.121 * \star$ & 196 & 205 & +1.6 & \pm 13.7 \\
\hline $\begin{array}{l}\text { Andrews Field, } \\
D C(A F B)\end{array}$ & 20.7 & $1955-61$ & 107 & $0.215^{\star *}$ & 181 & 197 & +8.8 & \pm 13.6 \\
\hline $\begin{array}{l}\text { Salistury, MD } \\
\text { (Wicomico Co. } \\
\text { Nirport) }\end{array}$ & 15.2 & $1949-50$ & 95 & $0.215 * 4$ & 196 & 192 & -2.0 & \pm 10.3 \\
\hline $\begin{array}{l}\text { Patuxent River, } \\
\text { Mn (NAS) }\end{array}$ & $\begin{aligned} 29.0 \\
4.0^{*}\end{aligned}$ & $\begin{array}{l}1955-57 \\
1960-64\end{array}$ & $\begin{array}{r}169 \\
57\end{array}$ & 0.215 & 278 & 235 & -15.5 & \pm 25.5 \\
\hline $\begin{array}{l}\text { Wallopes Island, } \\
\text { VA (HASA, tower } \\
x-85 \text { ) }\end{array}$ & 10.0 & $1967-76$ & 99 & $0.209 * 4$ & 259 & 245 & -5.4 & \pm 11.6 \\
\hline $\begin{array}{l}\text { Hampton, vn } \\
\text { (I.nngley } A \mathrm{Fn})\end{array}$ & $\begin{array}{l}29.3^{4} \\
4.0\end{array}$ & $\begin{array}{l}1955-59 \\
1960-64\end{array}$ & $\begin{array}{r}160 \\
57\end{array}$ & 0.209 & 213 & 220 & +3.3 & \pm 15.0 \\
\hline $\begin{array}{l}\text { Morfolk. Vn } \\
\text { (Reqional Nirport) }\end{array}$ & 17.7 & $1955-58$ & 142 & $0.209^{* *}$ & 260 & 230 & -11.5 & \pm 10.4 \\
\hline $\begin{array}{l}\text { Virginta Beach, VA } \\
\text { (Oceana HAS) }\end{array}$ & $\begin{array}{l}12.0^{\circ} \\
4.0\end{array}$ & $\begin{array}{l}1955-59 \\
1960-64\end{array}$ & $\begin{array}{r}122 \\
73\end{array}$ & 0.240 & 313 & 250 & -20.1 & \pm 19.2 \\
\hline
\end{tabular}


Table 1 (cont.)

\begin{tabular}{|c|c|c|c|c|c|c|c|c|}
\hline $\begin{array}{l}\text { Station } \\
\text { Name }\end{array}$ & $\begin{array}{l}\text { Anemometer } \\
\text { Height (m) }\end{array}$ & $\begin{array}{c}\text { Years of } \\
\text { Data }\end{array}$ & $\begin{array}{c}\text { Single-Level } \\
\text { Annual nuerage } \\
\text { Power Density }\left(\omega^{-2} \mathrm{~m}^{-2}\right)\end{array}$ & Exponent (a) & $\begin{array}{r}100 \mathrm{~m} \\
\text { Average } \mathrm{P} \\
\text { From Data }\end{array}$ & $\begin{array}{l}\text { Layer-Mean Amual } \\
\text { Ower Density }\left(\mathrm{W} \mathrm{m}^{-2}\right) \\
\text { From Figs. } 21,25 \text { or } 29\end{array}$ & $\begin{array}{l}\text { Prediction } \\
\text { Error (8) }\end{array}$ & $\begin{array}{l}\text { Observed } \\
\text { Error (1) }\end{array}$ \\
\hline $\begin{array}{l}\text { Apalachee Bay } \\
\text { Area: }\end{array}$ & $\because$ & & - & & & & & \\
\hline $\begin{array}{l}\text { Tallahassee, FL } \\
\text { (nale Mabry Fleld, } \\
T-167)\end{array}$ & 16.5 & $1951-60$ & 31 & $0.066^{*}$ " & 37 & 72 & +94.6 & \pm 9.7 \\
\hline $\begin{array}{l}\text { Panama city, FL } \\
\text { (Tyndall } \wedge \mathrm{FD})\end{array}$ & $\begin{array}{l}10.3 \\
3.0\end{array}$ & $\begin{array}{l}1955-57 \\
1958-64\end{array}$ & $\begin{array}{l}75 \\
51\end{array}$ & 0.066 & 86 & 93 & +0.1 & \pm 12.9 \\
\hline $\begin{array}{l}\text { Tampa, FL } \\
\text { (MCOLI] } A F B)\end{array}$ & $\begin{array}{l}22.9 \\
4.0^{*}\end{array}$ & $\begin{array}{l}1955-57 \\
1950-64\end{array}$ & $\begin{array}{l}66 \\
47\end{array}$ & 0.061 & 72 & 67 & -6.9 & \pm 11.6 \\
\hline \multicolumn{9}{|l|}{$\begin{array}{l}\text { South Texas coast } \\
\text { nrea: }\end{array}$} \\
\hline $\begin{array}{l}\text { Corpus Chrlsti, TX } \\
\text { (NNS) }\end{array}$ & $\begin{array}{c}19.2^{\star} \\
6.7\end{array}$ & $\begin{array}{l}1955-60 \\
1961-64\end{array}$ & $\begin{array}{l}259 \\
160\end{array}$ & 0.213 & 456 & 142 & $-6 \theta .9$ & \pm 15.1 \\
\hline $\begin{array}{l}\text { Ktngsville, TX } \\
\text { (NnS) }\end{array}$ & 17.4 & $1955-61$ & 157 & $0.213^{* *}$ & 294 & 131 & -55.4 & \pm 14.0 \\
\hline $\begin{array}{l}\text { Hrownsille, TX } \\
\text { (Int. Mrport) }\end{array}$ & 17.1 & $1955-60$ & 191 & $0.213^{\star \star *}$ & 362 & 134 & -63.0 & \pm 15.6 \\
\hline
\end{tabular}

* lleiglit used as basis for computing layer-mean power density. Criteria for selection, length of record or, if record lengths equal, greater height,

*Expment not determinable for this station; value of nearest otation used. (In the case of Dover, DE, ntlantic City, HJ was used.) 
Table 2. Initialization and parameterization of the University of Virginia Mesoscale Model for the Chesapeake Bay Area on two operational days of the Wallops Island Verification Experiment

\begin{tabular}{|c|c|c|}
\hline Ezanen & so in $\equiv 0$ & $3 \bar{I}=30$ \\
\hline 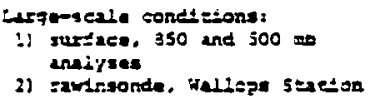 & $\begin{array}{l}30 / 60 \text { and } 122.31 / 003 \\
30 / 122 \text { and } 31 / 30 z\end{array}$ & $\begin{array}{l}3 / 00 \text { and } 122,4 / 00 z \\
3 / 32 z \text { and } 4 / 00 z\end{array}$ \\
\hline Yean baesfich $(\cdot \mathrm{y})$ & 38 & 20 \\
\hline 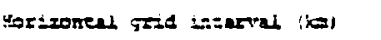 & $: 0$ & $10^{\circ}$ \\
\hline 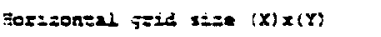 & $30 \times 36$ & $30 \times 36$ \\
\hline Versent ievels & $: 2 * \infty$ & $22 \cdots$ \\
\hline$\because=4 \operatorname{sep}(s)$ & jo & 50 \\
\hline $\begin{array}{l}\text { ind surface: } \\
\text { i) sibedo } \\
\text { 2) seughnose langh (a) }\end{array}$ & 0.25 & 33 \\
\hline 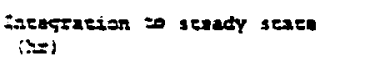 & $\vdots$ & 1 \\
\hline Z.25097acton taisiation & suarisese & sunetse \\
\hline $\begin{array}{l}\text { Enl=al planeeny bourdary } \\
\text { isyar }(=1\end{array}$ & 2200 & 300 \\
\hline 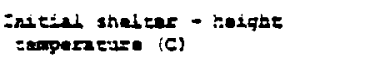 & -5.0 & -7.0 \\
\hline 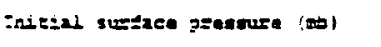 & $i \oplus 2 E .0$ & $: 025.0$ \\
\hline See surface temperature (C) & $7.0=0$ & 9.000 \\
\hline 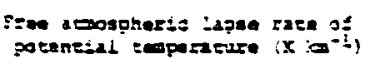 & 3.0 & 5.3 \\
\hline 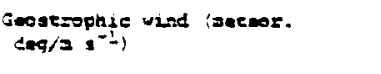 & $240 / 12.3=200 / 10.5$ & $120 / 13.5=0305 / 11.3^{*}$ \\
\hline 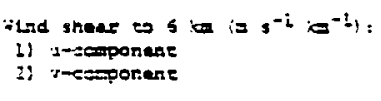 & -3.0 & 9.2 \\
\hline 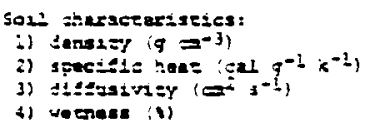 & $\begin{array}{l}1.75 \\
0.50 \\
0.5040 \\
1.5 .0\end{array}$ & $\begin{array}{l}1.75 \\
2.50 \\
2.5040 \\
1.50\end{array}$ \\
\hline
\end{tabular}

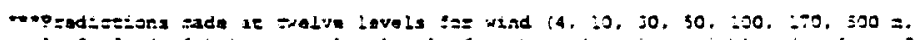

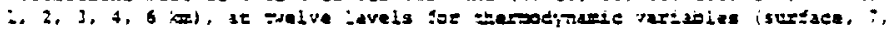

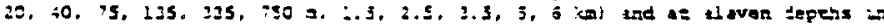
$\Rightarrow$ s021 is 0 is 7 as $5=$ intemisi.

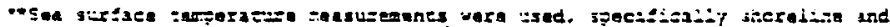

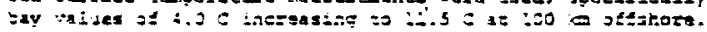

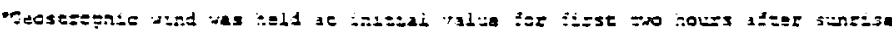

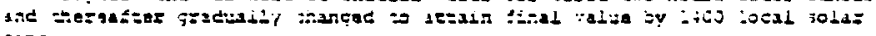


Table 3a. Observed and predicted wind speeds ( $\mathrm{m} \mathrm{s}^{-1}$ ) for the morning flight on $30 \mathrm{Jan} 80$, initial and final $50 \mathrm{~m}$ tracks. Observed values are two-minute averages centered at the time entered to the left; predicted values are at 15-minute intervals. These data are plotted in Figure 8. Letter entries refer to locations in Figures 5-7. * indicates a prediction outside the error limits in Table 5 .

\begin{tabular}{|c|c|c|c|c|}
\hline \multicolumn{3}{|c|}{ Observed Wind Speed -1} & \multicolumn{2}{|c|}{ Predicted wind Speed } \\
\hline \multirow[t]{2}{*}{ a } & 0711 & 8.9 & 0713 & 9.5 \\
\hline & 0713 & 10.4 & 0713 & 10.4 \\
\hline \multirow[t]{2}{*}{$b$} & 0715 & 11.4 & 0713 & 10.6 \\
\hline & 0717 & 10.9 & 0713 & 10.6 \\
\hline \multirow[t]{2}{*}{$c$} & 0719 & 11.4 & $\star 0713$ & 10.4 \\
\hline & 0721 & 11.8 & $\star 0728$ & 10.7 \\
\hline \multirow[t]{2}{*}{ d } & 0725 & 10.7 & 0728 & 10.6 \\
\hline & 0727 & 10.7 & 0728 & 10.6 \\
\hline \multirow[t]{2}{*}{ e } & 0729 & 11.1 & 0728 & 10.6 \\
\hline & 0731 & 11.3 & 0728 & 10.6 \\
\hline \multirow[t]{2}{*}{$f$} & 0735 & 11.6 & 0743 & 11.1 \\
\hline & 0737 & 10.9 & 0743 & 11.3 \\
\hline \multirow[t]{2}{*}{9} & 0739 & 11.5 & 0743 & 11.4 \\
\hline & 0741 & 11.6 & 0743 & 11.5 \\
\hline \multirow{2}{*}{\multicolumn{2}{|c|}{$\begin{array}{l}\text { Mean } \\
\text { Values }\end{array}$}} & & & \\
\hline & & 11.01 & & $10.7 I$ \\
\hline \multirow{2}{*}{\multicolumn{2}{|c|}{$\begin{array}{l}\text { Cbserved win } \\
\text { Time }\end{array}$}} & Speed & \multirow{2}{*}{\multicolumn{2}{|c|}{$\begin{array}{l}\text { Predicted wind Speed } \\
\text { Tine in } \mathrm{s}^{-1}\end{array}$}} \\
\hline & Time & $m s^{-1}$ & & \\
\hline \multirow[t]{2}{*}{ is } & 0941 & 12.6 & 0943 & 11.7 \\
\hline & 0943 & 13.0 & 0943 & 11.7 \\
\hline \multirow[t]{2}{*}{$i$} & 0945 & 12.9 & 0943 & 21.5 \\
\hline & 0947 & 12.0 & 0943 & 11.1 \\
\hline \multirow[t]{2}{*}{$j$} & 0949 & 11.3 & 0943 & 10.7 \\
\hline & 0951 & 10.1 & 0943 & 10.0 \\
\hline
\end{tabular}


Table 3b. Observed and predicted wind speeds $\left(\mathrm{m} \mathrm{s}^{-1}\right)$ for the morning flight on $30 \mathrm{Jan} 80$, both $170 \mathrm{~m}$ rectangles. (Otherwise the same as Table $3 a$ ).

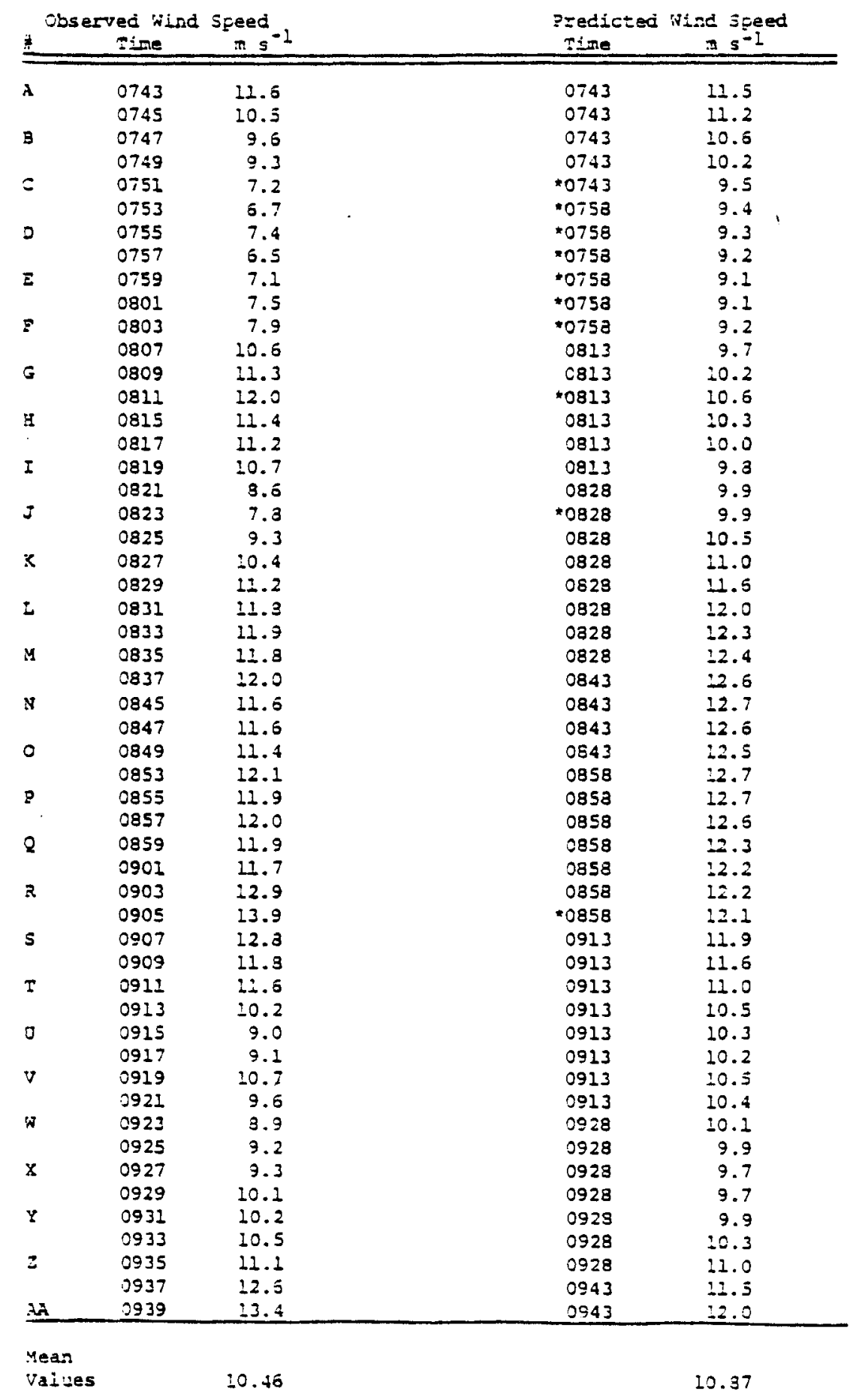


Table 3c. Observed and predicted wind speeds $\left(\mathrm{m} \mathrm{s}^{-1}\right)$ for the midday flight on 30 Jan 80 , initial and final $50 \mathrm{~m}$ tracks. (Otherwise the same as Table $3 a$ ).

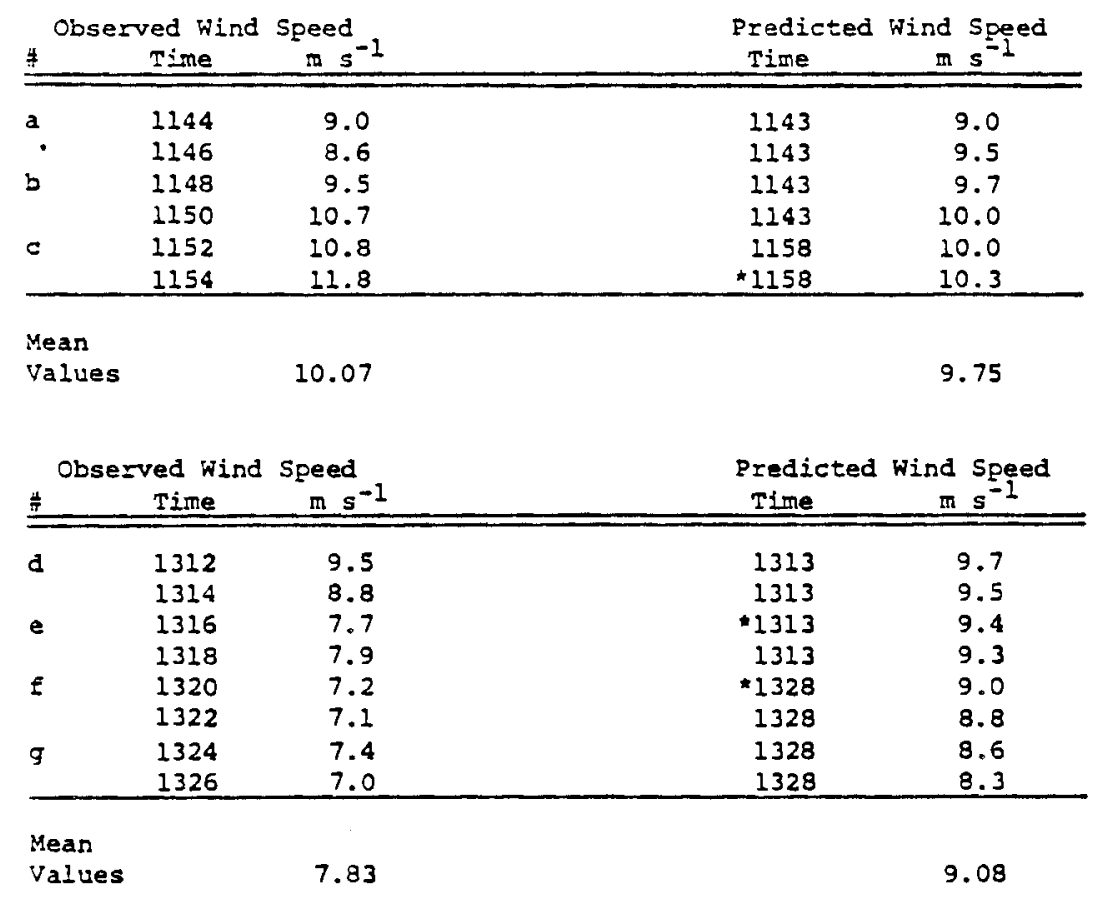


Table 3d. Observed and predicted wind speeds $\left(\mathrm{m} \mathrm{s}^{-1}\right)$ for the midday flight on $30 \mathrm{Jan} 80$, large $170 \mathrm{~m}$ rectangle. (Otherwise the same as Table 3a).

\begin{tabular}{|c|c|c|c|c|}
\hline 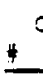 & $\begin{array}{l}\text { Ved } \mathrm{H} \\
\mathrm{SIme}\end{array}$ & $=s^{-1}$ & $\begin{array}{l}\text { Predicted } \\
\text { Ifre }\end{array}$ & $\begin{array}{r}\text { Wind Speed } \\
m 3^{3}\end{array}$ \\
\hline \multirow[t]{2}{*}{$\lambda$} & 1158 & 11.7 & 1258 & 10.7 \\
\hline & 1200 & 11.6 & 1258 & 10.6 \\
\hline \multirow[t]{2}{*}{3} & 1202 & 12.0 & 1258 & 10.4 \\
\hline & 1204 & 10.5 & 1258 & 10.2 \\
\hline \multirow[t]{2}{*}{$c$} & 1206 & 9.5 & 1213 & 9.9 \\
\hline & 1208 & 9.7 & 1213 & 9.7 \\
\hline \multirow[t]{2}{*}{ D } & 1210 & 8.5 & 1213 & 9.5 \\
\hline & 1212 & 8.0 & .1213 & 9.3 \\
\hline \multirow[t]{2}{*}{$\Sigma$} & 1214 & 8.6 & 1213 & 9.2 \\
\hline & 1216 & 8.5 & 1213 & 9.2 \\
\hline \multirow[t]{2}{*}{$F$} & 1218 & 9.4 & 1213 & 9.2 \\
\hline & 1220 & 9.6 & 1213 & 9.3 \\
\hline \multirow[t]{2}{*}{$G$} & 1222 & 9.3 & 1228 & 9.2 \\
\hline & 1224 & 9.3 & 1228 & 9.2 \\
\hline \multirow[t]{2}{*}{ в } & 1226 & 10.0 & 1229 & 9.2 \\
\hline & 1230 & 10.9 & 1228 & 9.1 \\
\hline \multirow[t]{2}{*}{$I$} & 1232 & 9.9 & 1228 & 9.0 \\
\hline & 1234 & 9.6 & 1228 & 8.9 \\
\hline \multirow[t]{2}{*}{$\mathrm{J}$} & 1236 & 9.7 & 2228 & 8.7 \\
\hline & 1240 & 8.5 & 1243 & 8.3 \\
\hline \multirow[t]{2}{*}{$\mathbf{R}$} & 1242 & 8.3 & 1243 & 8.5 \\
\hline & 1244 & 9.0 & 1243 & 8.4 \\
\hline \multirow[t]{2}{*}{ I } & 1246 & 8.3 & 1243 & 8.4 \\
\hline & 1248 & 9.2 & 1243 & 3.4 \\
\hline \multirow[t]{2}{*}{$y$} & 1250 & 9.2 & 1243 & a. 6 \\
\hline & 1252 & 10.0 & 1243 & 8.3 \\
\hline \multirow[t]{2}{*}{$\mathbf{N}$} & 1254 & 9.7 & 1258 & 9.1 \\
\hline & 1256 & 10.2 & 1258 & 9.3 \\
\hline \multirow[t]{2}{*}{0} & 1258 & 11.2 & 1258 & 9.5 \\
\hline & 1300 & 11.0 & 2258 & 9.8 \\
\hline \multirow[t]{2}{*}{$P$} & 1302 & 11.2 & 1258 & 9.9 \\
\hline & 1306 & 10.8 & 1258 & 10.0 \\
\hline$Q$ & 1308 & 10.3 & 1253 & 10.0 \\
\hline 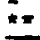 & 1310 & 10.3 & 1258 & 10.1 \\
\hline
\end{tabular}

twFinal obsezred wind speed not shown in Figure $6 \mathrm{~A}$ due to superposition with sirst value. 
Table $3 e$. Observed and predicted wind speeds ( $\mathrm{m} \mathrm{s}^{-1}$ ) for the afternoon flight on $30 \mathrm{Jan} 80$, initial and final $50 \mathrm{~m}$ tracks. (Otherwise the same as Table $3 a$ ).

\begin{tabular}{|c|c|c|c|c|}
\hline \multicolumn{3}{|c|}{ Observed Wind Speed } & \multirow{2}{*}{\multicolumn{2}{|c|}{ Predicted wind Speed }} \\
\hline$\#$ & Time & $\mathrm{m} \mathrm{s}^{-1}$ & & \\
\hline \multirow[t]{2}{*}{$\mathbf{a}$} & 1424 & 8.9 & 1428 & 8.1 \\
\hline & 1426 & 8.5 & 1428 & 8.6 \\
\hline \multirow[t]{2}{*}{$b$} & 1428 & 8.4 & 1428 & 8.9 \\
\hline & 1430 & 8.6 & 1428 & 9.0 \\
\hline \multirow[t]{2}{*}{ c } & 1432 & 8.6 & 1428 & 9.2 \\
\hline & 1434 & 8.6 & 1428 & 9.3 \\
\hline \multirow[t]{2}{*}{ d } & 1436 & 9.0 & $1 \$ 43$ & 9.3 \\
\hline & 1438 & 8.5 & 1443 & 9.4 \\
\hline \multirow[t]{2}{*}{ e } & 1440 & 8.3 & $\star 1443$ & 9.3 \\
\hline & 1442 & 8.9 & 1443 & 9.2 \\
\hline \multirow[t]{2}{*}{ 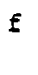 } & 1444 & 8.3 & 1443 & 9.1 \\
\hline & 1448 & 8.6 & 1443 & 9.0 \\
\hline \multirow[t]{2}{*}{$g$} & 1450 & 8.8 & 1458 & 9.0 \\
\hline & 1452 & 8.3 & 1458 & 8.8 \\
\hline$\underline{\mathbf{h}}$ & 1454 & 8.5 & 1458 & 8.7 \\
\hline
\end{tabular}

\begin{tabular}{|c|c|c|c|c|}
\hline$\#$ & $\begin{array}{l}\text { ed w: } \\
\text { Time }\end{array}$ & m $s^{-1}$ & $\begin{array}{l}\text { Predicte } \\
\text { Tine }\end{array}$ & $\begin{array}{c}\text { wind Speed } \\
\text { m s-1 }\end{array}$ \\
\hline h & 1650 & 9.9 & 1658 & 9.6 \\
\hline \multirow[t]{2}{*}{1} & 1652 & 9.3 & 1658 & 9.7 \\
\hline & 1654 & 9.5 & 1658 & 9.8 \\
\hline \multirow[t]{2}{*}{$j$} & 1656 & 9.3 & 1658 & 9.8 \\
\hline & 1658 & 9.1 & 1658 & 9.6 \\
\hline \multirow[t]{2}{*}{$k$} & 1700 & 9.5 & 1658 & 9.2 \\
\hline & 1702 & 8.8 & 1658 & 8.6 \\
\hline
\end{tabular}


Table 3f. Observed and predicted wind speeds $\left(\mathrm{m} \mathrm{s}^{-1}\right)$ for the afternoon flight on $30 \mathrm{Jan} 80$, both $170 \mathrm{~m}$ rectangles. (Otherwise the same as Table $3 a$ ).

\begin{tabular}{|c|c|c|c|c|}
\hline \multicolumn{3}{|c|}{ Observed ind speed } & \multicolumn{2}{|c|}{ Predicted wind speed } \\
\hline A & $\begin{array}{l}1456 \\
1458\end{array}$ & $\begin{array}{l}8.7 \\
8.3\end{array}$ & 1453 & 8.9 \\
\hline \multirow[t]{2}{*}{3} & 1500 & 8.0 & 1458 & 3.5 \\
\hline & 1502 & 7.4 & 1458 & 8.3 \\
\hline \multirow[t]{2}{*}{ c } & 1504 & 7.3 & $1+53$ & 3.2 \\
\hline & 1506 & 6.7 & $* 1513$ & 8.2 \\
\hline \multirow[t]{2}{*}{ D } & 1508 & 7.0 & 1513 & 8.1 \\
\hline & $I \leq I 0$ & 5.9 & 1513 & 8.1 \\
\hline \multirow[t]{2}{*}{$\Xi$} & 1512 & 7.2 & 1513 & 8.0 \\
\hline & 1514 & 8.2 & 1513 & 8.0 \\
\hline \multirow[t]{2}{*}{$\Xi$} & 1516 & 7.5 & 1513 & 7.9 \\
\hline & 1520 & 8.0 & $1 \leq 29$ & 8.1 \\
\hline \multirow[t]{2}{*}{ G } & 2522 & 8.3 & $: 528$ & 9.3 \\
\hline & 1524 & 3.3 & 1528 & 8.4 \\
\hline \multirow[t]{2}{*}{8} & 2528 & 7.5 & 1528 & 8.4 \\
\hline & 2530 & 8.3 & 1528 & 3.4 \\
\hline \multirow{2}{*}{$I$} & 1532 & 3.0 & $\$ 528$ & 3.5 \\
\hline & 1534 & 7.5 & 1528 & 8.6 \\
\hline \multirow[t]{2}{*}{$\mathrm{J}$} & 1536 & 7.6 & 1543 & 8.7 \\
\hline & 1538 & 7.3 & 1543 & 8.9 \\
\hline \multirow[t]{2}{*}{$\mathrm{x}$} & 2540 & 7.9 & 1543 & 9.2 \\
\hline & 1542 & 7.9 & 1543 & 9.4 \\
\hline \multirow[t]{2}{*}{ \pm} & 1544 & 7.8 & 1543 & 9.6 \\
\hline & $: 546$ & 7.5 & 1543 & 9.7 \\
\hline \multirow[t]{2}{*}{ M } & 1548 & 7.5 & $=1543$ & 9.3 \\
\hline & 1550 & 8.1 & 1543 & 9.9 \\
\hline \multirow[t]{2}{*}{$\mathrm{N}$} & 1554 & 7.5 & 1558 & 9.8 \\
\hline & 1556 & 7.2 & 1558 & 9.7 \\
\hline \multirow[t]{2}{*}{0} & 1558 & 7.0 & 1558 & 9.6 \\
\hline & 1602 & 7.6 & $\$ 1558$ & 9.6 \\
\hline \multirow[t]{2}{*}{ ? } & 1604 & 7.6 & .1553 & 9.5 \\
\hline & $\$ 606$ & 7.5 & +1513 & 9.5 \\
\hline \multirow[t]{2}{*}{$Q$} & $\$ 608$ & 7.5 & 1613 & 9.5 \\
\hline & 1610 & 7.6 & $\$ 1613$ & 9.4 \\
\hline \multirow[t]{2}{*}{$\mathbf{R}$} & 1612 & 7.3 & 1613 & 9.6 \\
\hline & 2614 & 7.9 & 1613 & 9.7 \\
\hline$s$ & 1616 & 8.3 & 1613 & 9.7 \\
\hline & 1618 & 3.0 & 1613 & 9.6 \\
\hline$z$ & 1620 & 3.0 & 1613 & 9.4 \\
\hline & 1622 & 9.2 & 1628 & 9.2 \\
\hline v & 2624 & 9.5 & 2628 & 9.0 \\
\hline & 1626 & 9.5 & 2628 & 9.8 \\
\hline$v$ & 2628 & 9.2 & 1628 & 3.7 \\
\hline & 1630 & 9.3 & 1628 & 3.8 \\
\hline ผ & 1632 & 3.4 & 1628 & 8.6 \\
\hline & 1634 & 8.9 & 1628 & 3.4 \\
\hline$x$ & 1636 & 3.1 & 1643 & 8.4 \\
\hline & 2638 & 8.5 & 1643 & 8.3 \\
\hline$\underline{y}$ & 1640 & 8.7 & 1643 & 3.5 \\
\hline & 1542 & 8.9 & 1543 & 8.5 \\
\hline$z$ & 1644 & 9.7 & $: 543$ & 3.9 \\
\hline & 1646 & 9.5 & 1543 & 9.3 \\
\hline.$A$ & 1548 & 9.7 & 1543 & 0.6 \\
\hline
\end{tabular}


Table 4a. Observed and predicted wind speed $\left(\mathrm{m} \mathrm{s}^{-1}\right.$ ) for the morning flight on $3 \mathrm{Feb} 80$, initial and final $50 \mathrm{~m}$ tracks. Observed values are two-minute averages centered at the time entered to the left; predicted values are at 15-minute intervals. These data are plotted in Figure 12. Letter entries refer to locations in Figures 9-11. * indicates a prediction outside the error limits in Table 5 .

\begin{tabular}{|c|c|c|c|c|}
\hline \multicolumn{2}{|c|}{ Observed wind } & $\begin{array}{l}\text { Speed } \\
\mathrm{m} \mathrm{s}^{-1}\end{array}$ & \multicolumn{2}{|c|}{ Predicted Wind Speed } \\
\hline \multirow[t]{2}{*}{ a } & 0704 & 9.3 & 0708 & 8.8 \\
\hline & 0706 & 12.8 & $\star 0708$ & 9.8 \\
\hline \multirow[t]{2}{*}{$b$} & 0708 & 13.6 & $* 0708$ & 10.5 \\
\hline & 0710 & 13.4 & $* 0708$ & 10.9 \\
\hline \multirow[t]{2}{*}{$c$} & 0712 & 12.9 & $* 0708$ & 11.0 \\
\hline & 0714 & 12.8 & $* 0708$ & 11.0 \\
\hline \multirow[t]{2}{*}{ d } & 0716 & 12.5 & $\star 0708$ & 11.0 \\
\hline & 0720 & 12.0 & 0723 & 11.5 \\
\hline \multirow[t]{2}{*}{ e } & 0722 & 12.5 & 0723 & 11.5 \\
\hline & 0724 & 12.7 & $* 0723$ & 11.4 \\
\hline \multirow[t]{2}{*}{$f$} & 0726 & 13.3 & $* 0723$ & 11.4 \\
\hline & 0730 & 13.2 & 0723 & 11.4 \\
\hline \multirow[t]{2}{*}{ g } & 0732 & 12.5 & 0738 & 11.9 \\
\hline & 0734 & 12.4 & 0738 & 12.0 \\
\hline \multirow[t]{2}{*}{$\mathrm{h}$} & 0736 & 12.3 & 0738 & 11.9 \\
\hline & 0738 & 13.0 & 0738 & 11.8 \\
\hline \multicolumn{2}{|l|}{$\begin{array}{l}\text { Mean } \\
\text { Values }\end{array}$} & 12.5 & & 11.1 \\
\hline \multirow{2}{*}{\multicolumn{2}{|c|}{$\begin{array}{c}\text { Observed wind } \\
\begin{array}{c}* \\
\text { Time }\end{array}\end{array}$}} & Speed & \multirow{2}{*}{\multicolumn{2}{|c|}{$\begin{array}{l}\text { Predicted Wind Speed } \\
\text { Time }\end{array}$}} \\
\hline & & $\mathrm{ms}$ & & \\
\hline \multirow[t]{2}{*}{$i$} & 0946 & 14.3 & 0953 & 13.0 \\
\hline & 0948 & 13.9 & 0953 & 13.0 \\
\hline \multirow[t]{2}{*}{ j } & 0950 & 12.7 & 0953 & 12.9 \\
\hline & 0952 & $11=5$ & 0953 & 12.8 \\
\hline \multirow[t]{2}{*}{$k$} & 0954 & 11.1 & 0953 & 12.4 \\
\hline & 0956 & 10.9 & 0953 & 12.0 \\
\hline \multirow[t]{2}{*}{1} & 0958 & 11.1 & 0953 & 11.4 \\
\hline & 1000 & 9.8 & 0953 & 10.7 \\
\hline $\begin{array}{l}\text { Mean } \\
\text { Values }\end{array}$ & & 11.9 & & 12.3 \\
\hline
\end{tabular}


Table 4b. Observed and predicted wind speeds $\left(\mathrm{m} \mathrm{s}^{-1}\right.$ ) for the morning flight on $3 \mathrm{Feb} 80$, both $170 \mathrm{~m}$ rectangles. (Otherwise the same as Table 4 a).

\begin{tabular}{|c|c|c|c|c|}
\hline \multirow{3}{*}{ A } & 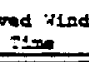 & ipeod ${ }^{-1}$ & \multicolumn{2}{|c|}{ Predictad Fised seend } \\
\hline & 0740 & 12.7 & 0798 & 19.3 \\
\hline & $\$ 742$ & 52.3 & 0738 & 19.5 \\
\hline \multirow[t]{2}{*}{3} & 0744 & $: 2.3$ & 0718 & 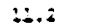 \\
\hline & 0746 & 22.3 & 19738 & 10.3 \\
\hline \multirow[t]{2}{*}{$=$} & 0743 & 12.4 & .0753 & 0.5 \\
\hline & 0730 & 20.3 & 9733 & \pm 0.3 \\
\hline \multirow[t]{2}{*}{0} & 0732 & 9.7 & 0753 & $: 0.2$ \\
\hline & 5734 & $\therefore 0.2$ & 5753 & 0.1 \\
\hline \multirow[t]{2}{*}{$\Xi$} & 9756 & 3.0 & 3753 & 0.2 \\
\hline & gisa & 3.3 & 359 & \pm 0.2 \\
\hline \multirow[t]{2}{*}{$z$} & 2900 & $9 . ;$ & 2753 & :0.3 \\
\hline & 2804 & 9.4 & 2808 & 10.7 \\
\hline \multirow[t]{2}{*}{$=$} & 5008 & 11.5 & 2808 & 12.1 \\
\hline & 5808 & 23.0 & 2868 & $\because .4$ \\
\hline \multirow[t]{2}{*}{3} & 5010 & 13.5 & 12808 & 3.5 \\
\hline & 6815 & 13.3 & 3808 & i.? \\
\hline \multirow[t]{2}{*}{ : } & 0813 & 13.0 & 3923 & $: 2.7$ \\
\hline & 5820 & 12.: & jaz3 & $\vdots .5$ \\
\hline \multirow[t]{2}{*}{ s } & 2822 & 21.7 & 0923 & 5.3 \\
\hline & 6824 & $\div 0.9$ & 6823 & 1.1 \\
\hline \multirow[t]{2}{*}{ ? } & 2825 & $=2.3$ & 0923 & $\therefore 1.1$ \\
\hline & 6828 & 12.3 & 8823 & L.J \\
\hline \multirow[t]{2}{*}{5} & 3030 & 2.9 & 2823 & $\because \div .9$ \\
\hline & 2032 & 23.0 & 5838 & 2.5 \\
\hline \multirow[t]{2}{*}{$y$} & 3834 & $: 3 .:$ & 6838 & $: 3.0$ \\
\hline & 3836 & 23.5 & $383 a$ & 43.3 \\
\hline \multirow[t]{2}{*}{$\mathbf{s}$} & 0838 & .3 .2 & 6838 & $: 3.6$ \\
\hline & 0840 & 22.7 & 0938 & 13.9 \\
\hline 0 & 0844 & 22.1 & 0938 & $: 3.3$ \\
\hline & 5846 & 12.6 & .838 & 13.3 \\
\hline 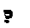 & 0948 & 12.3 & 2853 & $: 4.0$ \\
\hline & 2850 & 12.3 & 685.3 & $: 3.9$ \\
\hline$z$ & 7834 & 22.7 & 6953 & $: 3.9$ \\
\hline & $08 \leq 6$ & $\therefore 3.0$ & jas3 & 13.3 \\
\hline $\mathbf{a}$ & 0358 & & $2 a 53$ & 13.5 \\
\hline & 9900 & 12.3 & 2953 & $: 3.5$ \\
\hline 3 & 2902 & 13.5 & & 13.3 \\
\hline & 8904 & 13.5 & 8908 & $: 3.4$ \\
\hline$\Sigma$ & 0906 & 13.7 & 2908 & $\$ 3 . ;$ \\
\hline & 2908 & 23.2 & 6908 & $\$ 3.3$ \\
\hline D & 2910 & -3.3 & 5908 & .2 .9 \\
\hline & 2912 & $\therefore 2.7$ & 0908 & -2.5 \\
\hline 7 & 2914 & $: 3.0$ & 8908 & $: 2.2$ \\
\hline & 2916 & 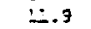 & 3908 & $\therefore .3$ \\
\hline 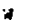 & $\therefore 918$. & $: 3.2$ & 0923 & B. \\
\hline & 2920 & $: 4.3$ & .0923 & $\because . .5$ \\
\hline$x$ & 0922 & 23.0̈ & 3923 & :...7 \\
\hline & 2924 & 13.5 & 0923 & $\therefore .3$ \\
\hline$?$ & ;926 & 22.5 & 3923 & $\therefore$ : \\
\hline & 2828 & $\because .2$ & 0923 & :...t \\
\hline$z$ & $=930$ & 20.1 & 2923 & $\because$ \\
\hline & 9932 & $: 0.3$ & 2938 & $\therefore .2$ \\
\hline i & 3934 & $\because .0$ & 9938 & $: 0.3$ \\
\hline & 2036 & i-..5 & 2938 & $\$ 1.0$ \\
\hline 38 & 0938 & 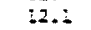 & & b.t. \\
\hline & 0740 & 22.7 & $29 ? 8$ & $: 1.3$ \\
\hline$\therefore$ & 2942 & $: 3.2$ & $\$ 939$ & :2.3 \\
\hline & $: 944$ & $\because \therefore$ & .978 & $\therefore \therefore$ \\
\hline
\end{tabular}


Table 4c. Observed and predicted wind speeds $\left(\mathrm{m} \mathrm{s}^{-1}\right.$ ) for the midday flight on $3 \mathrm{Feb} 80$, initial and final $50 \mathrm{~m}$ tracks. (Otherwise the same as Table $4 a$ ).

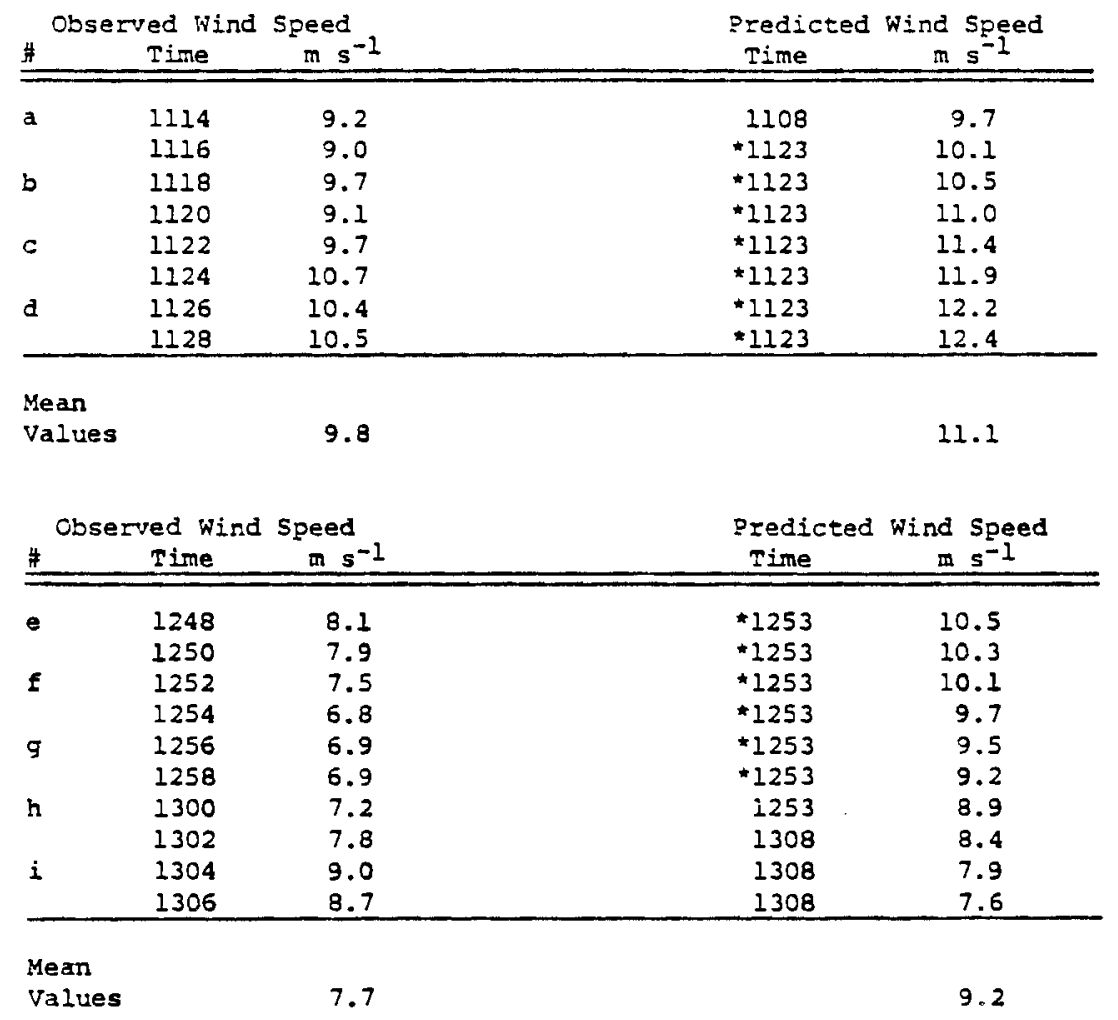


Table 4d. Observed and predicted wind speeds $\left(\mathrm{m} \mathrm{s}^{-1}\right)$ for the midday flight on $3 \mathrm{Feb} 80$, large $170 \mathrm{~m}$ rectangle. (Otherwise the same as Table 4 a).

\begin{tabular}{|c|c|c|c|c|}
\hline \multicolumn{3}{|c|}{ Obsarved wind speed } & \multicolumn{2}{|c|}{ Predicred Find Spẹed } \\
\hline \multirow[t]{2}{*}{ i } & 1130 & 10.2 & $\$ 1223$ & 12.5 \\
\hline & 1132 & 10.4 & $* 1138$ & 11.9 \\
\hline \multirow[t]{2}{*}{3} & 1134 & 10.3 & $* 1138$ & 11.6 \\
\hline & 1136 & 9.9 & .1138 & 11.2 \\
\hline \multirow[t]{2}{*}{ c } & 1138 & 9.3 & $* 1238$ & 10.9 \\
\hline & 1140 & 9.1 & $* 1138$ & 10.6 \\
\hline \multirow[t]{2}{*}{$\mathrm{D}$} & 1142 & 7.7 & 11238 & 10.3 \\
\hline & 1144 & 7.3 & -1138 & 9.9 \\
\hline \multirow[t]{2}{*}{$\Xi$} & 1146 & 8.1 & 11138 & 9.7 \\
\hline & 1148 & 3.6 & 1153 & 9.2 \\
\hline \multirow[t]{2}{*}{$\Xi$} & 1150 & 9.6 & 1253 & 9.2 \\
\hline & 1152 & 20.4 & $1 \geq \leq 3$ & 9.4 \\
\hline \multirow[t]{2}{*}{$G$} & 1154 & 10.5 & 1253 & 9.5 \\
\hline & 1156 & 11.3 & 1153 & 9.5 \\
\hline \multirow[t]{2}{*}{$\mathrm{a}$} & 1158 & 11.6 & $\star 1153$ & 9.6 \\
\hline & 1200 & 11.2 & 11253 & 9.6 \\
\hline \multirow[t]{2}{*}{ I } & 1204 & 10.9 & $=1208$ & 9.3 \\
\hline & 1206 & 12.1 & 1208 & 9.2 \\
\hline \multirow[t]{2}{*}{ J } & 1208 & 9.8 & 1208 & 9.0 \\
\hline & 1210 & 10.4 & -1208 & 3.9 \\
\hline \multirow[t]{2}{*}{$\mathbf{K}$} & 1212 & 9.3 & 1208 & 8.3 \\
\hline & 1214 & 9.3 & 1208 & 8.7 \\
\hline \multirow[t]{2}{*}{ I } & 1216 & 9.1 & 1208 & 8.5 \\
\hline & 1218 & 9.1 & 1223 & 8.4 \\
\hline \multirow[t]{2}{*}{.} & 1220 & 9.3 & 1223 & 8.3 \\
\hline & 1222 & 9.0 & 1223 & 3.3 \\
\hline \multirow[t]{2}{*}{$\mathrm{N}$} & 1224 & 9.2 & 1223 & 8.4 \\
\hline & 1226 & 8.4 & 1223 & 3.6 \\
\hline \multirow[t]{2}{*}{0} & 1228 & 9.1 & 1223 & 9.0 \\
\hline & 1230 & 9.8 & 1223 & 9.5 \\
\hline \multirow[t]{2}{*}{ ?. } & 1232 & 9.7 & 2238 & 9.8 \\
\hline & 1234 & 10.3 & $\lcm{238}$ & 20.3 \\
\hline \multirow[t]{2}{*}{$Q$} & 1236 & 9.3 & $i 238$ & 10.6 \\
\hline & 1240 & 9.3 & 1238 & 20.9 \\
\hline \multirow[t]{2}{*}{$\mathbf{R}$} & 1242 & 9.3 & $\$ 1238$ & 12.0 \\
\hline & 1244 & 8.5 & 1238 & 11.0 \\
\hline $\mathbf{s}$ & 1246 & 8.1 & +1238 & 11.1 \\
\hline
\end{tabular}


Table 4e. Observed and predicted wind speeds $\left(\mathrm{m} \mathrm{s}^{-1}\right)$ for the afternoon flight on $3 \mathrm{Feb} 80$, initial and final $50 \mathrm{~m}$ track. (Otherwise the same as Table $4 a$ ).

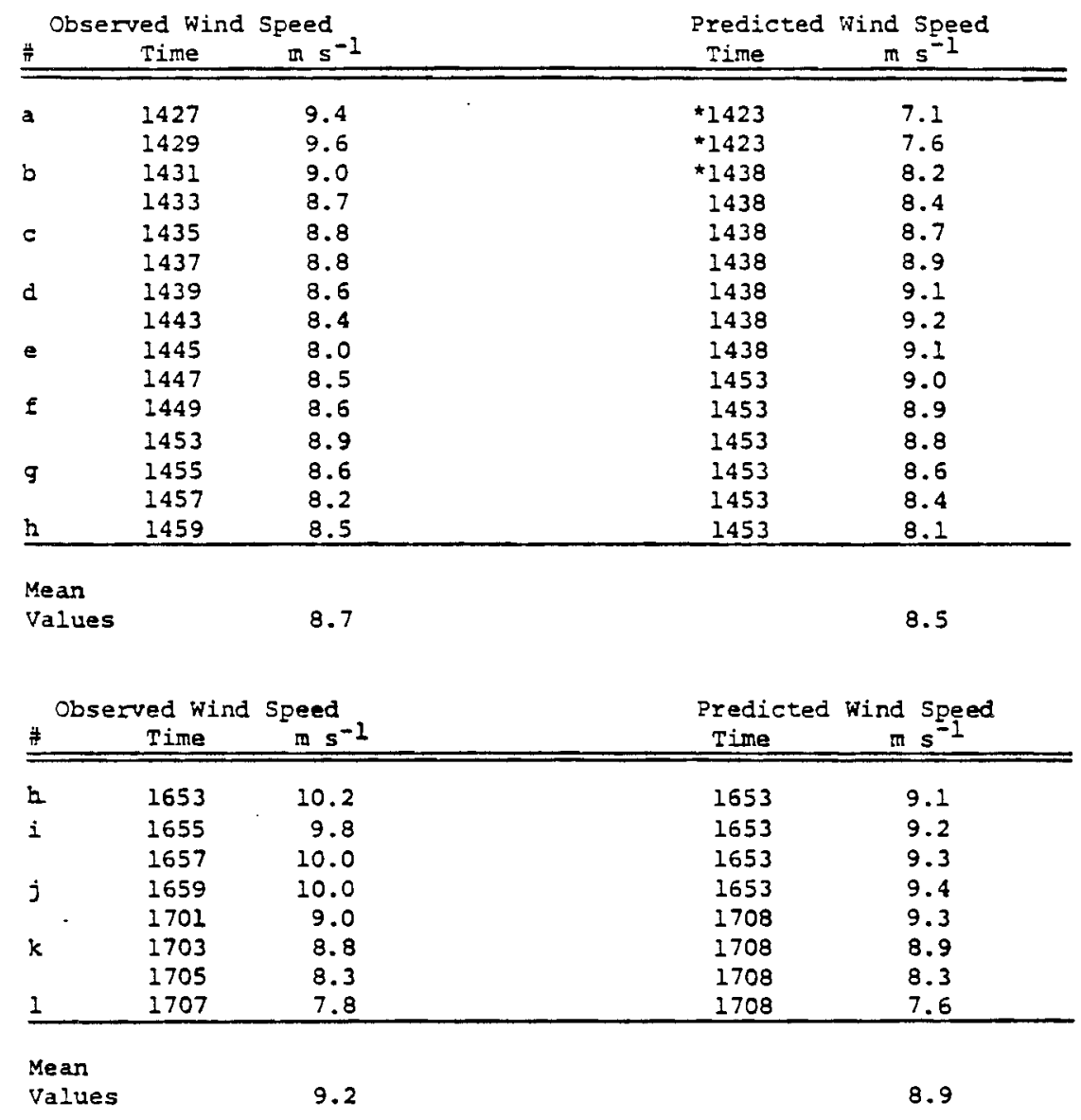


Table 4f. Observed and predicted wind speeds $\left(\mathrm{m} \mathrm{s}^{-1}\right)$ for the afternoon flight on $3 \mathrm{Feb} 80$, both $170 \mathrm{~m}$ rectangles. (Otherwise the same as Table 4 a).

\begin{tabular}{|c|c|c|c|c|}
\hline 4 & $\begin{array}{l}\text { red winc } \\
\text { Time }\end{array}$ & $\begin{array}{l}\text { Speed } \\
\text { il } s^{-1} \\
\end{array}$ & $\begin{array}{l}\text { Pzedicted } \\
\text { Iine }\end{array}$ & $\begin{array}{c}\text { Wind speed } \\
\pi s^{-1}\end{array}$ \\
\hline \multirow[t]{2}{*}{$\lambda$} & 1501 & 8.8 & $i 508$ & 8.2 \\
\hline & 1503 & 8.7 & 1508 & 8.0 \\
\hline \multirow[t]{2}{*}{ B } & 1505 & 7.9 & 1508 & 7.3 \\
\hline & 1507 & 8.9 & 1508 & 7.3 \\
\hline \multirow[t]{2}{*}{$c$} & 1509 & 9.4 & 1508 & 7.4 \\
\hline & 1511 & 9.2 & 1508 & 7.4 \\
\hline \multirow[t]{2}{*}{$D$} & 1513 & 10.5 & 1508 & 7.4 \\
\hline & 1515 & 9.1 & $=1508$ & 7.4 \\
\hline \multirow[t]{2}{*}{$z$} & 1517 & 9.7 & +1523 & 7.4 \\
\hline & 1519 & 8.9 & $\$ 1523$ & 7.3 \\
\hline \multirow[t]{2}{*}{ 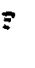 } & 1521 & 9.4 & 1523 & 7.3 \\
\hline & 1525 & 9.3 & $* 1523$ & 7.3 \\
\hline \multirow[t]{2}{*}{ G } & 1527 & 9.4 & $\$ 1523$ & 7.5 \\
\hline & 1529 & 9.4 & $\| \leq 23$ & 7.5 \\
\hline \multirow{2}{*}{ I } & 1531 & 8.7 & 1538 & 7.6 \\
\hline & 1533 & 8.0 & 2538 & 7.6 \\
\hline \multirow[t]{2}{*}{$I$} & 1535 & 9.2 & 1538 & 7.5 \\
\hline & 1537 & 9.2 & .1538 & 7.6 \\
\hline \multirow[t]{2}{*}{$J$} & 1539 & 9.5 & $* 1538$ & 7.7 \\
\hline & 1541 & 9.6 & +1538 & 7.3 \\
\hline \multirow{2}{*}{$x$} & 1543 & 9.9 & $\$ 1538$ & 3.0 \\
\hline & 1545 & 9.9 & 1538 & 3.4 \\
\hline \multirow[t]{2}{*}{ 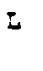 } & 1547 & 9.8 & 1553 & 8.9 \\
\hline & 1549 & 10.0 & 1553 & 9.2 \\
\hline \multirow[t]{2}{*}{$M$} & 1551 & 9.6 & 1553 & 9.4 \\
\hline & 1553 & 9.2 & 1553 & 9.7 \\
\hline \multirow[t]{2}{*}{$N$} & 1555 & 9.3 & 1553 & 9.8 \\
\hline & 1559 & 8.7 & 1553 & 9.7 \\
\hline \multirow[t]{2}{*}{0} & 1601 & 8.1 & 1608 & 9.6 \\
\hline & 1603 & 7.9 & $* 1608$ & 9.5 \\
\hline \multirow[t]{2}{*}{2} & 1607 & 8.4 & 1608 & 9.4 \\
\hline & 1609 & 7.7 & 1608 & 9.3 \\
\hline \multirow[t]{2}{*}{$Q$} & 1611 & 9.0 & 1608 & 9.1 \\
\hline & 1613 & 7.8 & 1608 & 8.9 \\
\hline \multirow[t]{2}{*}{$\mathbf{R}$} & 1615 & 8.2 & 2608 & 8.9 \\
\hline & 1617 & 8.7 & 1623 & 9.2 \\
\hline \multirow[t]{2}{*}{$s$} & 1619 & 10.0 & 1623 & 9.3 \\
\hline & 1621 & 10.1 & 1623 & 9.3 \\
\hline \multirow[t]{2}{*}{$\Gamma$} & 1523 & 10.0 & 1623 & 9.1 \\
\hline & 1625 & 9.8 & 1623 & 8.3 \\
\hline ठ & 1627 & 9.1 & 1623 & 8.4 \\
\hline & 1629 & 8.3 & 1623 & 8.1 \\
\hline$v$ & 1631 & 9.1 & 1638 & 8.1 \\
\hline & 1633 & 9.0 & 1638 & 8.0 \\
\hline$\omega$ & 1635 & 8.3 & 1638 & a. 0 \\
\hline & 1637 & 8.5 & 1638 & 7.3 \\
\hline$x$ & 1639 & 9.4 & 1638 & 7.7 \\
\hline & 1641 & 8.5 & 1638 & 7.5 \\
\hline$Y$ & 1643 & 9.9 & 1638 & 7.6 \\
\hline & 1645 & 10.3 & 1538 & 7.8 \\
\hline$z$ & 1647 & 10.3 & 11653 & 3.2 \\
\hline & $i 649$ & 10.6 & 1653 & 3.7 \\
\hline $\mathrm{AA}$ & 1651 & 10.1 & $\$ 553$ & 9.1 \\
\hline
\end{tabular}


Table 5. Absolute* error limits $\left( \pm \mathrm{m} \mathrm{s}^{-1}\right)$ for measured wind speeds from beginning to end of each flight component. Time (hh $\mathrm{mm}, E S T$ ) at which inertial navigation system aligned is given in parentheses for each flight.

\begin{tabular}{cccc} 
Day & Morning & $\begin{array}{c}\text { FIIGHT } \\
\text { Midday }\end{array}$ & Afternoon \\
\hline 30 Jan 80 & $(0639)$ & $(1102)$ & $(1348)$ \\
& \pm 0.8 to 2.1 & \pm 0.9 to 1.7 & \pm 0.8 to 2.1 \\
3 Feb 80 & $(0606)$ & $(1032)$ & $(1402)$ \\
& \pm 1.0 to 2.4 & \pm 0.9 to 1.8 & \pm 0.7 to 2.0 \\
\hline
\end{tabular}

*The absolute error is equivalent to $\div 2$ standard deviations, i.e. the probability is less than 1 in $20^{\circ}$ that the true value of the horizontal wind speed, in any instance, is outside these limits. 
Table 6. Numbers of "correct" wind speed predictions and percentages by flight and daily total for two WIVEX days. "Correct" means predicted value departs from observed value by not more than the absolute measurement error.

\begin{tabular}{|c|c|c|c|c|}
\hline Day & Morning & Midday & Afternoon & :otal \\
\hline $30 \operatorname{Jan} 30$ & $\begin{array}{c}51 \text { of } 73 \\
344\end{array}$ & $\begin{array}{c}42 \text { of } 48 \\
884\end{array}$ & $\begin{array}{c}59 \text { of } 75 \\
794\end{array}$ & $\begin{array}{c}162 \text { of } 196 \\
338\end{array}$ \\
\hline 3 : 5 bo & $\begin{array}{c}69 \text { of } 32 \\
348\end{array}$ & $\begin{array}{c}24 \text { of } 55 \\
448\end{array}$ & $\begin{array}{c}53 \text { of } 76 \\
\text { 70s }\end{array}$ & $\begin{array}{c}146 \text { of } 213 \\
59\end{array}$ \\
\hline
\end{tabular}


Table 7. Coefficient of linear correlation $(r)$ and significance tests for all pairs of predicted and observed wind speeds on two wIVEX days. $N$ is the number of pairs, $n$ is the number of degrees of freedom $\sqrt{N}) . \quad F=r^{2}(n-1) /\left(1-r^{2}\right)$. The $0.5 \%$ test values of $F$ are taken from Bethea et al. (1975), Table VI.

\begin{tabular}{cccccc} 
Day & $\mathrm{N}$ & $\underline{\mathrm{n}}$ & $\mathrm{n}$ & $F$ & $F(0.58)$ \\
\hline 30 Jan 80 & 196 & 0.793 & 14 & 22.03 & 11.10 \\
3 Feb 80 & 213 & 0.749 & 15 & 17.89 & 10.80 \\
\hline
\end{tabular}

Table 8. Average of the square of the urbiased differences for all wind speeds on two WIVEx days. Refer to text for explanation of elements.

\begin{tabular}{cccc} 
Day & $E$ & $E_{\max }$ & $\varepsilon$ \\
\hline $30 \operatorname{Jan} 80$ & 1.024 & 5.399 & 0.810 \\
3 Eeb 80 & 1.702 & 6.975 & 0.756 \\
\hline
\end{tabular}


Table 9. Skill ratings ( 8 ) determined by various analyses.

\begin{tabular}{cccc} 
Day & $\begin{array}{c}\text { Measurement } \\
\text { Error }\end{array}$ & $\begin{array}{c}\text { Correlation } \\
\text { Coefficient }\end{array}$ & $\begin{array}{c}\text { Unbiased } \\
\text { Differences }\end{array}$ \\
\hline 30 Jan 80 & 83 & 79 & 81 \\
3 Feb 80 & 69 & 75 & 76 \\
\hline Overall & 75 & 77 & 78
\end{tabular}


FIGURES 1-3. Annual average power density $\left(\mathrm{W} \mathrm{m}^{-2}\right)$, layer-mean given for each $100 \mathrm{~km}^{2}$ (10 km north-south $\times 10 \mathrm{~km}$ east-west) as determined from meteorological

variables predicted by the numerical model of the atmosphere. Centers of relative maximum $(X)$ and minimum (N) are indicated along with solid isolines at $50 \mathrm{~W} \mathrm{~m}^{-2}$ intervals. Land areas are shaded. The land-water boundary is depicted in detail for ease of orientation and location whereas in the computer integrations the character of the surface for each grid-square is represented by its percent of land area. The locations of meteorological stations used to verify predictions are shown as heavy solid dots. 
FIGURE 1.

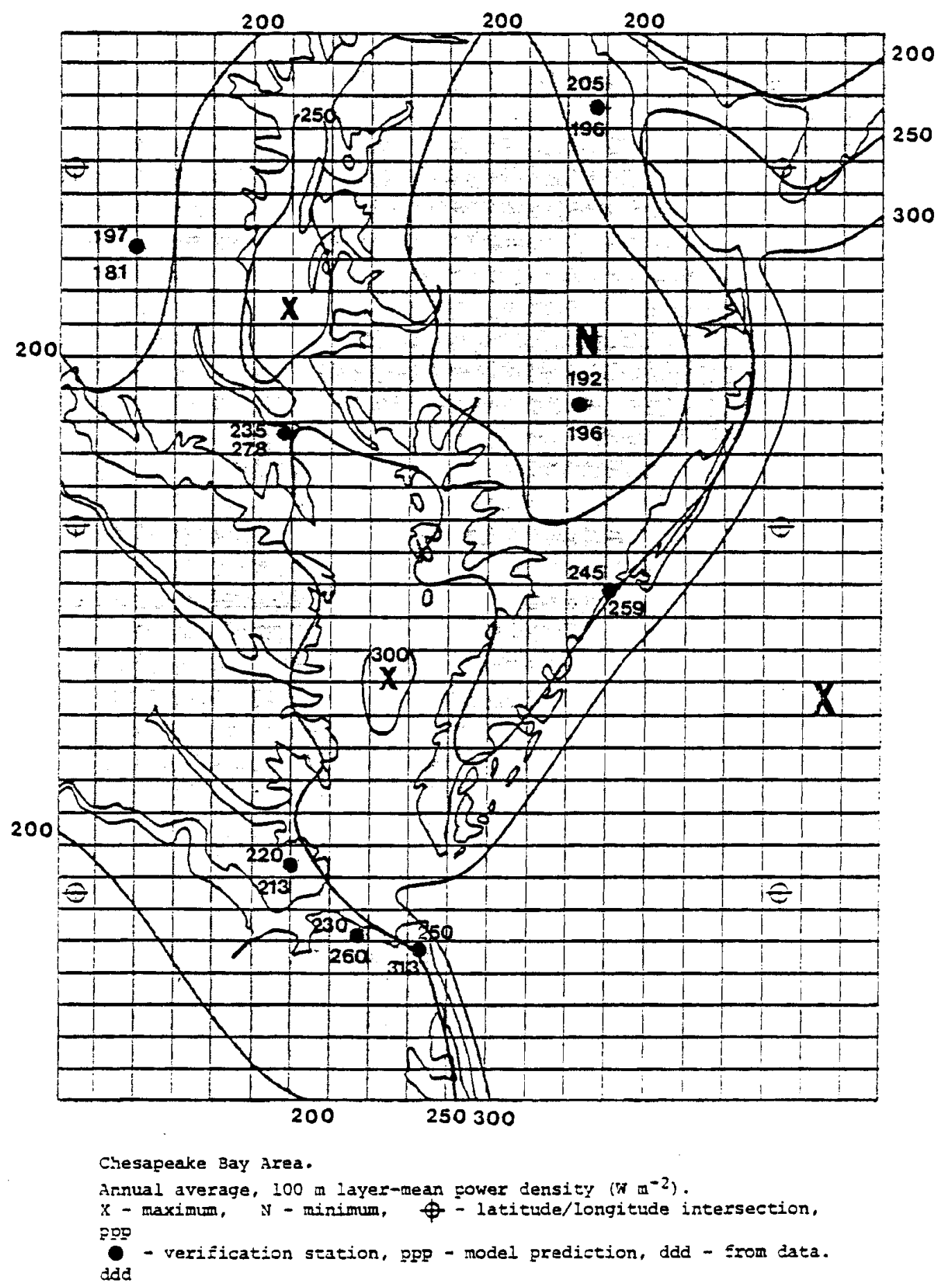


FIGURE 2 .

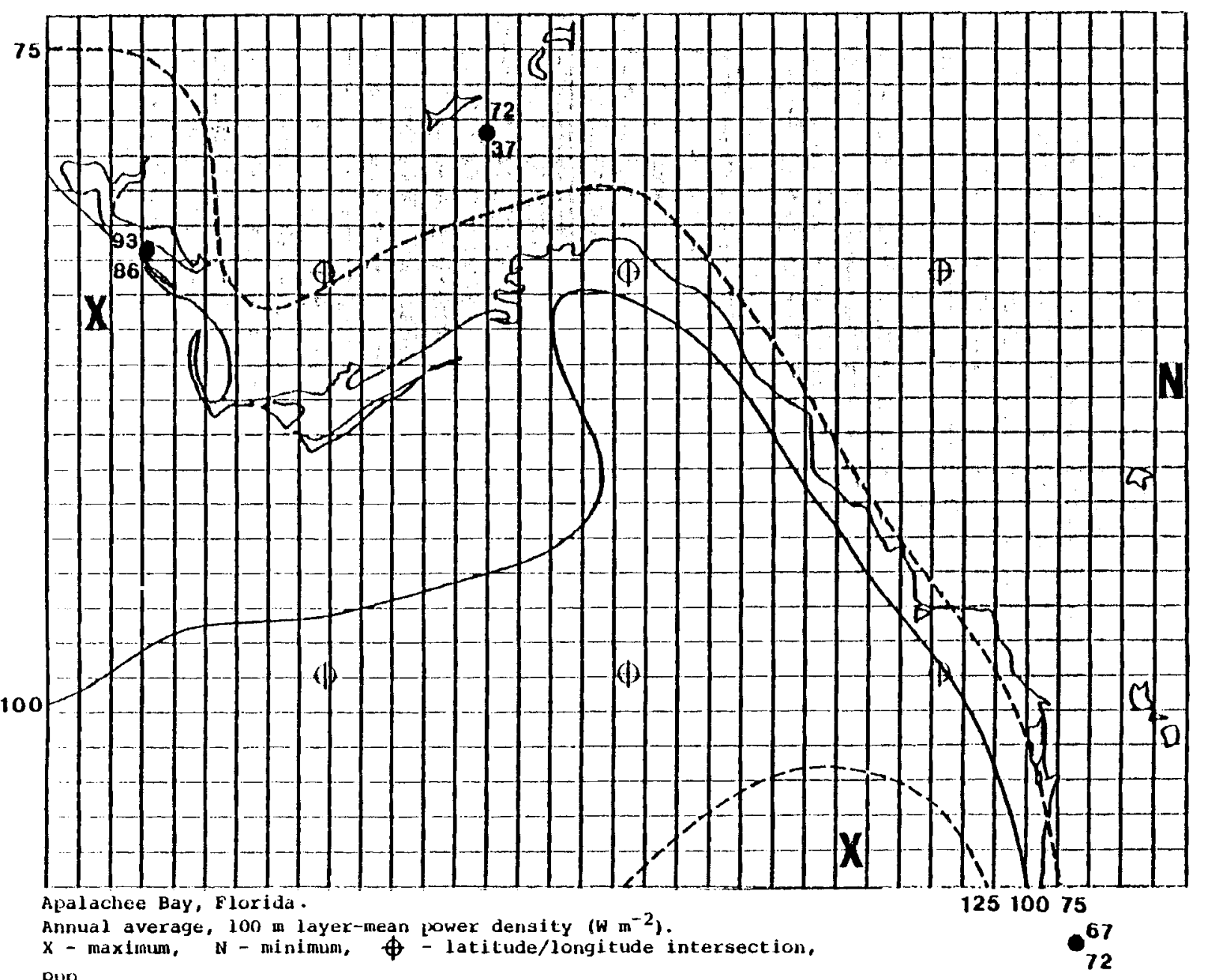

ddd - verification station, ppp - model prediction, ddd - from data. 
FIGURE 3.

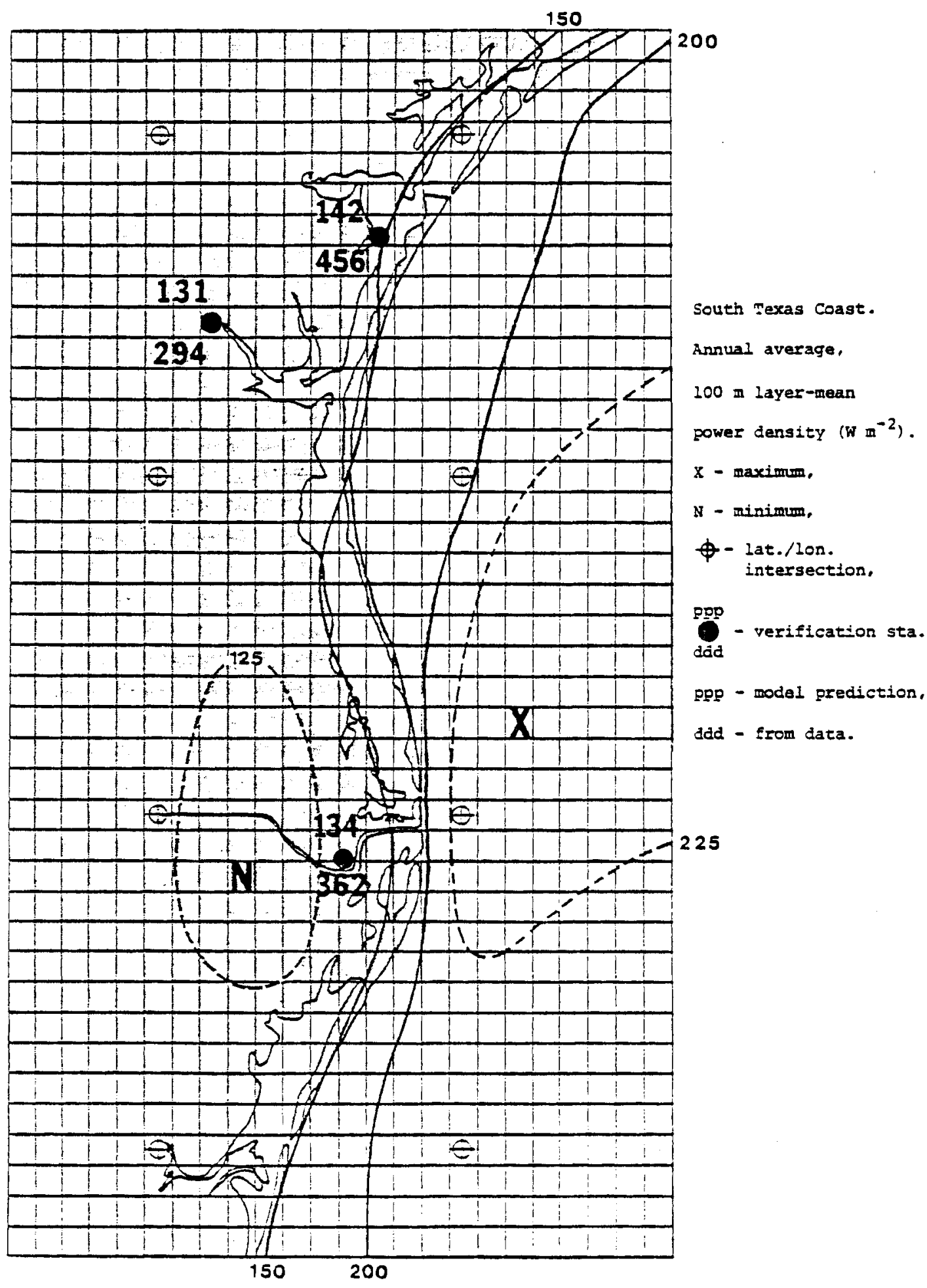


FIGURE 4. Outlines of the $120 \times 30 \mathrm{~km}$ aircraft flight-track (solid rectangle) located within the $140 \times 100 \mathrm{~km}$ Wallops Island verification experiment study area (broken rectangle). The outlines are superimposed upon a model-produced daily average, layer-mean (surface to $100 \mathrm{~m}$ ) power density distribution for typical wintertime conditions in the Chesapeake Bay area. Isolines are in $\mathrm{W} \mathrm{m}^{-2}$, ' $\mathrm{x}$ ' marks center of maximum, ' $N$ ' minimum power density. Circled numbers are way-points along the flight-track. 


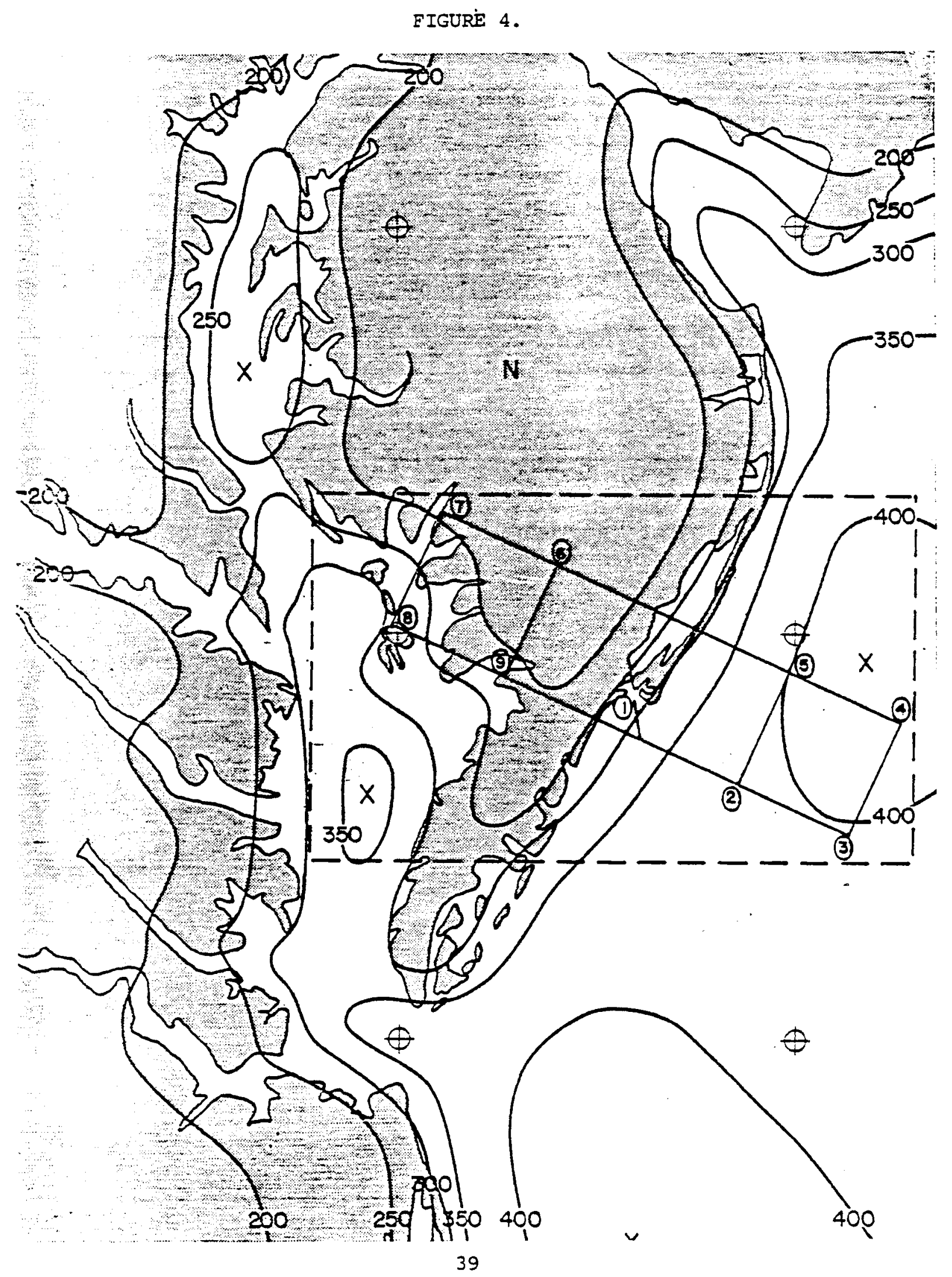


FIGURES 5A-7A. Observed wind speeds ( $\mathrm{ms}^{-1}$ ) and wind directions (meteorological deg.) at $170 \mathrm{~m}$ above the surface for aircraft flights made on $30 \mathrm{Jan} 80$. Each value is a two-minute average of one-second data. The +'s are the aircraft positions halfway through each averaging interval. The coastline is shown as a light solid line with the rectangular flight track overlaid. The letters identify every other location for orientation with respect to $\mathrm{Figures} 5 \mathrm{~B}-7 \mathrm{~B}$ and correspond to entries in Table 3 and Figure 8. All flight tracks proceed alphabetically with small letters signifying $50 \mathrm{~m}$ and capital letters $170 \mathrm{~m}$ measurements.

FIGURES 5B-7B. Predicted wind speeds ( $\mathrm{m} \mathrm{s}^{-1}$ ) and wind directions (meteorological deg.) at $170 \mathrm{~m}$ above the surface for $30 \mathrm{Jan}$ 80. Predictions, made by the University of Virginia mesoscale model, are available at 15-minute intervals and are given for each $10 \times 10 \mathrm{~km}$ grid-square of the WIVEX study area. The local solar time (hhmm) of the entries appears in the margin and the spacial extent of each time is shown as a light broken line. The coastline and the overlaid rectangular flight track are shown as light solid lines. The center point of any grid-square is located midway between the decimal point of the speed entry and the top of the center digit of the direction entry. Solid squares and letters correspond to observational locations shown in Figures $5 \mathrm{~A}-7 \mathrm{~A}$. 


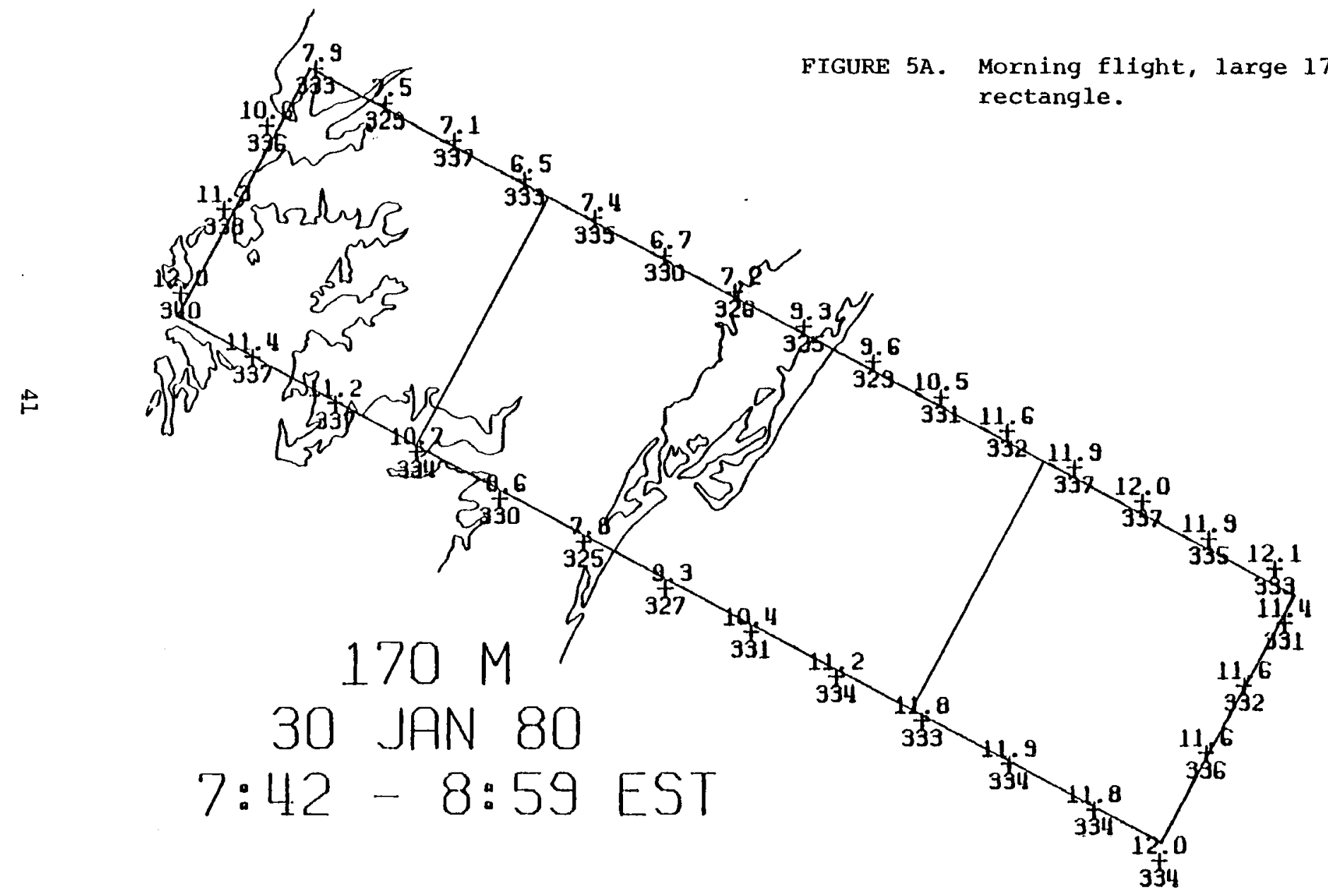




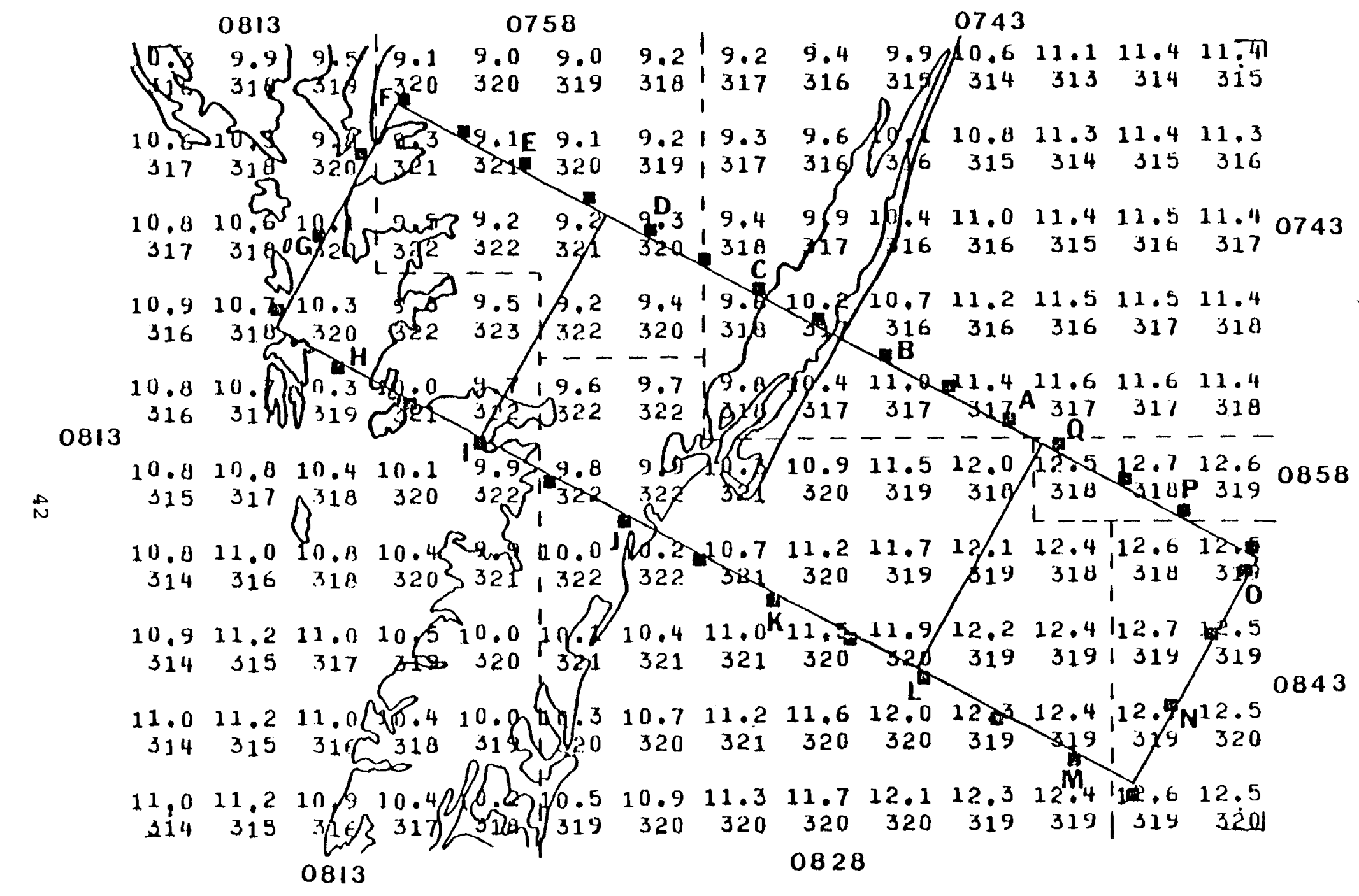

FIGURE 5B. Morning flight, 30 Jan 80 , large $170 \mathrm{~m}$ rectangle. 


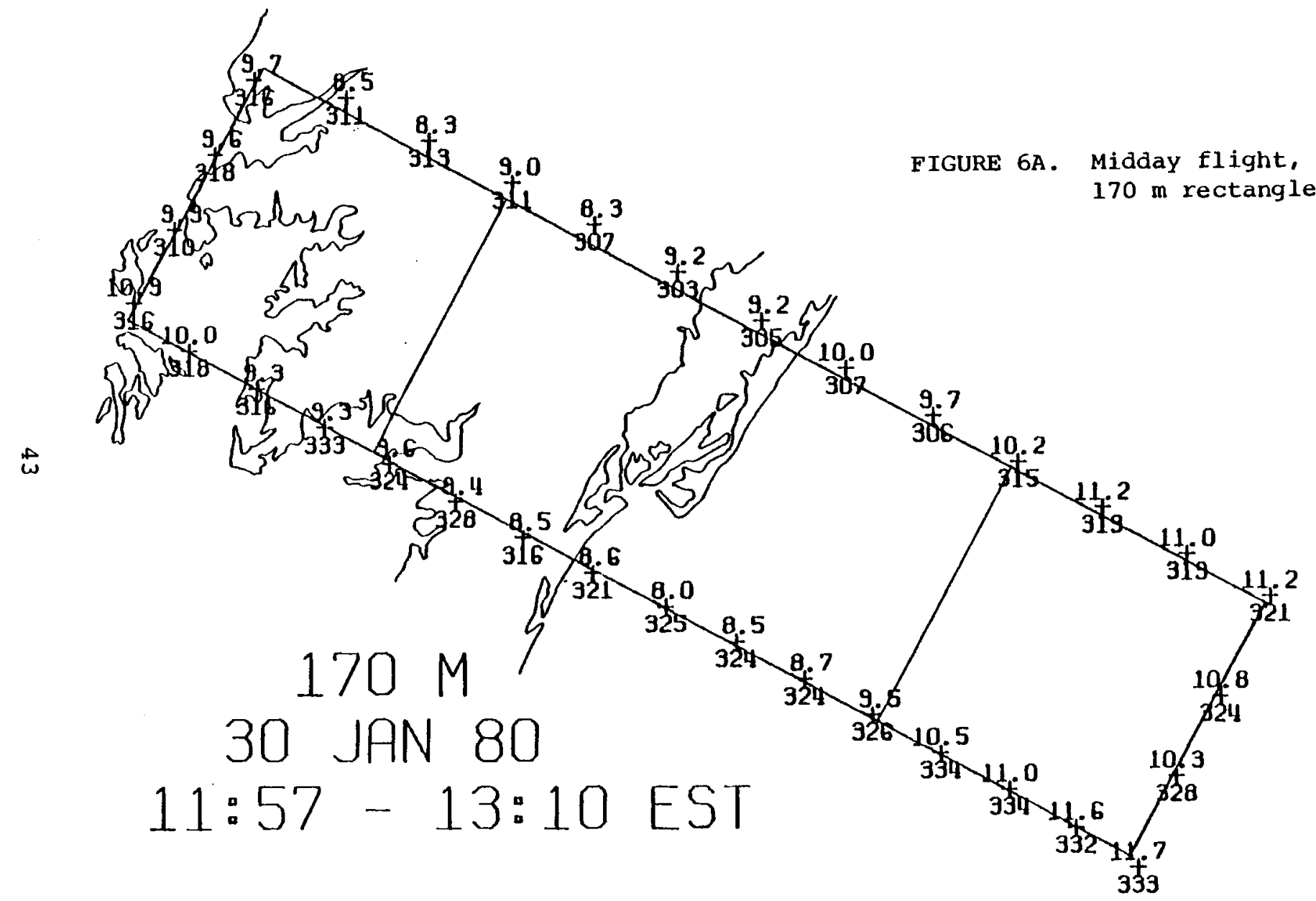




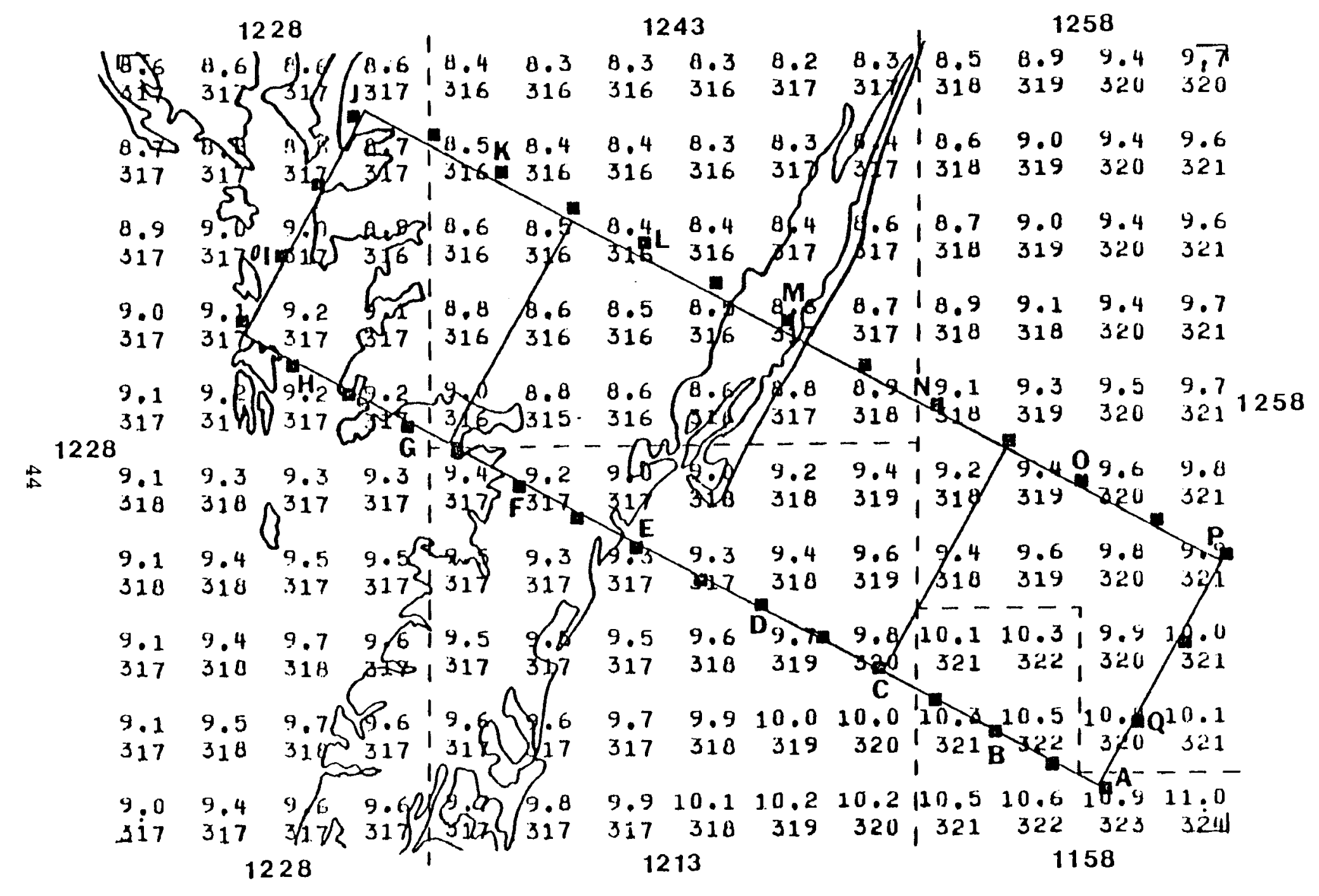

FIGURE 6B. Midday flight, 30 Jan 80 , large $170 \mathrm{~m}$ rectangle. 


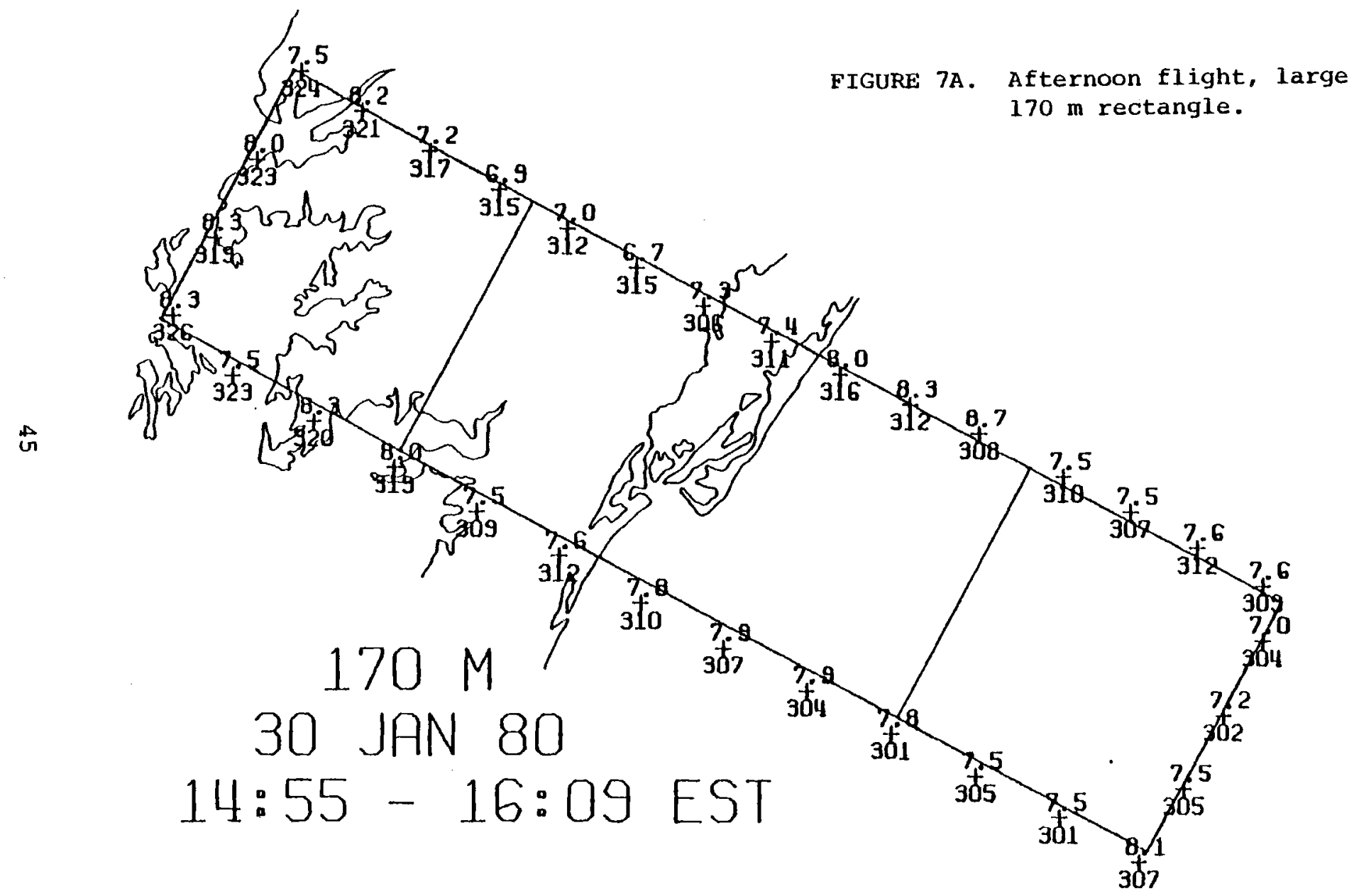




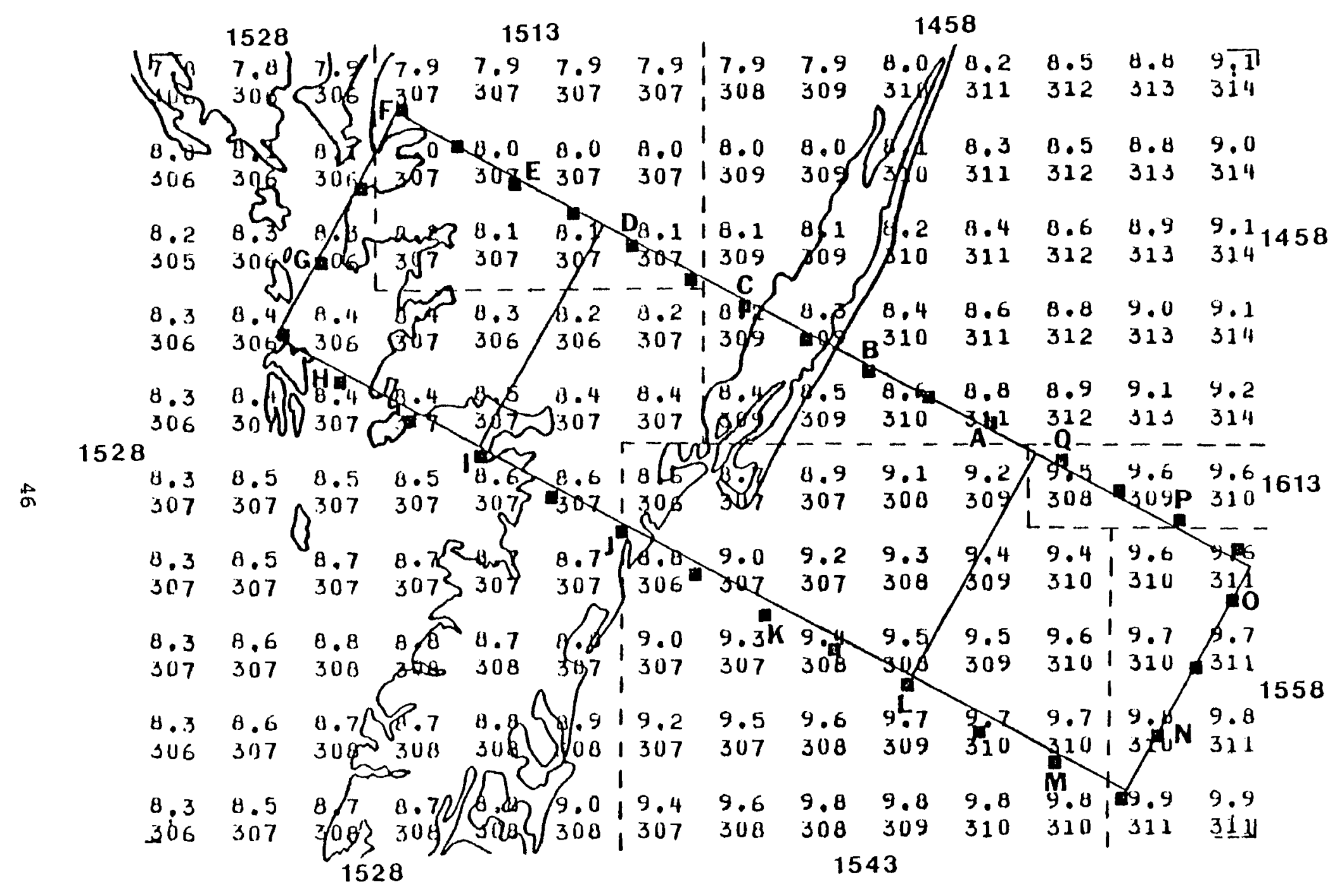

FIGURE 7B. Afternoon flight, $30 \mathrm{Jan} 80$, large $170 \mathrm{~m}$ rectangle. 
FIGURES 8A-F. Space-time series of observed (solid dots) and predicted (open circles) wind speeds ( $\mathrm{m} \mathrm{s}^{-1}$ ) at 50 and $170 \mathrm{~m}$ above the surface within the WIVEx study area on $30 \mathrm{Jan} 80$. Abscissa letters refer to locations in Figures $5-7$. 
FIGURE 8A. Morning flight, $30 \mathrm{Jan} 80$, initial and final $50 \mathrm{~m}$ tracks.

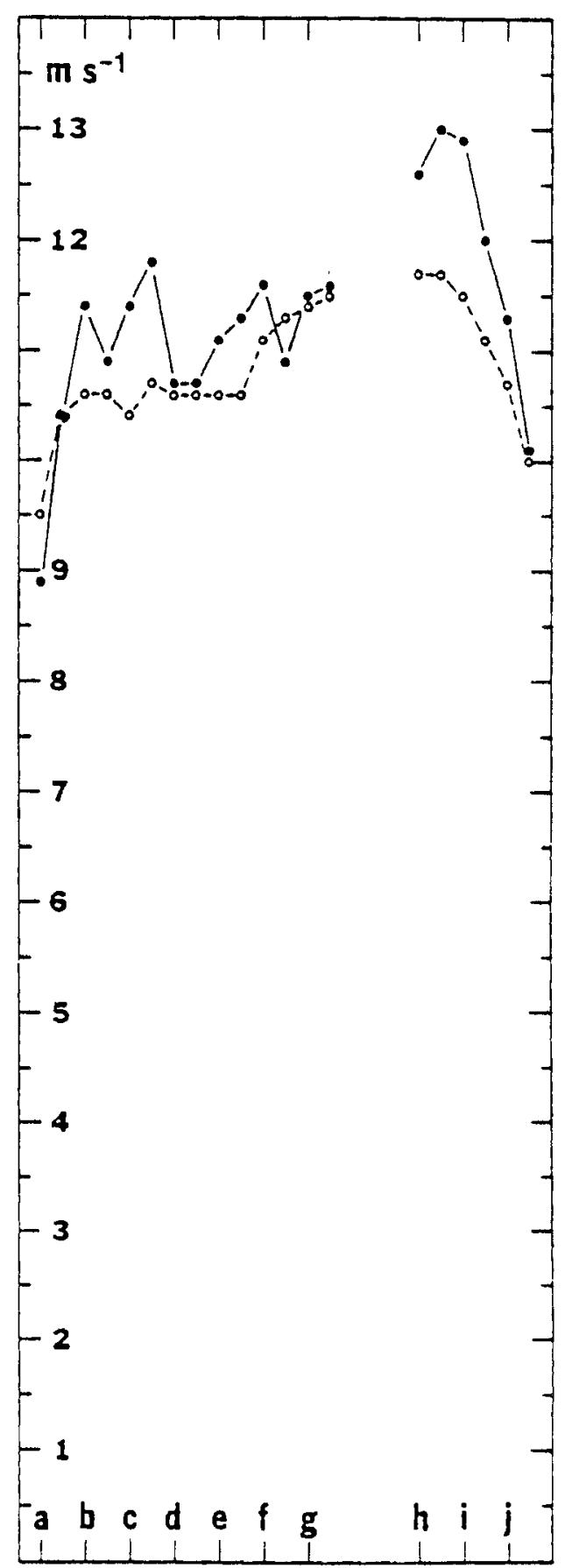


FIGURE 8B. Morning flight, 30 Jan 80 , both $170 \mathrm{~m}$ rectangular tracks.

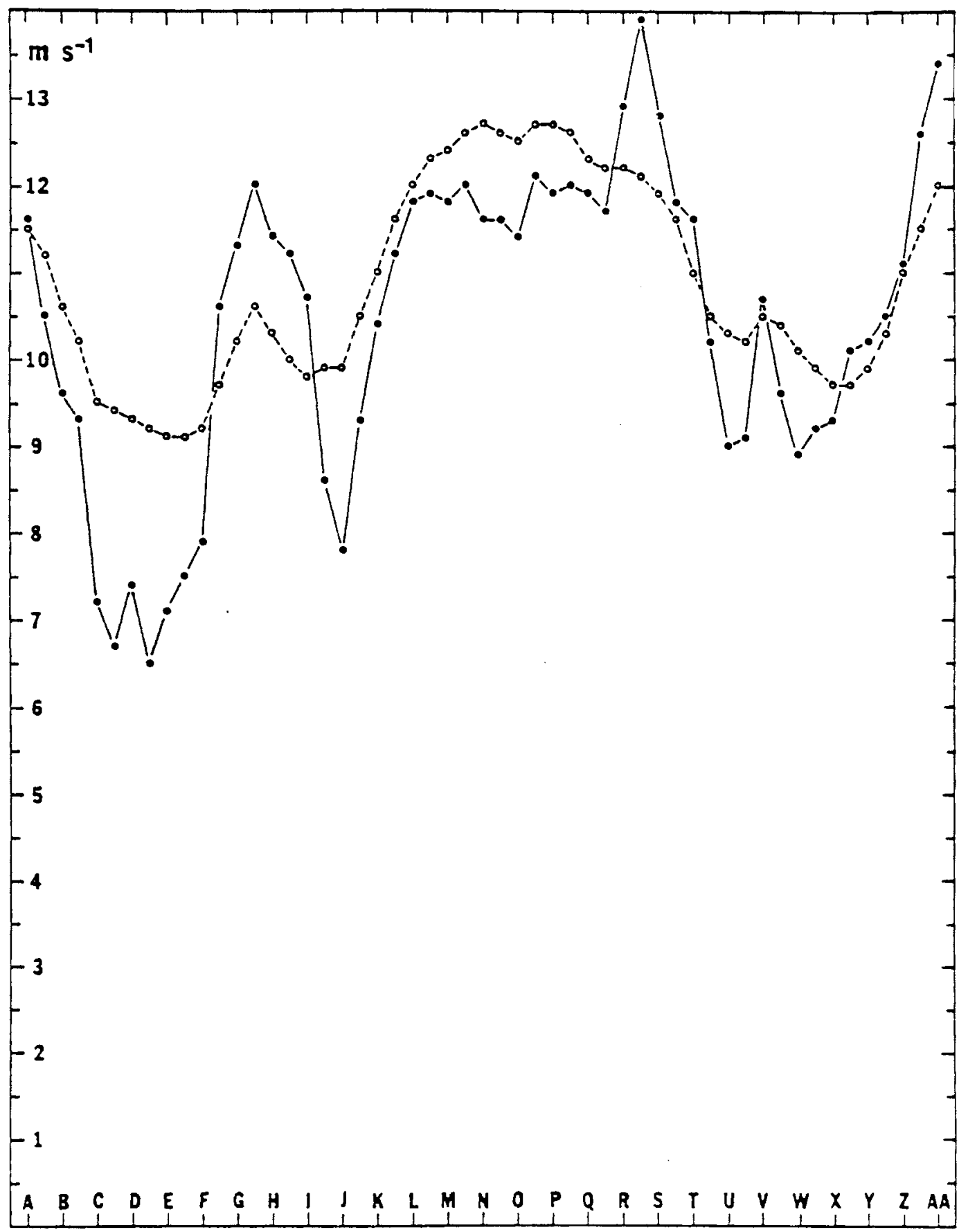


FIGURE 8C. Midday flight, $30 \mathrm{Jan} 80$, initial and final $50 \mathrm{~m}$ tracks.

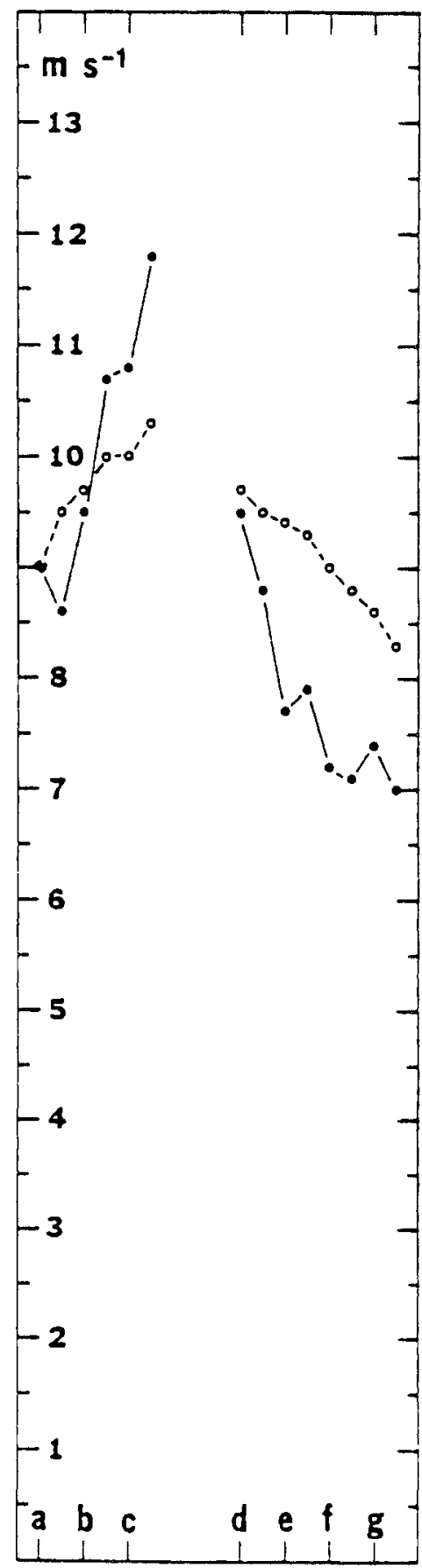


FIGURE 8D. Midday flight, $30 \mathrm{Jan} 80$, large $170 \mathrm{~m}$ rectangular track.

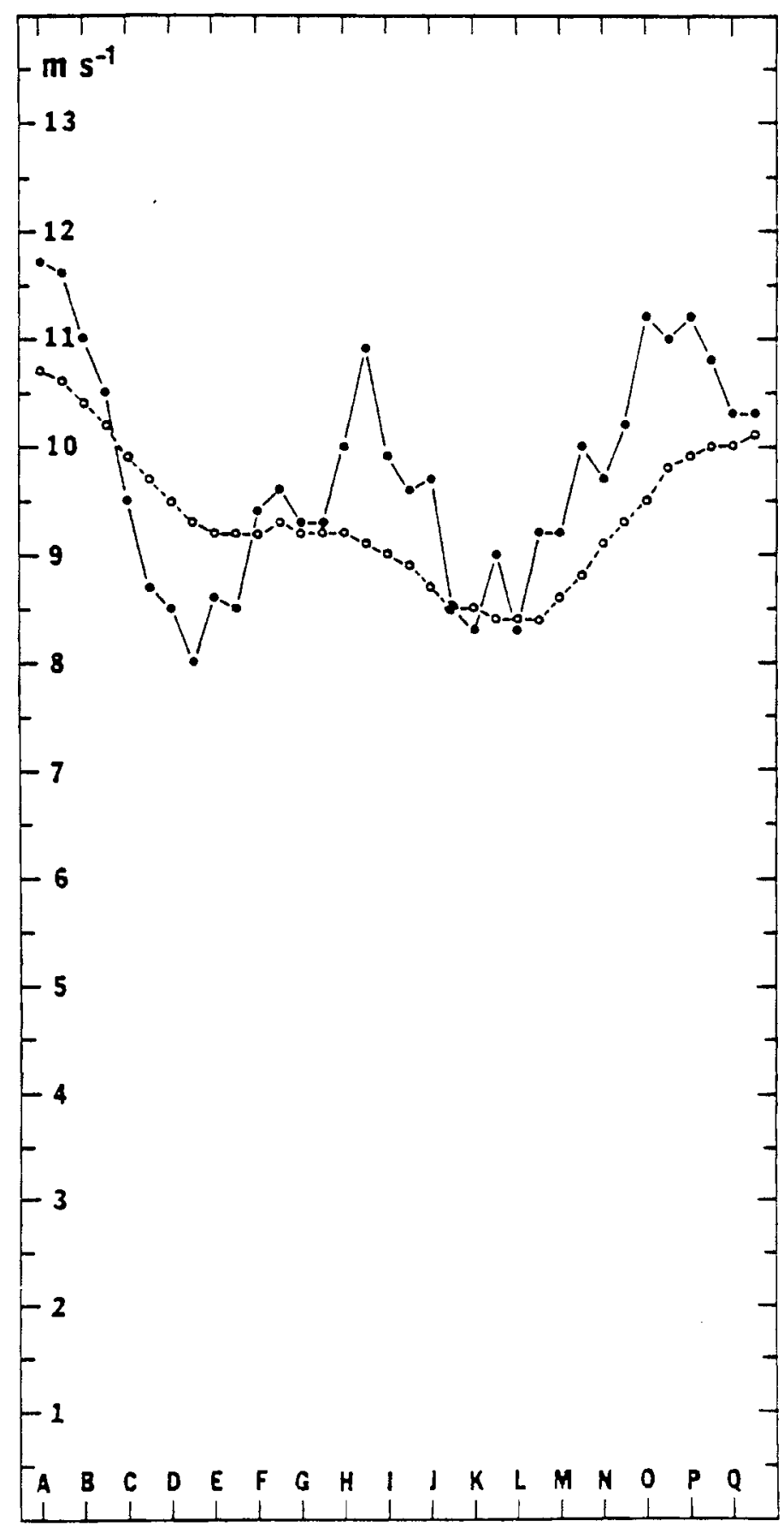


FIGURE 8E. Afternoon flight, 30 Jan 80, initial and final $50 \mathrm{~m}$ tracks.

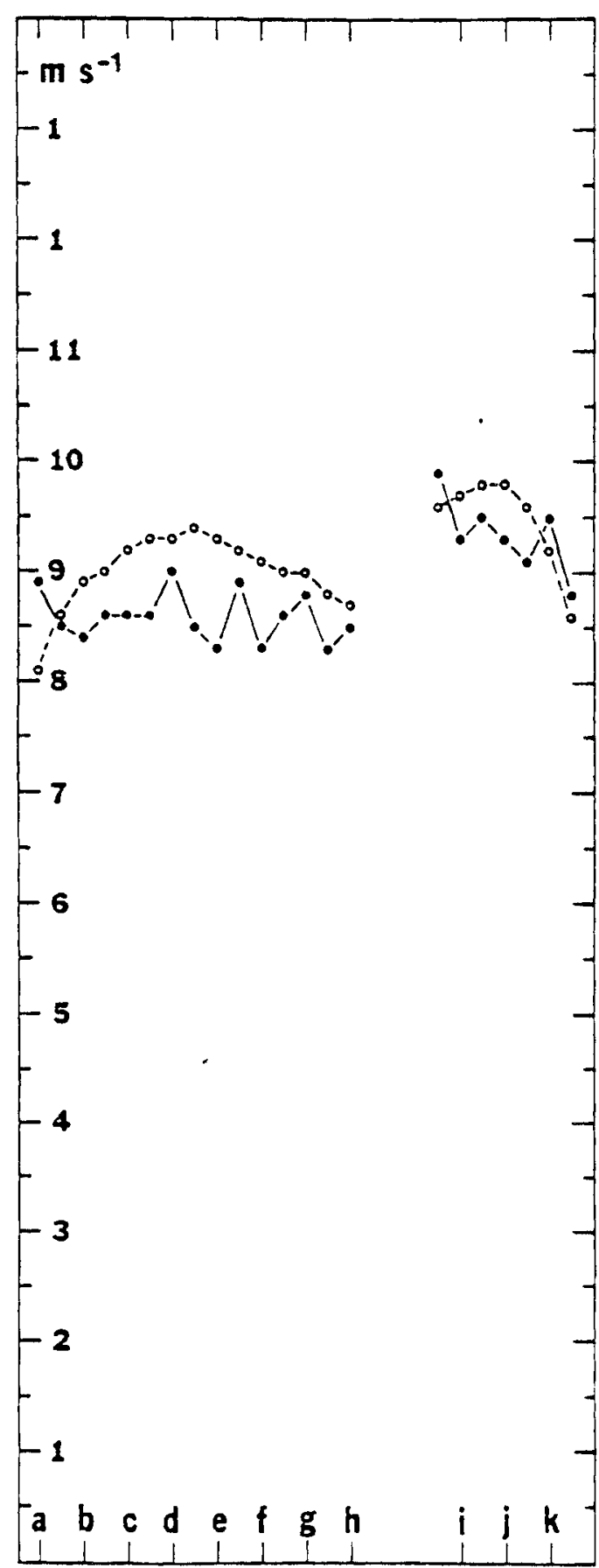


FIGURE 8F. Afternoon flight, $30 \mathrm{Jan} 80$, both $170 \mathrm{~m}$ rectangular tracks.

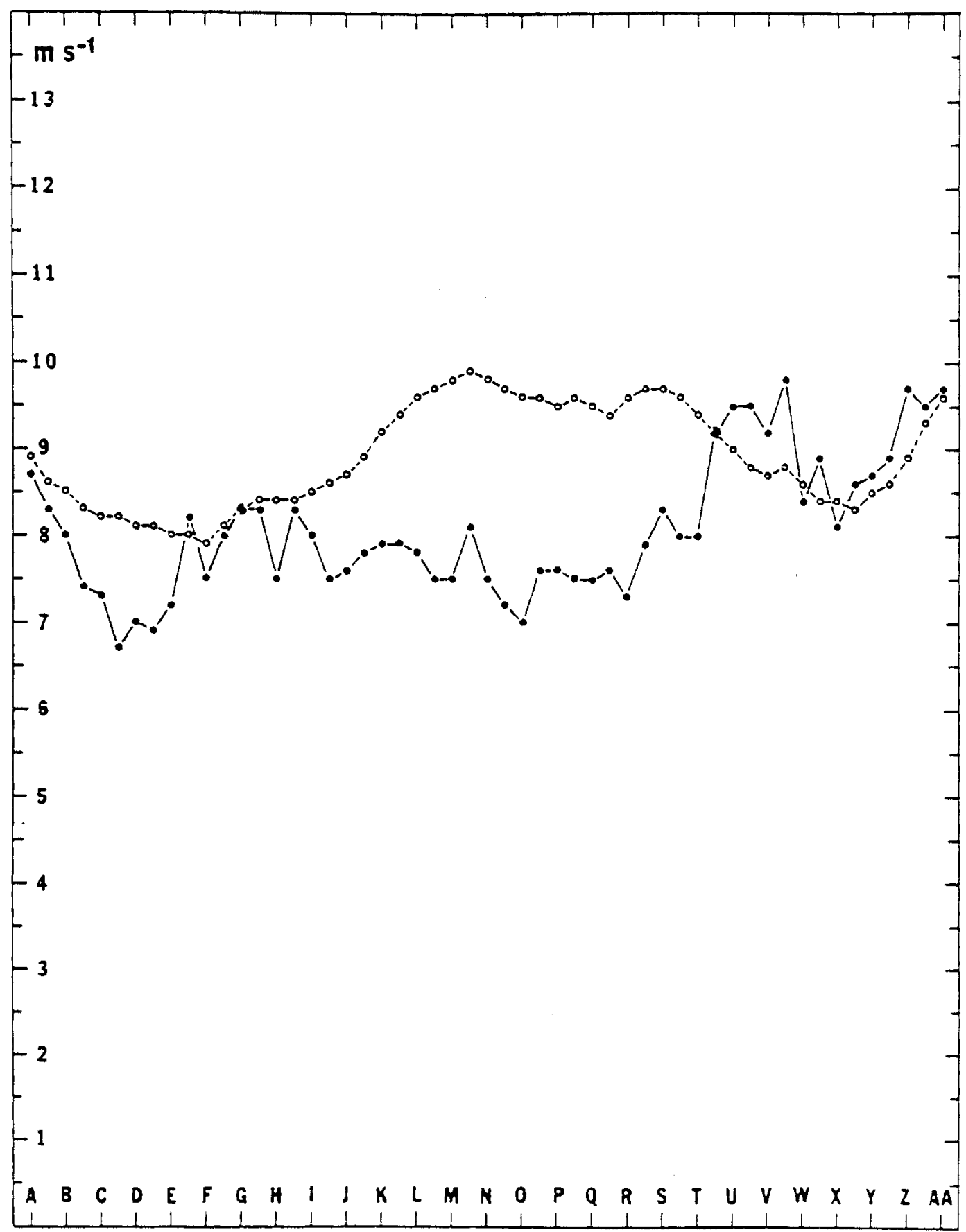


FIGURES 9A-ILA. Observed wind speeds $\left(\mathrm{m} \mathrm{s}^{-1}\right)$ and wind directions (meteorological deg.) at $170 \mathrm{~m}$ above the surface for aircraft flights made on $3 \mathrm{Feb} 80$. Each value is a two-minute average of one-second data. The +'s are the aircraft positions halfway through each averaging interval. The coastline is shown as a light solid line with the rectangular flight track overlaid. The letters identify every other location for orientation with respect to Figures $9 \mathrm{~B}-11 \mathrm{~B}$ and correspond to entries in Table 4 and Figure 12. All flight tracks proceed alphabetically with small letters signifying $50 \mathrm{~m}$ and capital letters $170 \mathrm{~m}$ measurements.

FIGURES 9B-11B. Predicted wind speeds $\left(\mathrm{m} \mathrm{s}^{-1}\right)$ and wind directions (meteorological deg.) at $170 \mathrm{~m}$ above the surface for $3 \mathrm{Feb} 80$. Predictions, made by the University of Virginia mesoscale model, are available at 15-minute intervals and are given for each $10 \times 10 \mathrm{~km}$ grid-square of the WIVEx study area. The local solar time (hhmm) of the entries appears in the margin and the spacial extent of each time is shown as a light broken line. The coastline and the overlaid rectangular flight track are shown as light solid lines. The center point of any grid-square is located midday between the decimal point of the speed entry and the top of the center digit of the direction entry. Solid squares and letters correspond to observational locations shown in Figures 9A-1IA. 


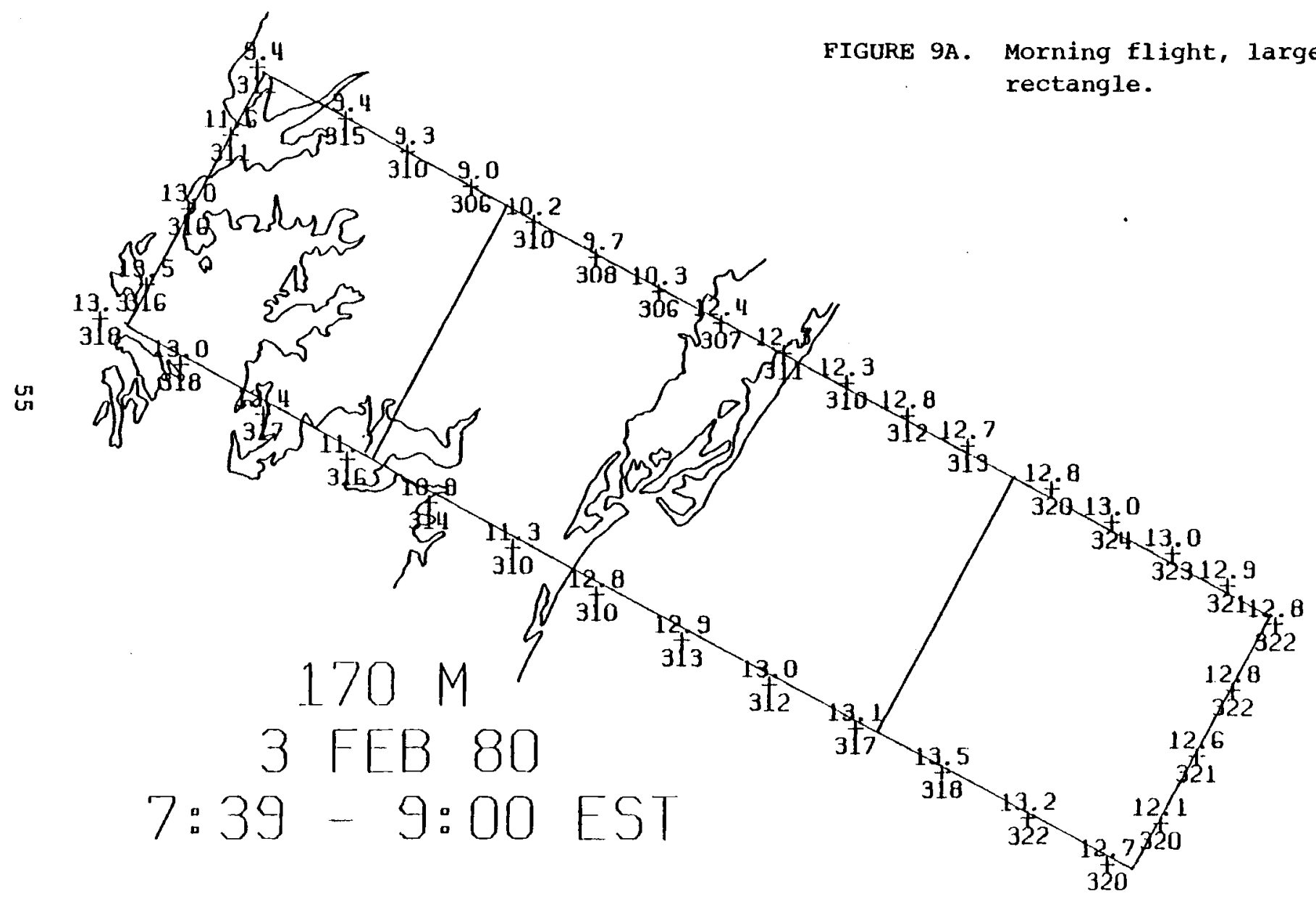




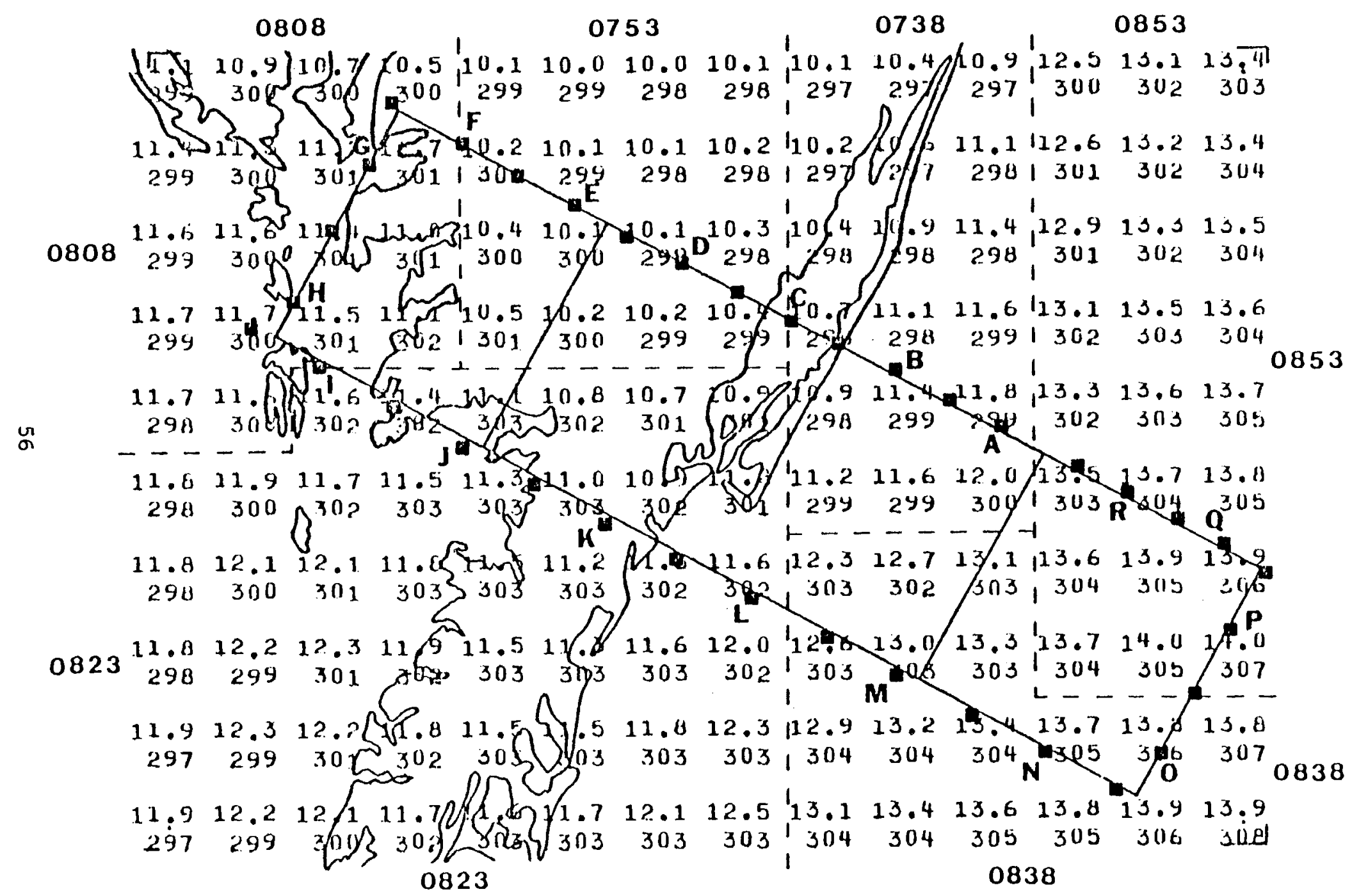

EIGURE 9B. Morning flight, 3 Feb 80 , large $170 \mathrm{~m}$ rectangle. 


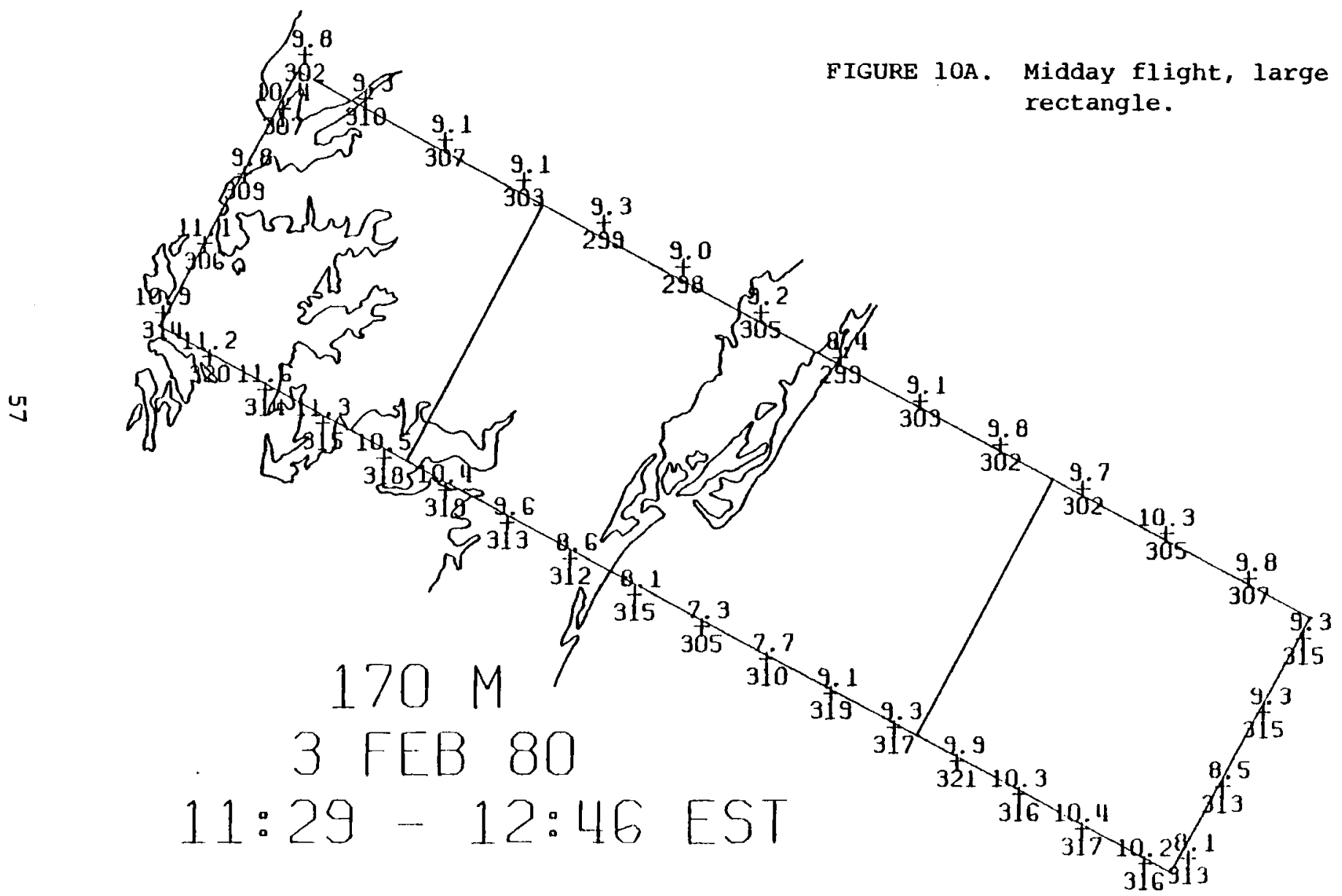




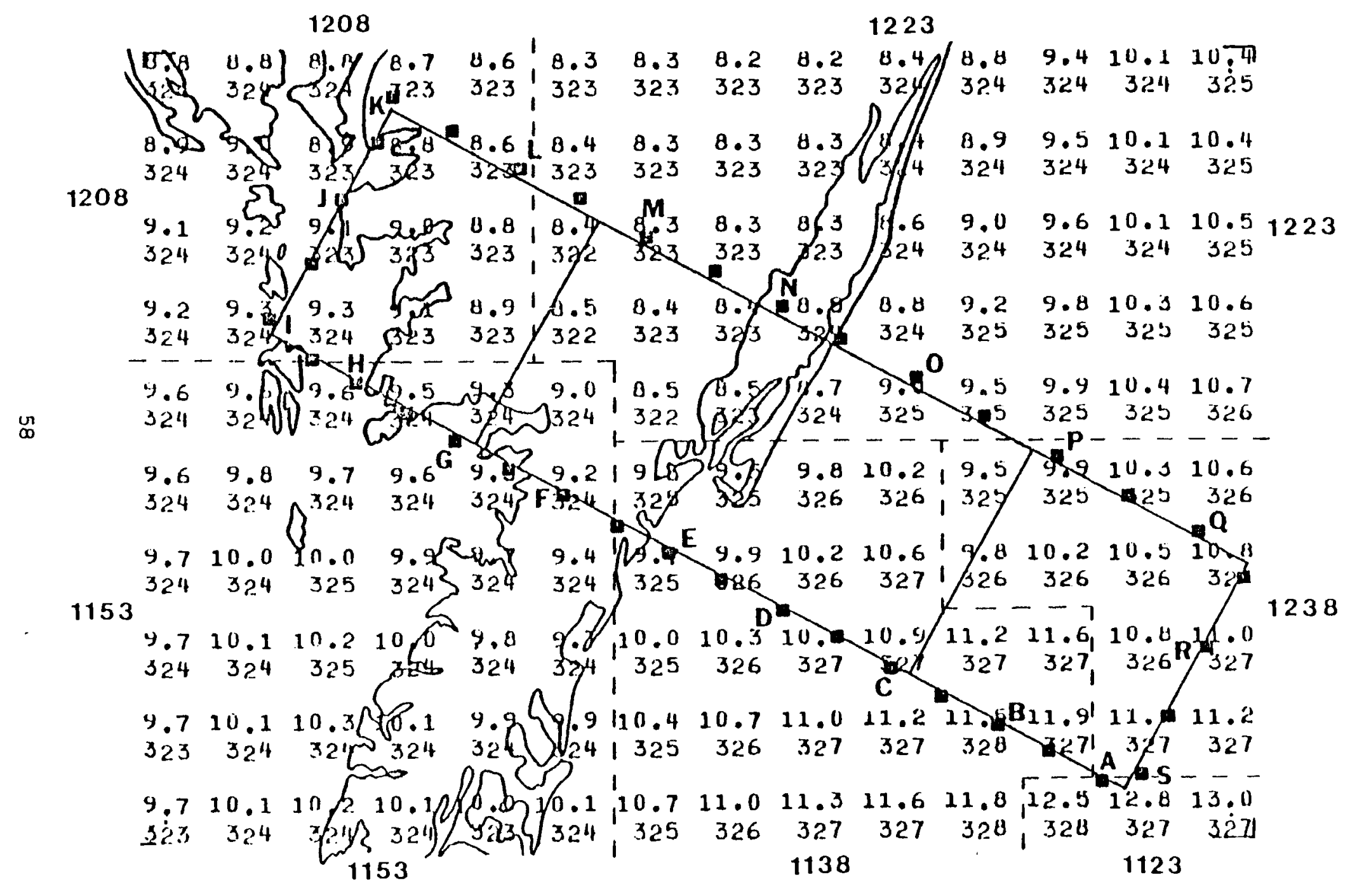

FIGURE 10B. Midday flight, 3 Feb 80 , large $170 \mathrm{~m}$ rectangle. 


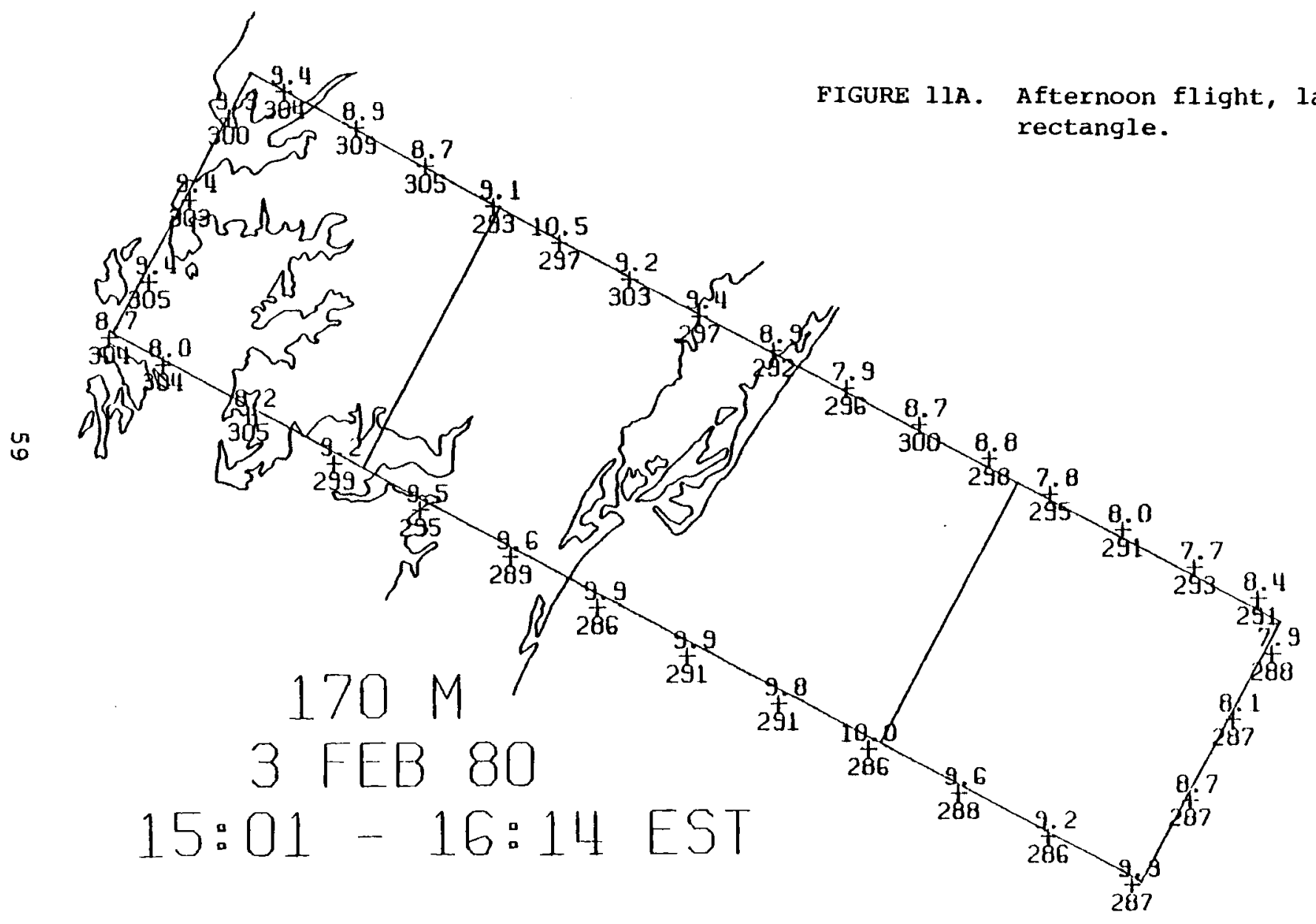




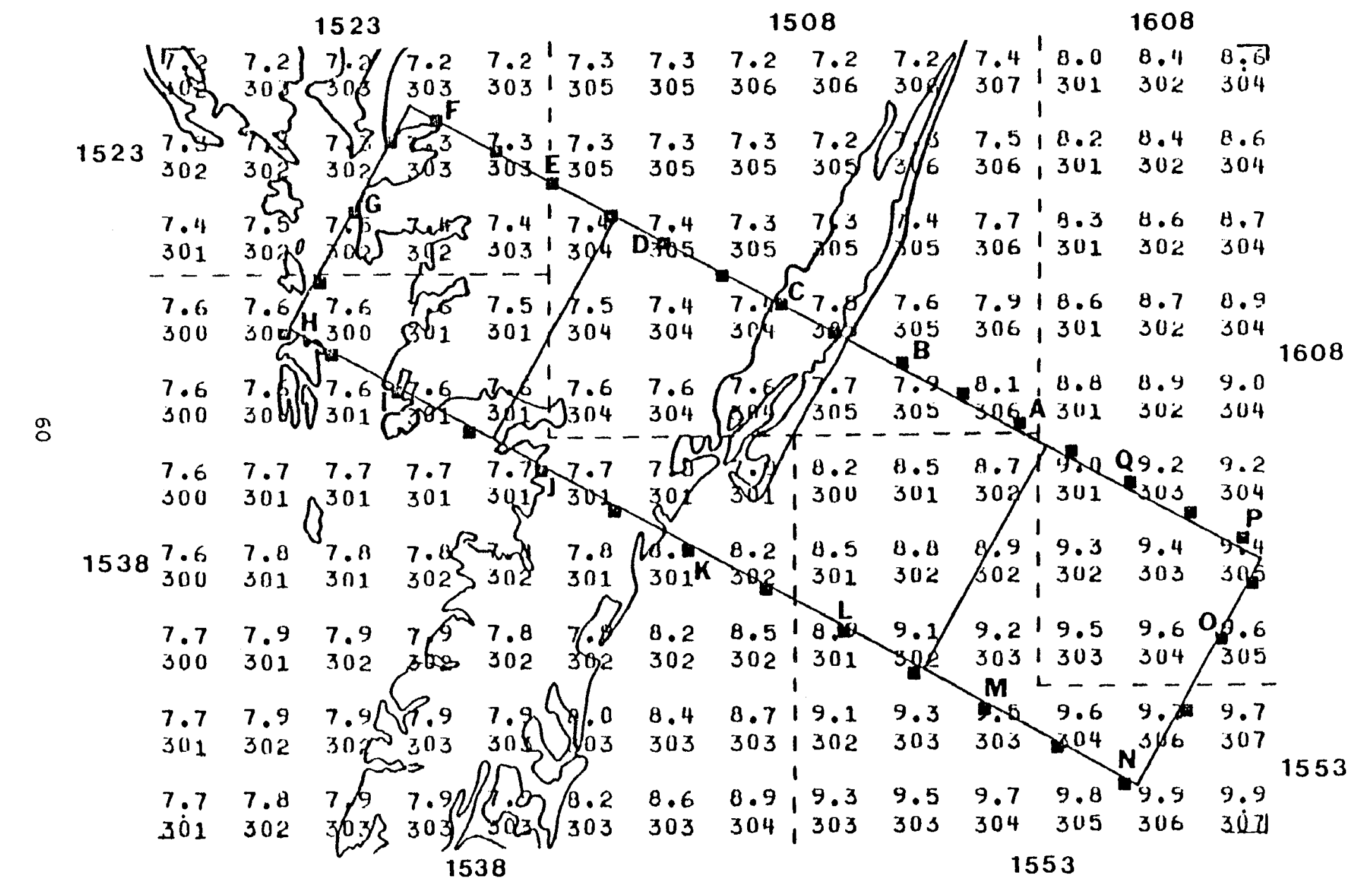

FIGURE 11B. Afternoon flight, 3 Feb 80, large $170 \mathrm{~m}$ rectangle. 
FIGURES 12A-F. Space-time series of observed (solid dots) and predicted (open circles) wind speeds ( $\mathrm{m} \mathrm{s}^{-1}$ ) at 50 and $170 \mathrm{~m}$ above the surface within the WIVEX study area on $3 \mathrm{Feb} 80$. Abscissa letters refer to locations in Figures 9-11. 
FIGURE 12A. Morning flight, 3 Feb 80, initial and final $50 \mathrm{~m}$ tracks.

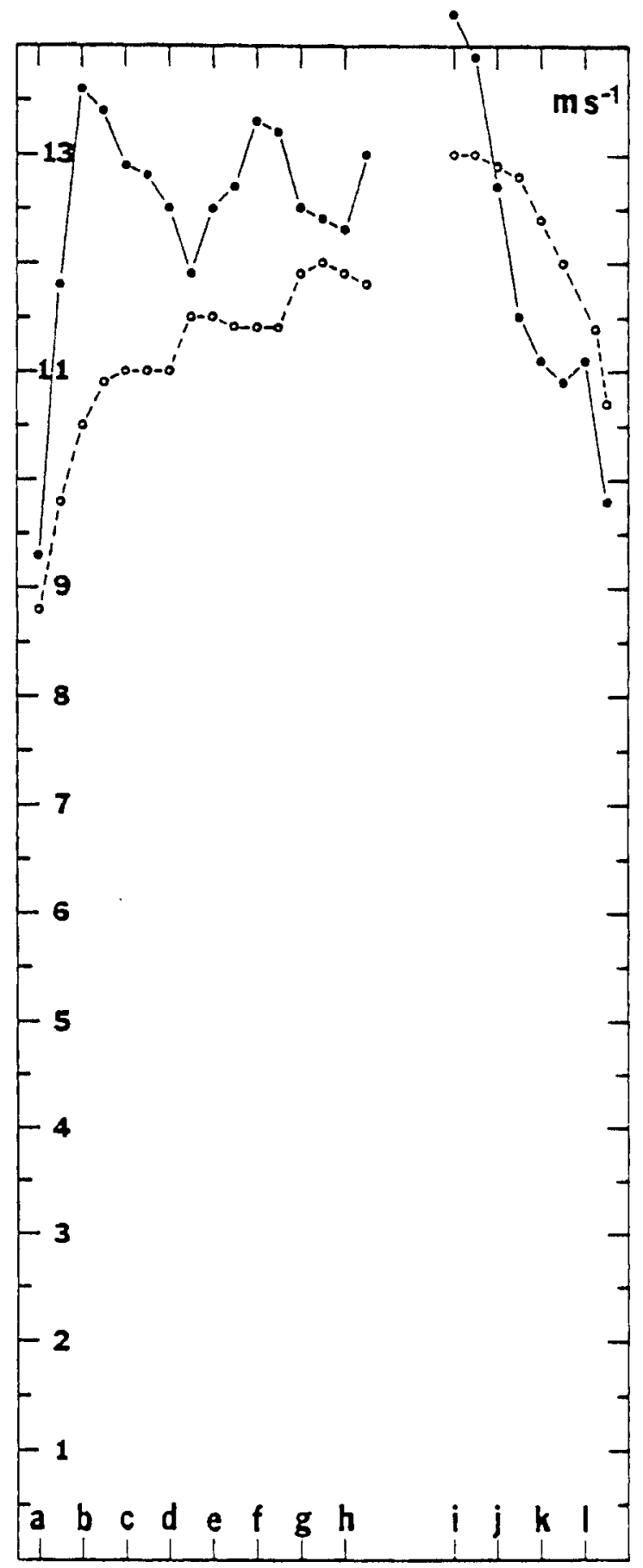


FIGURE 128. Morning flight, 3 Feb 80 , both $170 \mathrm{~m}$ rectangular tracks.

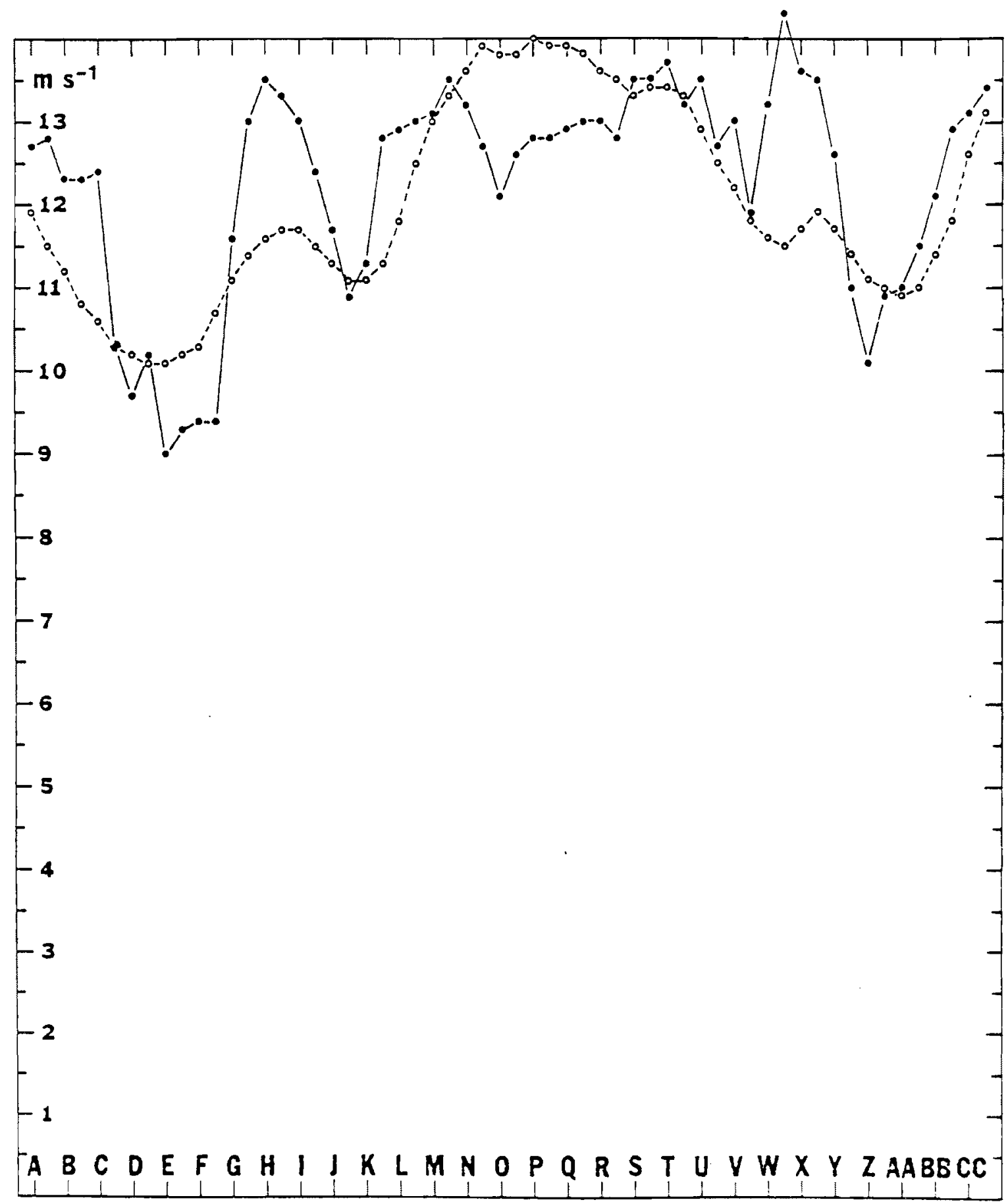


FIGURE 12C. Midday flight, $3 \mathrm{Feb} 80$, initial and final $50 \mathrm{~m}$ tracks.

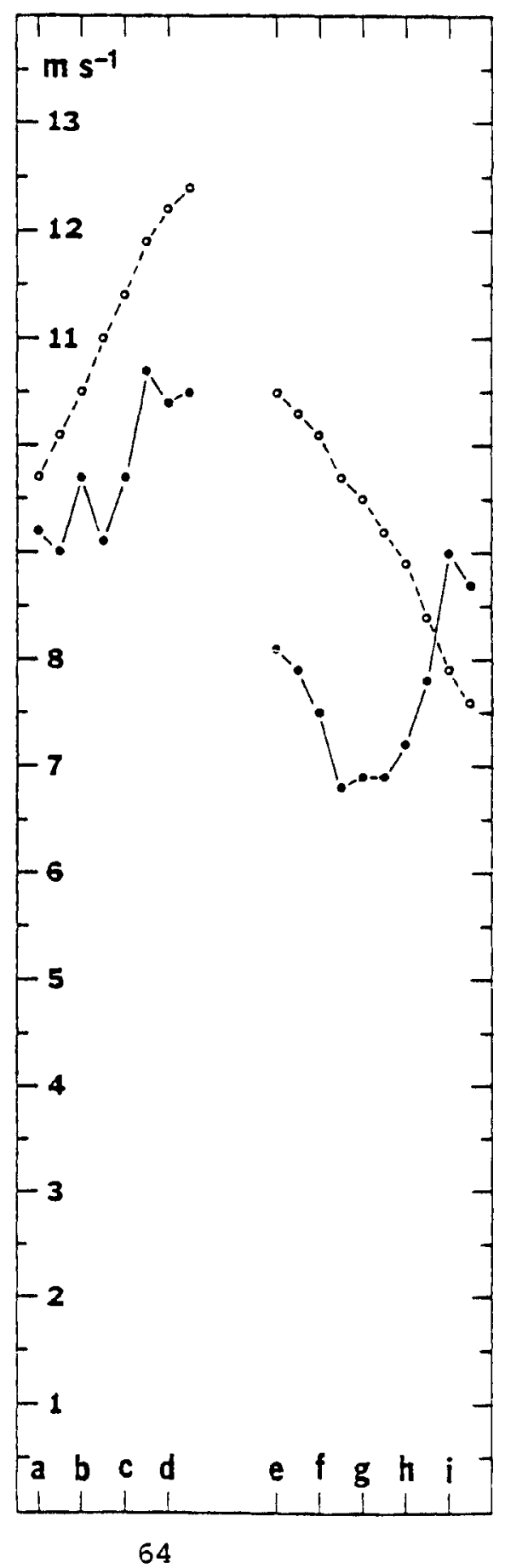


FIGURE 12D. Midday flight, 3 Feb 80 , large $170 \mathrm{~m}$ rectangular track.

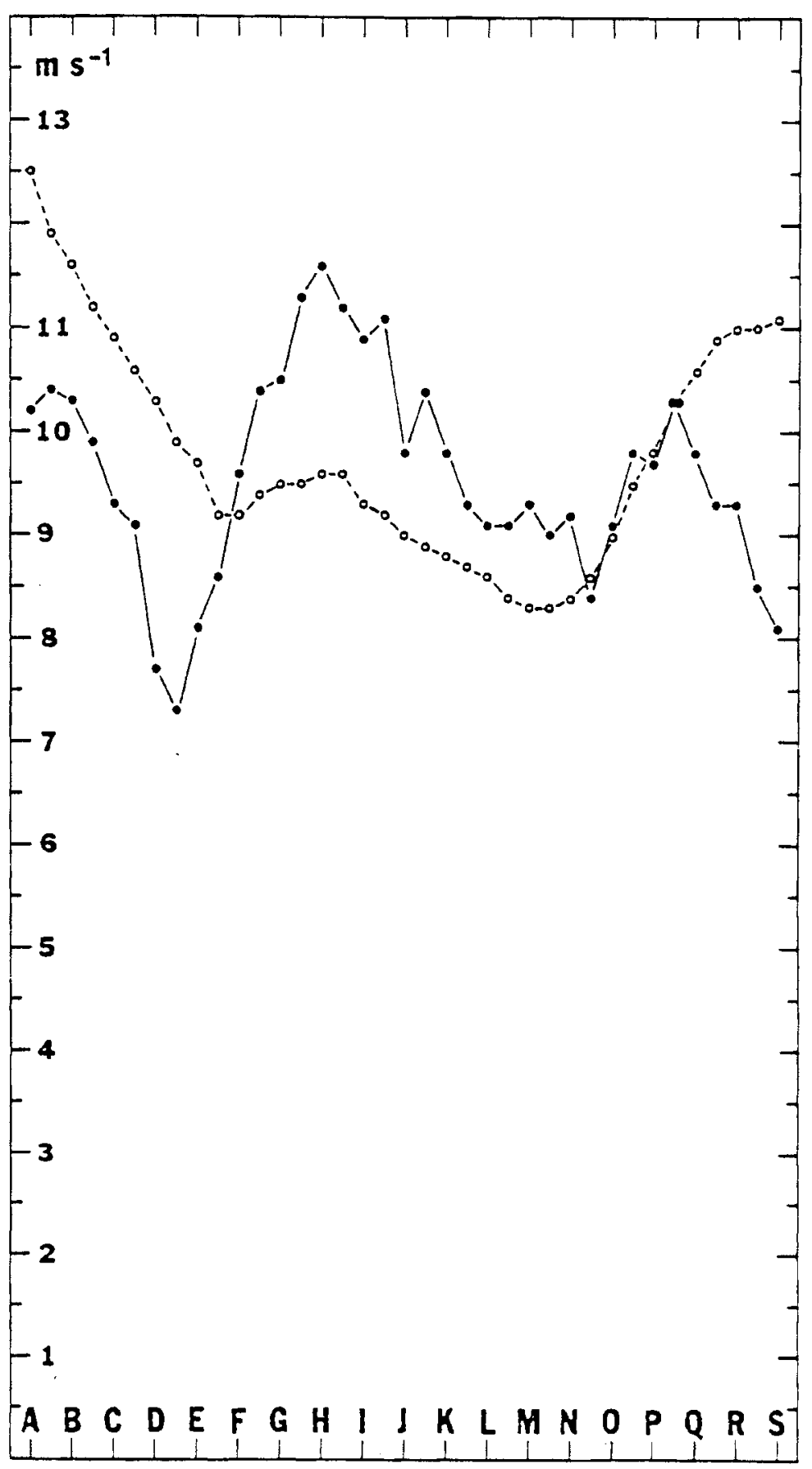


FIGURE 12E. Afternoon flight, $3 \mathrm{Feb} 80$, initial and final $50 \mathrm{~m}$ tracks.

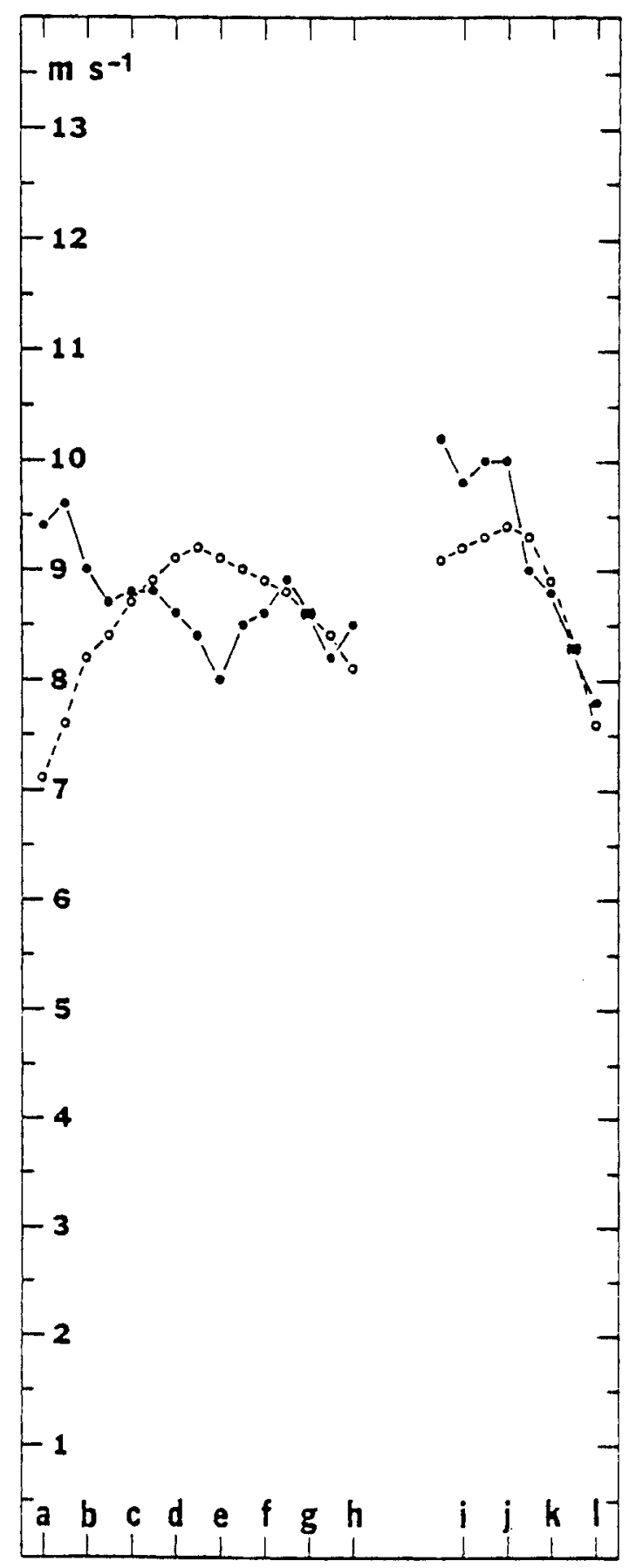


FIGURE 12F. Afternoon flight, 3 Feb 80 , both $170 \mathrm{~m}$ rectangular tracks.

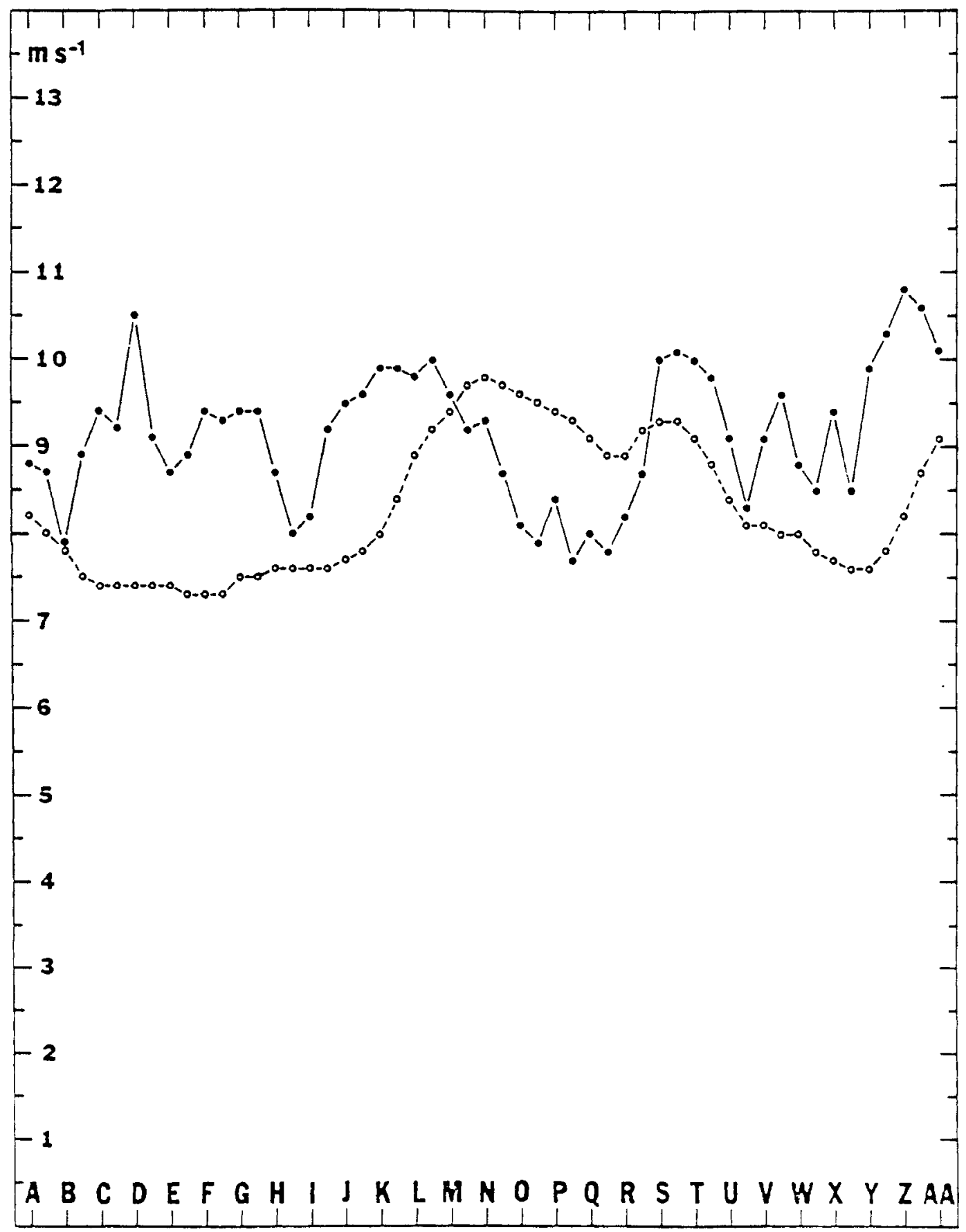




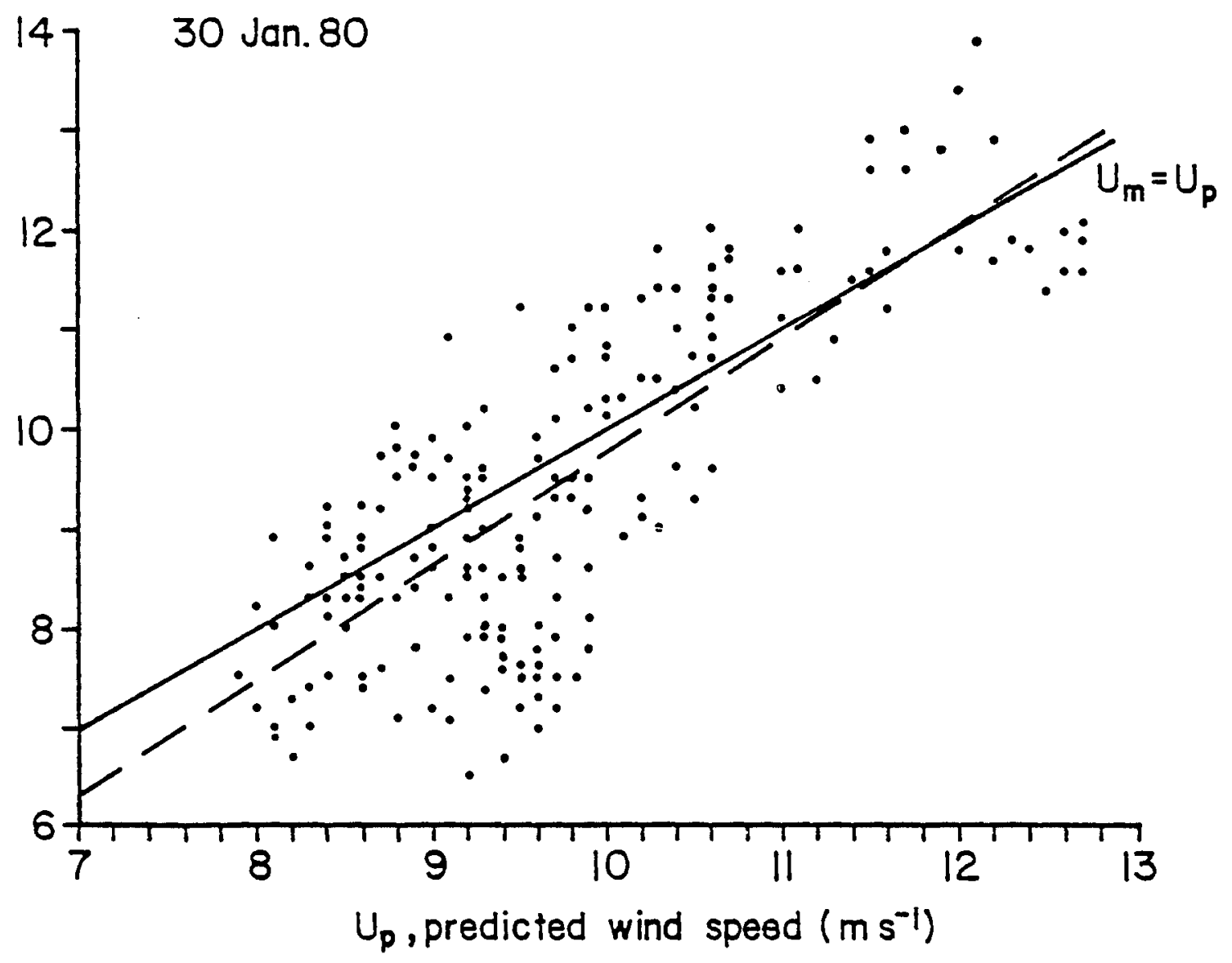

FIGURE 13A. Scatter diagram of wind speeds, $30 \mathrm{Jan} 80$. Broken line is regression, $U_{m}=1.13 U_{p}-1.58$. Perfect prediction is solid line, $U_{m}=U_{p}$. Over-predictions are below, under-predictions above the solid line. 


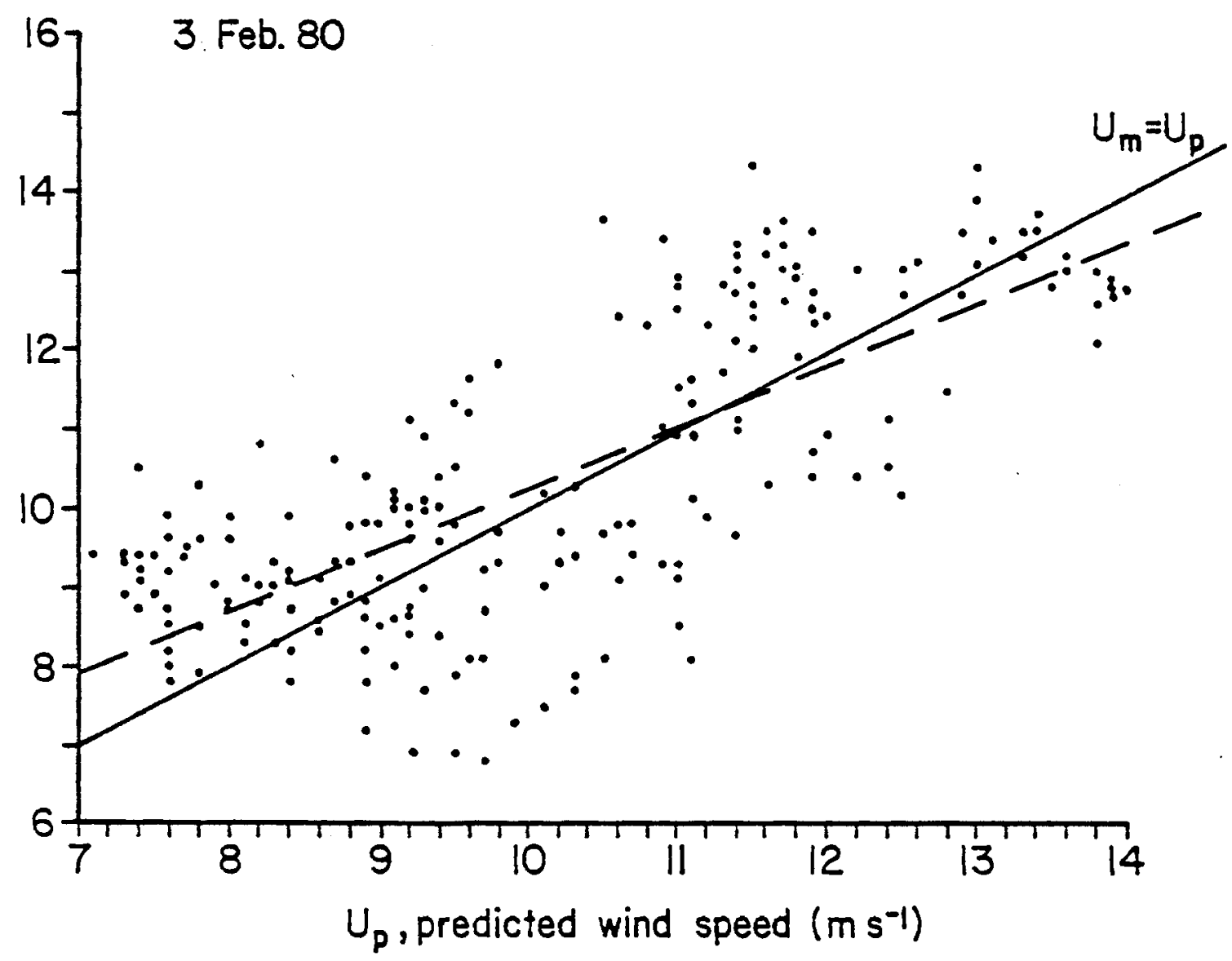

FIGURE 13B. Scatter diagram of wind speeds, 3 Feb 80 . Broken Iine is regression, $U_{m}=0.77 U_{p}+2.55$. Perfect prediction is solid Iine, $U_{m}=U_{p}$. Over-predictions are below, under-predictions above the solid line. 


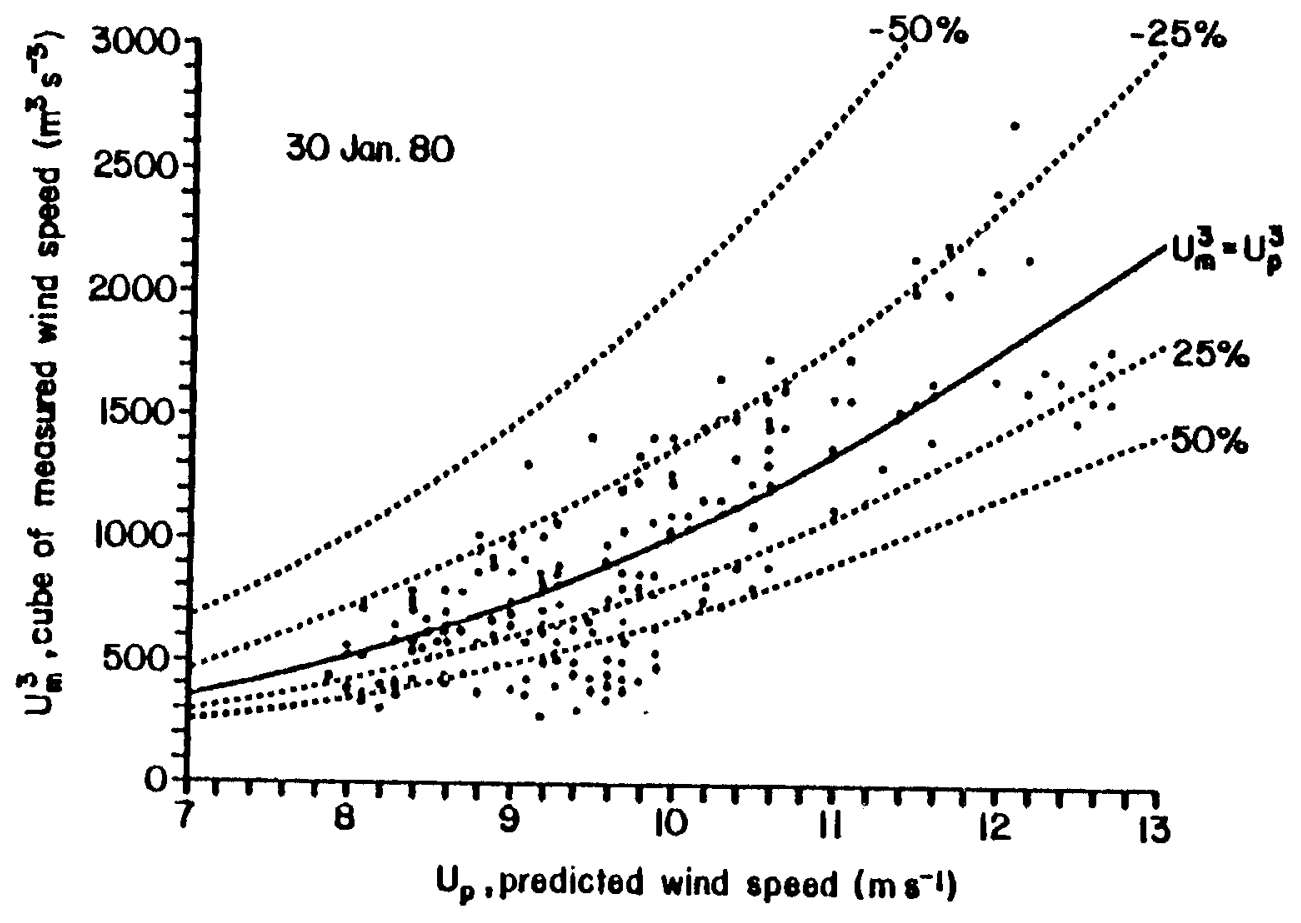

FIGURE 14A. Scatter diagrams of the cube of measured wind speed, $\mathrm{u}_{\mathrm{m}}{ }^{3}$, versus predicted wind speed, $\mathrm{U}_{\mathrm{p}}$, for $30 \mathrm{Jan} 80$. Isolines of percent error in predicted wind power, $\left(\mathrm{u}_{\mathrm{p}} 3-\mathrm{u}_{\mathrm{m}}{ }^{3}\right) / \mathrm{u}_{\mathrm{m}}{ }^{3}=$ $\ell \ell$, where $\ell \ell=-50,-25, \pm 0,+25$ and +508 , are plotted. $\left(\mathrm{U}^{3}\right.$ is wind power density divided by the atmospheric density. However, since the percent error in atmospheric density contributes little to the percent error in power, the $\ell \ell$ values are essentially the percent errors in power.) overpredictions are below, under-predictions above the tot error, the solid line. 


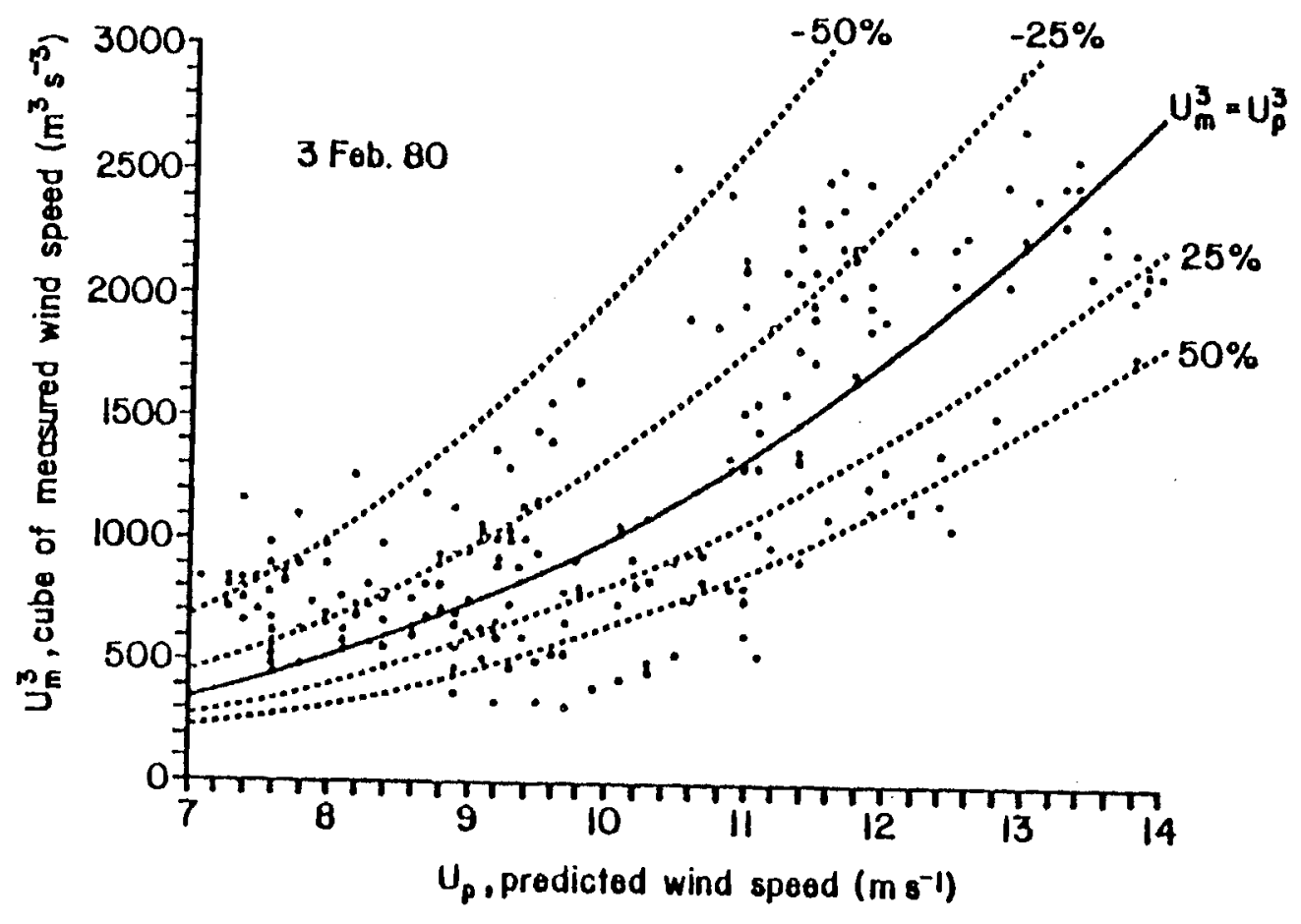

FIGURE 14B. Scatter diagrams of the cube of measured wind speed, $u_{m}{ }^{3}$, versus predicted wind speed, $\mathrm{U}_{\mathrm{p}}$, for $3 \mathrm{Feb} 80$. Isolines of percent error in predicted wind power, $\left(u_{p}{ }^{3}-u_{m}{ }^{3}\right) / u_{m}{ }^{3}=$ $\ell \ell$, where $\ell \ell=-50,-25, \pm 0,+25$ and $+50 z$, are plotted.

$\left(\mathrm{U}^{3}\right.$ is wind power density divided by the atmospheric density. However, since the percent error in atmospheric density contributes little to the percent error in power, the $\ell \ell$ values are essentially the percent errors in power.) overpredictions are below, under-predictions above the tof error, the solid line. 
FIGURE 15. Areal distribution of measured wind power density $\left(10^{2}\right.$ $\left(\mathrm{m} \mathrm{m}^{-2}\right.$ ) at $170 \mathrm{~m}$ above the surface, 0742-0859 EST, 30 $\operatorname{Jan} 80$, within the WIVEX $120 \times 30 \mathrm{~km}$ aircraft track. ' $\mathrm{X}$ ' specifies area of maximum power density ( $1260 \mathrm{w} \mathrm{m}^{-2}$ ), ' $N$ ' the area of minimum (approximately $150 \mathrm{~W} \mathrm{~m}^{-2}$ ). Dashed line is the Maryland-Virginia border. Aircraft position at 0828 is shown. 
FIGURE 15.

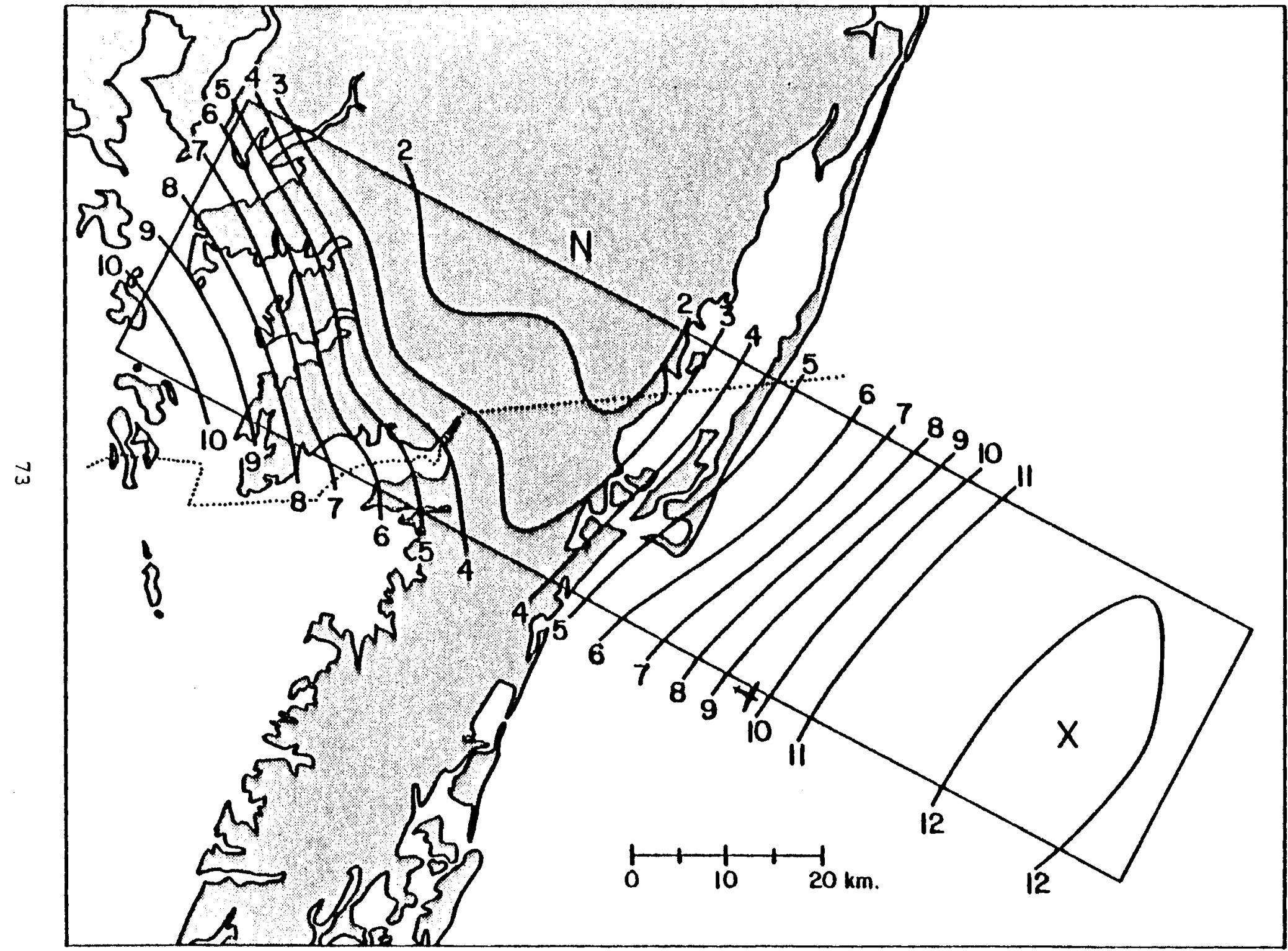




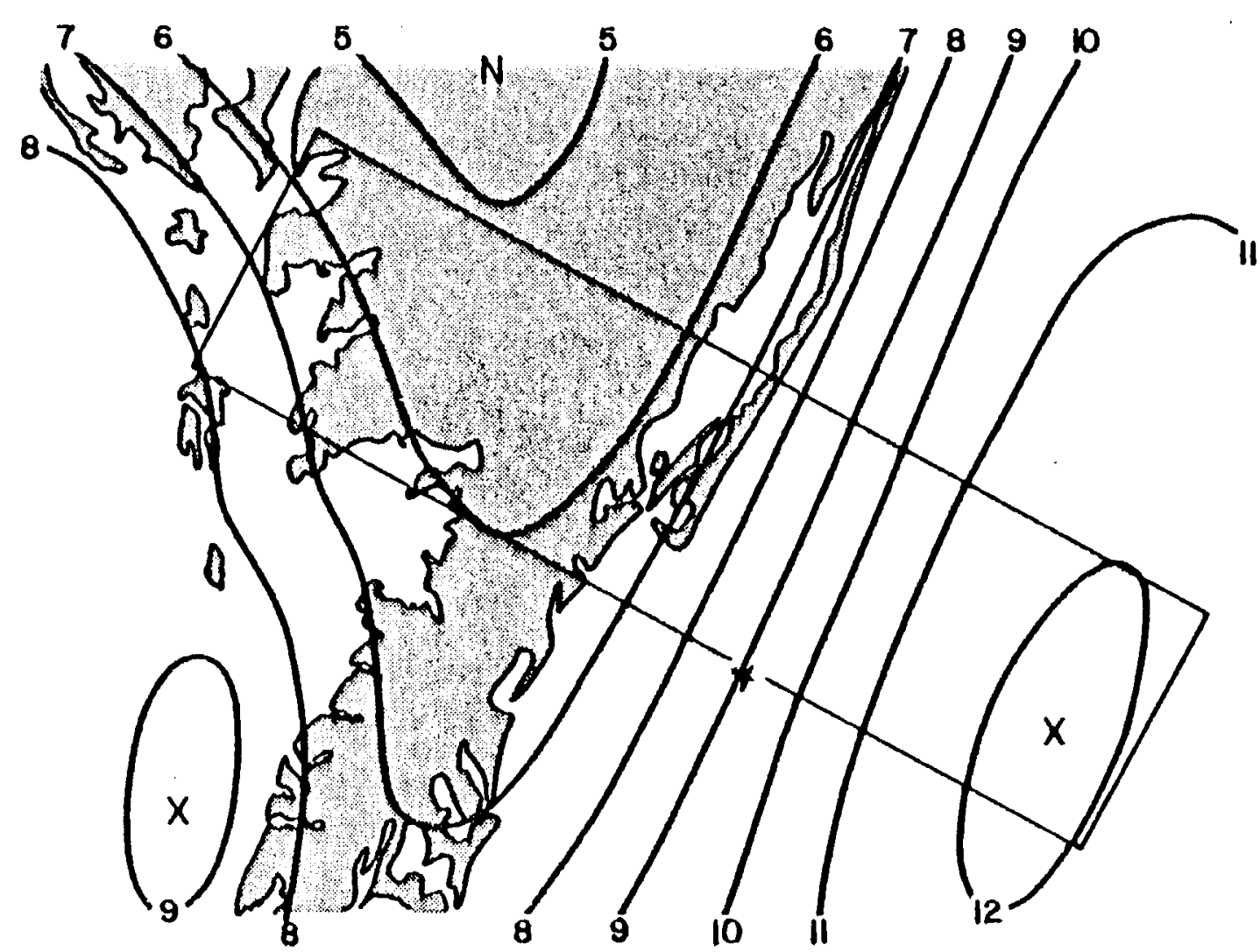

FIGURE 16. Areal distribution of predicted wind power density $\left(10^{2} \mathrm{~W} \mathrm{~m}^{-2}\right)$ at $170 \mathrm{~m}$ above the surface at 0828 EST, for the WIVEX study area. Predictions made by the University of Virginia mesoscale model initialized for 30 Jan 80. ' $X$ ' specifies areas of maximum power density (offshore $1210 \mathrm{~W} \mathrm{~m}^{-2}$ ), ' $N$ ' the area of minimum $\left(490 \mathrm{~W} \mathrm{~m}^{-2}\right)$. Aircraft position at 0828 is shown. 


\section{DISTRIBUTION}

No. of

Copies

OFFSITE

A. A. Churm

DOE Chicago Patent Group

9800 S. Cass Avenue

Argonne, IL 60439

D. Ancona

Department of Energy

Wind Energy Technology Division

1000 Independence Avenue

Forrestal Building, Room 5F059

Washington, DC 20585

C. I. Aspliden

Battelle Memorial Institute

Washington Operations Office

2030 M Street, N.W.

Washington, DC 20036

S. D. Berwager

Department of Energy

Wind Energy Technology Division

1000 Independence Avenue

Forrestal Building, Room 5F059

Washington, DC 20585

G. P. Tennyson

Department of Energy

Albuquerque Operations Office

P.0. Box 5400

Albuquerque, NM 87110

27 DOE Technical Information Center

Dr. K. C. Spengler

American Meteorological Society

45 Beacon Street

Boston, MA 02108

Tom Gray

American Wind Energy Association

1621 Connecticut Avenue, N.W.

Washington, DC 20009
No. of

Copies
Richard Katzenberg

3100 Highland Place

Washington, DC 20008

E. J. Warchol

Bonneville Power Administration

P.0. Box 3621

Portland, OR 97208

S. J. Hightower

Bureau of Reclamation

Denver Federal Center

Building 67, Code 254

Denver, CO 80225

Joe Hennessy

Wind Energy Program

California Energy Commission

1111 Howe Avenue, Mai1 Stop 66

Sacramento, CA 95825

R. Nolan Clark

Department of Agriculture

S.W. Great Plains

Research Center

Bushland, TX 79012

Jay Tappan

Department of Energy

State of Oregon

Labor and Industries Building

Room 111

Salem, OR 98310

Dr. Edgar DeMeo

Electric Power Research Institute 3412 Hillview Avenue

Palo Alto, CA 94303

Thomas R. Hiester

Flow Research

21414 68th Avenue, South

Kent, WA 98031 
No. of

Copies

Dr. Walter Frost

FWG Associates, Inc.

Route 2, Box 271-A

Tullahoma, TN 37388

James $D$. West

HQ MAC/DEEE

Scott AFB, IL 62225

Gary G. Worley, Maj. USAF

HQ AF-ESC/RDVA

Tyndal1 AFB, FL 32403

Gary L. Johnson

Electrical Engineering Department

Kansas State University

Manhattan, KN 66506

Marlatt and Associates

3611 Richmond Drive

Fort Collins, CO 80521

V. F. Garrett

Montana Energy and MHD Research and Development Institute, Inc. P.0. Box 3809

Butte, MT 59701

J. Konigsberg

Montana Energy Office

Capital Station

Helena, MT 59601

Phillip French

NASA Scientific and Technical

Information Facility

P.0. Box 8757

Bal timore/Washington International Airport

Baltimore, MD 21240

R. A. Wolf

NASA/Lewis Research Center

Mai1 Stop 500-201

Cleveland, $\mathrm{OH} \quad 44135$
No. of

Copies

M. J. Changery

National Oceanic and Atmospheric Administration

National Climatic Center

Federal Building

Asheville, NC 28801

C. F. Chappe11

Office of Weather Research and Modification

National Oceanic and Atmospheric Administration

Boulder, CO 80303

E. W. Hewson/J. E. Wade Atmospheric Sciences Department Oregon State University Corvalitis, OR 97331

Terry J. Healy/C. Hansen

Rockwe 11 Internationa 1

Rocky Flats Plant

P.0. Box 464

Golden, CO 80401

E. Kadlec

Sandia Laboratories

Division 5443

P.0. Box 5800

Albuquerque, NM 87115

W. A. Tolbert, Capt. USAF

SERI Site Office/RTLO

1617 Cole Boulevard

Golden, CO 80401

Solar Energy Research Institute

1617 Cole Boulevard

Golden, CO 80401

Bruce Bailey

Atmospheric Sciences Research Center

State University of New York at Albany

Albany, NY 12222 
N. E. Suhs

Tennessee Valley Authority

1360 Commerce Union Bank Building

Chattanooga, TN 37401

Dr. Tom Schroeder

University of Hawaij at Manoa

Department of Meteorology

2525 Correa Road

Honolulu, HI 96822

Dr. N. K. Wagner

Department of Civil Engineering

University of Texas

Austin, TX 78712

Dr. Michael Garstang

Department of Environmental Sciences

University of Virginia

Charlottesville, VA 22903

G. D. Thomann

Wichita State University

P.0. Box 44

Wichita, KS 67208

Farrell Smith Seiler

Wind Energy Report

Box 14 - 104 S. Village Avenue

Rockville Centre, NY 11571

W. Van Dyke

Wind Farms, Ltd.

639 Front Street

San Francisco, CA 94111

Richard L. Berry

Atmospheric Environment

4905 Dufferin Street

Downsview, Ontario

M3H 5 T4

CANADA

Dr. Neil Cherry

Lincoln College

Canterbury

NEW ZEALAND
ONSITE

DOE Richland Operations Office

P.0. Box 550

Richland, WA 99352

H. E. Ransom

43 Pacific Northwest Laboratory Battelle Boulevard

Richland, WA 99352

W. R. Barchet

J. W. Buck

J. R. Connel1

J. C. Doran

C. E. Elderkin

D. L. Elliott

W. J. Formica

R. L. George

D. L. Hadley

S. K. Heflick

V. K. Hopkins (15)

A. H. Miller

E. L. Owczarski

W. T. Penne 11

D. C. Powe 11

J. J. Praino

J. V. Ramsde 11

D. S. Renné

W. F. Sandusky

H. L. Wegley

L. L. Wende 11

R. K. Woodruff

Technical Information - Library (5)

Publishing Coordination (2) 


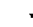

